Florida International University FIU Digital Commons

3-11-2009

\title{
Investigative Interviewing and Memory: How Accurate Are Interviewers' Recollections of Investigative Interviews?
}

Amy Hyman Gregory

Florida International University

DOI: $10.25148 /$ etd.FI10022523

Follow this and additional works at: https://digitalcommons.fiu.edu/etd

\section{Recommended Citation}

Hyman Gregory, Amy, "Investigative Interviewing and Memory: How Accurate Are Interviewers' Recollections of Investigative Interviews?" (2009). FIU Electronic Theses and Dissertations. 199.

https://digitalcommons.fiu.edu/etd/199 


\section{FLORIDA INTERNATIONAL UNIVERSITY}

Miami, Florida

INVESTIGATIVE INTERVIEWING AND MEMORY: HOW ACCURATE ARE INTERVIEWERS' RECOLLECTIONS OF INVESTIGATIVE INTERVIEWS?

A dissertation submitted in partial fulfillment of the

requirements for the degree of

DOCTOR OF PHILOSOPHY

in

PSYCHOLOGY

by

Amy Hyman Gregory

2009 


\section{To: Dean Kenneth Furton}

College of Arts and Sciences

This dissertation, written by Amy Hyman Gregory, and entitled Investigative Interviewing and Memory: How Accurate Are Interviewers' Recollections of Investigative Interviews?, having been approved in respect to style and intellectual content, is referred to you for judgment.

We have read this dissertation and recommend that it be approved.

$\begin{array}{r}\text { Janat Parker } \\ \hline \text { Ronald Fisher } \\ \hline \text { Nadja Schreiber Compo, Major Professor }\end{array}$

Date of Defense: March 11, 2009

The dissertation of Amy Hyman Gregory is approved.

$\begin{array}{r}\begin{array}{r}\text { Dean Kenneth Furton } \\ \text { College of Arts and Sciences }\end{array} \\ \hline \begin{array}{r}\text { Dean George Walker } \\ \text { University Graduate School }\end{array}\end{array}$

Florida International University, 2009 


\section{DEDICATION}

This dissertation is dedicated to the loving memory of my grandfather, Bernard Hyman. Though he did not live to see me accomplish this goal, I never would have made it this far without his spirit heartening me to want and seek more out of life. 


\section{ACKNOWLEDGMENTS}

First, I would like to thank Nadja Schreiber Compo for her unconditional support and invaluable guidance. Together we turned a tiny idea into a large scale dissertation project. I am indebted to you for making me a better researcher and for teaching me that high quality research takes time to perfect. Second, I would like to thank my committee members for their insights and for challenging me. My dissertation is better because of your feedback. Thank you for your flexibility and support throughout the dissertation process. Third, I would like to acknowledge and thank my research assistants who worked long and hard to make this project possible. There are too many to name but I am indebted to each and every one of you for making this line of research possible. Fourth, I would like to acknowledge the Jack D. Gordon Institute for Public Policy and Citizenship Studies for awarding me a Graduate Student Research Award in the amount of \$3,000 to support my dissertation research. I am grateful to the institute for their generosity, which helped to make the completion of my dissertation more manageable. Finally, I would like to thank my husband, family, and friends for their unconditional love and support. Thank you for keeping me grounded and calm throughout my graduate studies. 


\begin{abstract}
OF THE DISSERTATION
INVESTIGATIVE INTERVIEWING AND MEMORY: HOW ACCURATE ARE

INTERVIEWERS' RECOLLECTIONS OF INVESTIGATIVE INTERVIEWS?
\end{abstract}

\author{
by
}

Amy Hyman Gregory

Florida International University, 2009

Miami, Florida

\title{
Professor Nadja Schreiber Compo, Major Professor
}

Contrary to interviewing guidelines, a considerable portion of witness interviews are not recorded. Investigators' memory, their interview notes, and any subsequent interview reports therefore become important pieces of evidence; the accuracy of interviewers' memory or such reports is therefore of crucial importance when interviewers testify in court regarding witness interviews. A detailed recollection of the actual exchange during such interviews and how information was elicited from the witness will allow for a better assessment of statement veracity in court.

Two studies were designed to examine interviewers' memory for a prior witness interview. Study One varied interviewer note-taking and type of subsequent interview report written by interviewers by including a sample of undergraduates and implementing a two-week delay between interview and recall. Study Two varied levels of interviewing experience in addition to report type and note-taking by comparing experienced police interviewers to a student sample. Participants interviewed a mock witness about a crime, while taking notes or not, and wrote an interview report two weeks later (Study One) or immediately after (Study Two). Interview reports were written either in a summarized 
format, which asked interviewers for a summary of everything that occurred during the interview, or verbatim format, which asked interviewers to record in transcript format the questions they asked and the witness's responses. Interviews were videotaped and transcribed. Transcriptions were compared to interview reports to score for accuracy and omission of interview content.

Results from both studies indicate that much interview information is lost between interview and report especially after a two-week delay. The majority of information reported by interviewers is accurate, although even interviewers who recalled information immediately after still reported a troubling amount of inaccurate information. Note-taking was found to increase accuracy and completeness of interviewer reports especially after a two week delay. Report type only influenced recall of interviewer questions. Experienced police interviewers were not any better at recalling a prior witness interview than student interviewers. Results emphasize the need to record witness interviews to allow for more accurate and complete interview reconstruction by interviewers, even if interview notes are available. 


\section{TABLE OF CONTENTS}

CHAPTER

PAGE

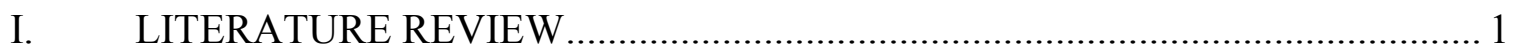

Interview Type and Interviewer Recall ........................................................... 2

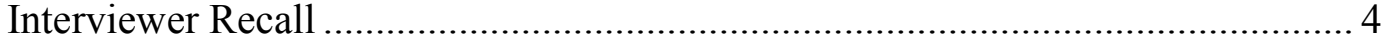

Interviewer Memory for Questions Asked........................................................ 6

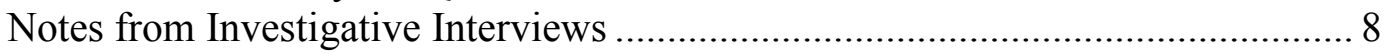

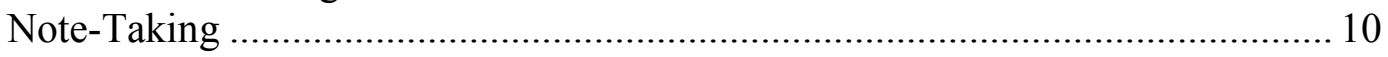

Note-Taking in Non-Academic Settings ............................................................ 13

Interviewing and Expectation Bias .................................................................... 14

Note-Taking and Interview Quality ................................................................ 15

Potential Problems with Interviewer Note-Taking............................................ 16

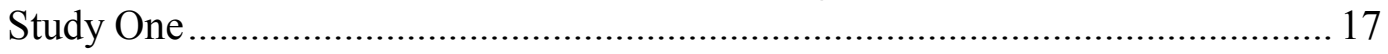

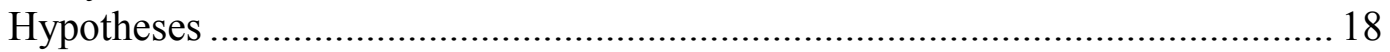

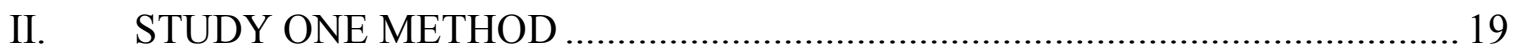

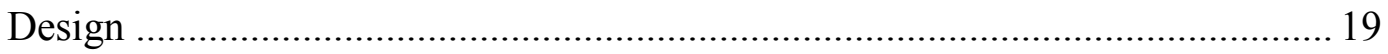

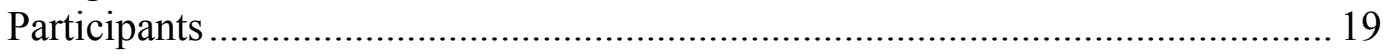

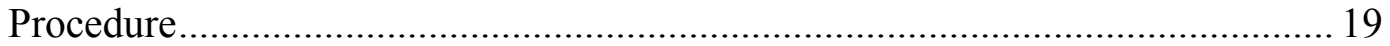

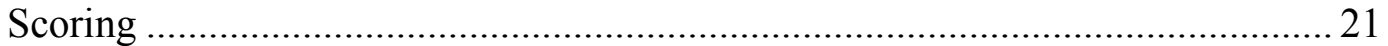

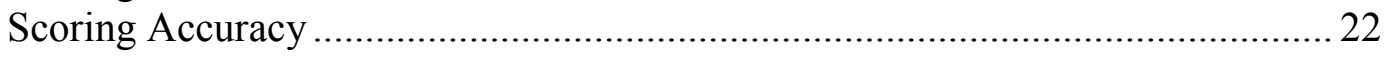

Scoring accuracy of witness information ............................................... 22

Scoring false additions ................................................................ 23

Scoring false modifications........................................................... 23

Scoring accuracy of how information was elicited vs. reported ................ 24

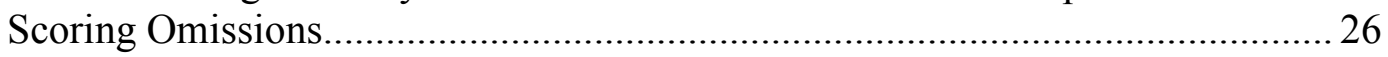

Scoring completeness of witness information............................................ 26

Scoring completeness of interviewer questions .......................................2 26

Scoring Interview Quality ................................................................................ 28

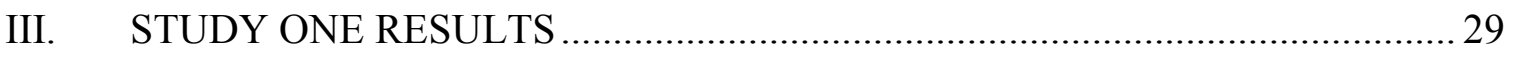

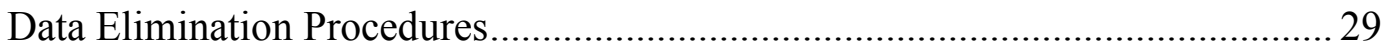

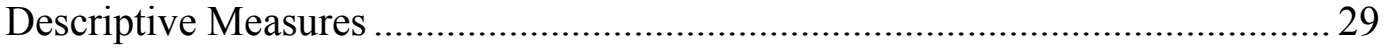

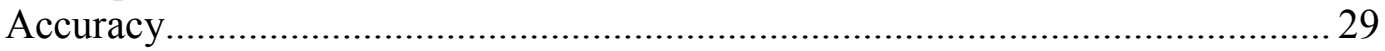

Accuracy of witness information .......................................................... 30

Accuracy of how information was elicited vs. reported............................. 31

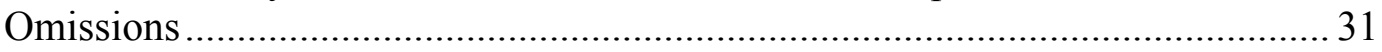

Completeness of witness information ................................................... 32

Completeness of interviewer questions .................................................. 32

Interview Quality ......................................................................................... 34

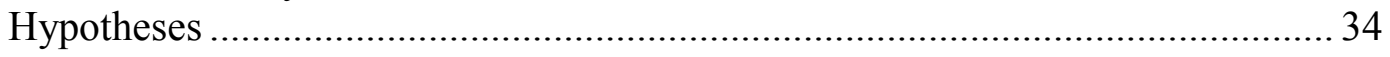

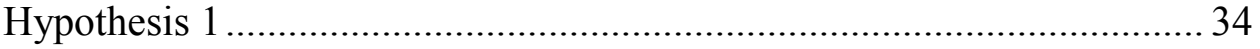

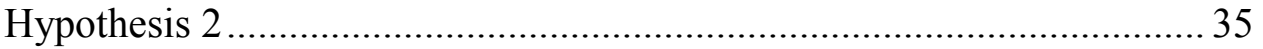




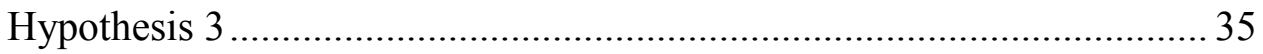

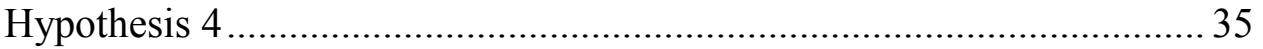

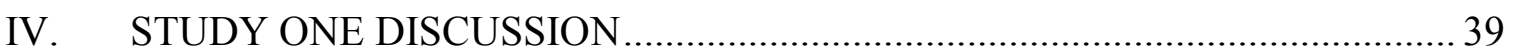

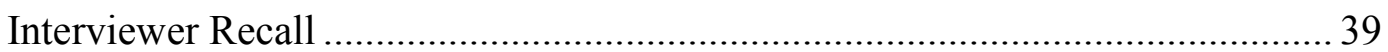

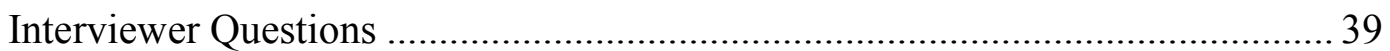

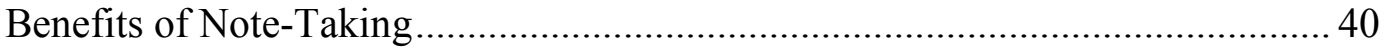

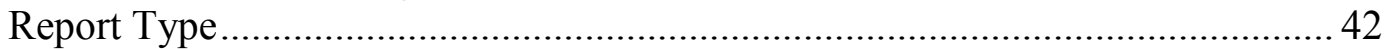

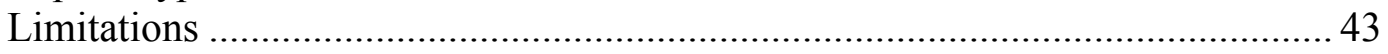

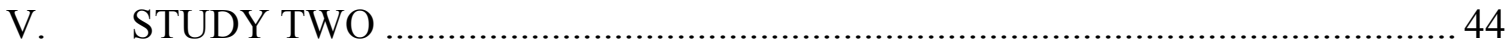

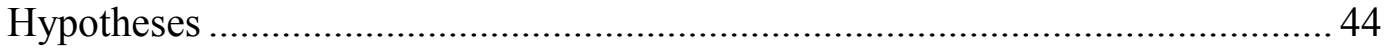

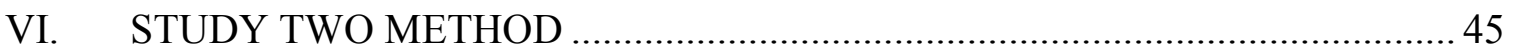

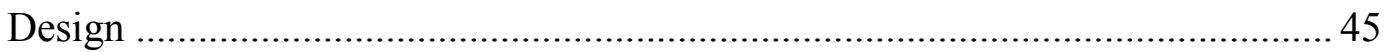

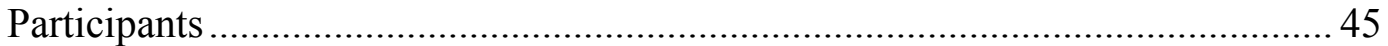

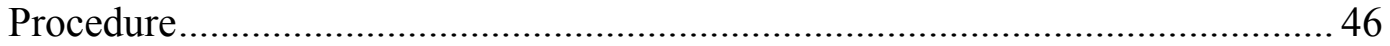

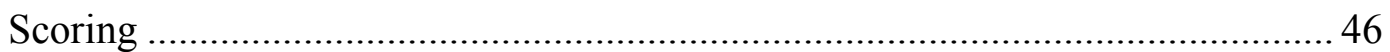

Scoring accuracy of witness information ................................................. 47

Scoring accuracy of how information was elicited vs. reported ................ 47

Scoring completeness of witness information........................................... 47

Scoring completeness of interviewer questions ....................................... 48

Scoring interview quality .................................................................... 48

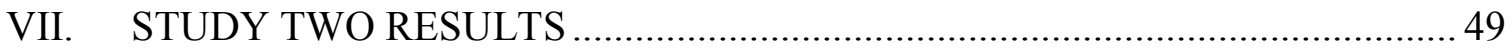

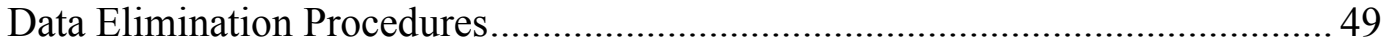

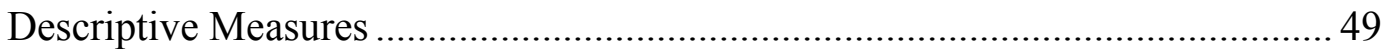

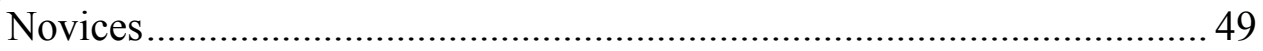

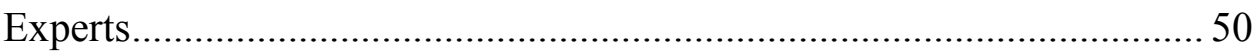

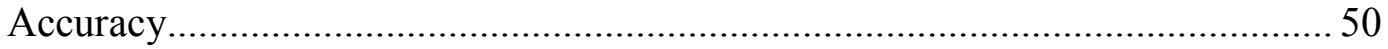

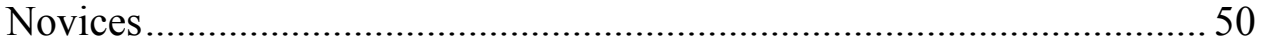

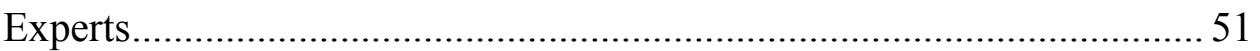

Accuracy of witness information ............................................................ 51

Accuracy of how information was elicited vs. reported............................ 52

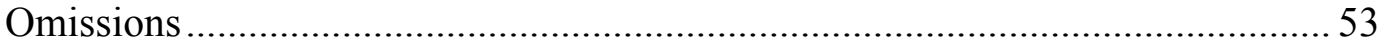

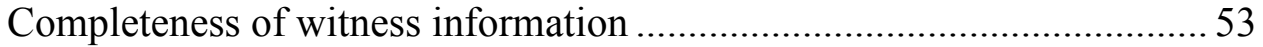

Completeness of interviewer questions ...................................................... 53

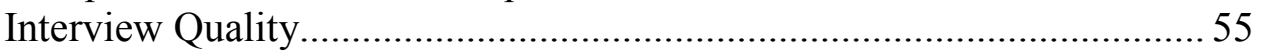

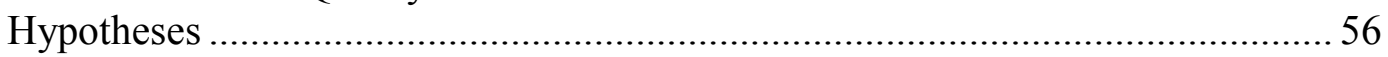

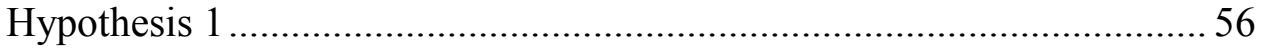

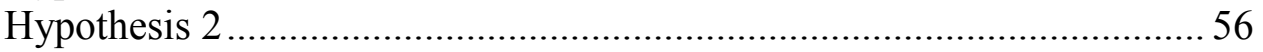

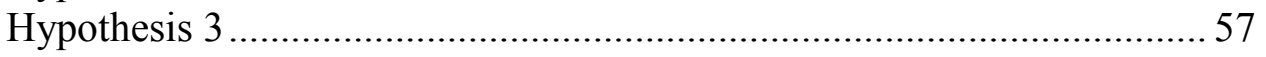

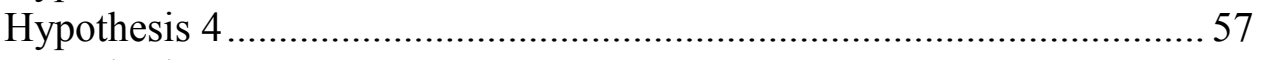

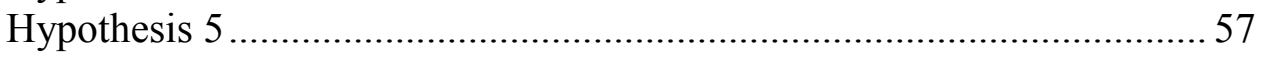




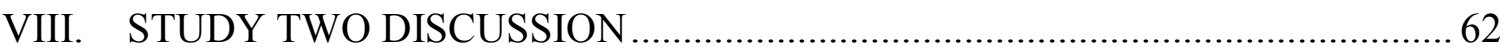

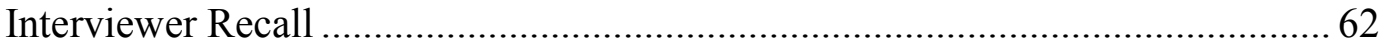

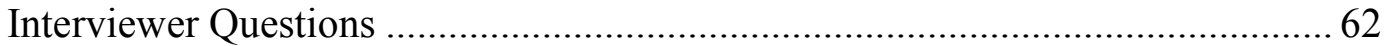

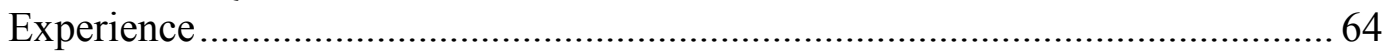

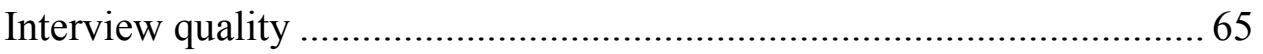

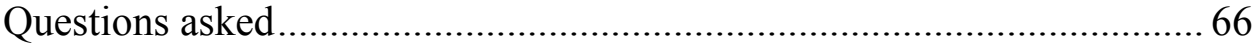

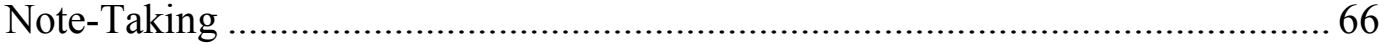

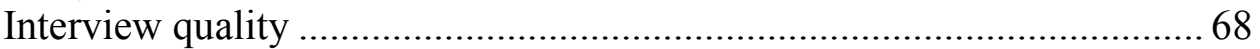

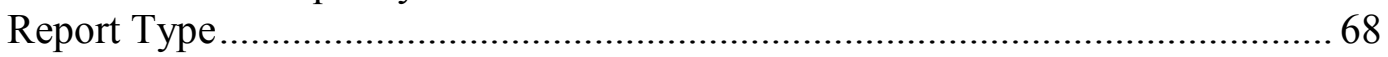

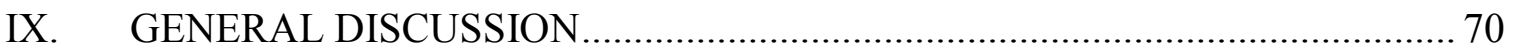

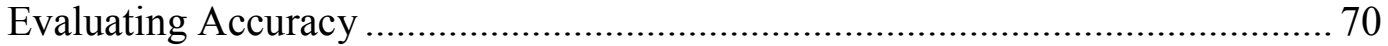

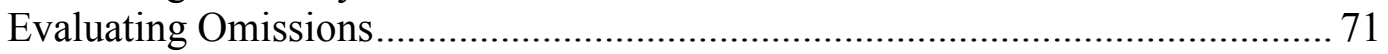

Interviewer Questions ........................................................................... 73

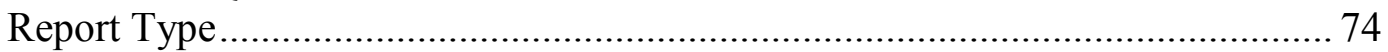

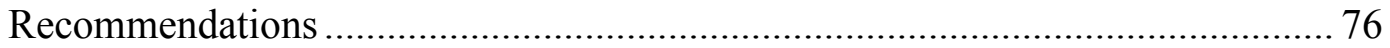

Limitations and Future Directions................................................................ 78

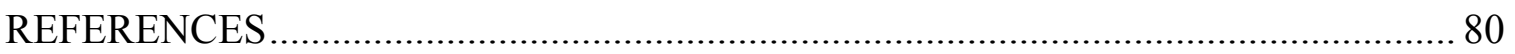

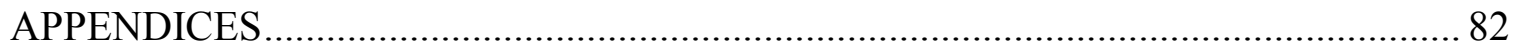

VITA 


\section{LIST OF TABLES}

TABLE

PAGE

1 Comparisons between Note-Taking vs. No Note-Taking Groups for Accuracy of Reported Information (Study One) 36

2 Comparisons between Summarized vs. Verbatim Groups for Accuracy of How Witness Information was Elicited vs. Reported (Study One)

3 Comparisons between Summarized vs. Verbatim Report Groups for Interviewer Questions Reported (Study One)

4 Comparisons between Summarized vs. Verbatim Groups for Accuracy of How Witness Information was Elicited vs. Reported (Study Two)

5 Comparisons between Police vs. Student Interviewers for Questions Asked During the Interview (Study Two)

6 Interaction between Report Type and Experience Groups for Completeness of Interviewer Questions Reported (Study Two)

7 Interaction between Report Type and Note-Taking Groups for Completeness of Interviewer Questions Reported (Study Two).... 


\section{Chapter I}

\section{Literature Review}

One of the main goals of investigative interviews is to obtain as much information as possible from witnesses about the event in question. All parties involved in investigations benefit from complete and accurate witness information especially if there is little to no physical evidence in a case. Investigative interviewers must therefore acquire all relevant information from witnesses and may need to recall this information at a later stage in the investigation. Interviewers would therefore not only benefit from any techniques that might help them elicit more accurate information from witnesses but also from any techniques that promote subsequent recall of that information. One such technique may be note-taking.

Records of investigative interviews with witnesses are crucial when interviewers are asked to testify in court. When recording devices (i.e., audio/video equipment) are not available during interviews, interviewers may rely on other methods to preserve the accuracy of information elicited during interviews including their memory, notes taken during interviews, and any subsequent written interview reports. In cases where interviews are not recorded, the interviewers' notes, their subsequent written reports based on those notes and their recollections from the interview may be the only remaining sources of "accurate" interview information. When called to testify in court, both investigators and/or expert witnesses may rely solely on these sources when reconstructing investigative interviews. Therefore, it is necessary to determine how accurate interviewers' recollections and written accounts of interviews are in order to ensure the veracity of their content in court. An understanding of the dynamics behind 
investigative interviewing reports can further help improve this process. As interviewers will possibly take notes while conducting investigative interviews, these notes may be essential in creating written reports. It is therefore also important to understand the impact of note-taking behavior on accuracy of interviewer recall and subsequent written reports of investigative interviews.

\section{Interview Type and Interviewer Recall}

Investigative interviewing research has generally focused on the accuracy of interviewee responses while ignoring the accurate recollection of interviewer information based on written accounts/reports from interviews (Köhnken, Thürer, \& Zoberbier, 1994). In laboratory studies, interview accuracy has often been measured solely on interviewee responses recalled by the interviewer from interview transcripts. However, using interview transcriptions as a measure of interviewee accuracy is rendered impossible in the real world, if interviews are not recorded. Without video or audio recordings interview transcriptions cannot be created. Therefore, many real-world investigators do not have interview transcriptions available to them when writing subsequent written reports. Rather, interviewers often take notes during interviews and may later use those notes in addition to their recollections of the interview to generate a summarized report (Köhnken et al., 1994). Thus, as interviewers' written reports are often the only source of information from the interview, their accuracy is crucial to preserving the accuracy of the witness's statement.

Köhnken et al. (1994) recognized the importance of accurate interviewer memory reports and proposed that interviewers may be able to write more accurate reports depending on the type of interview conducted. They asked interviewers to conduct either 
a standard interview or the enhanced cognitive interview (see Fisher \& Geiselman, 1992). Interviewers were introductory psychology students who received cognitive interview training or training in a control interview condition (standard interview). Interviewees were undergraduates who were not psychology students. They watched a blood donation film and five to eight days later were asked to return for an interview. They were unaware that they would be asked to recall the film. Each interviewee was assigned to a different interviewer who conducted either a standard interview or the cognitive interview. Interviewers were informed that they would have to produce a written report after the interview. Interviews were audio taped and transcribed. Interviewers were not permitted to take notes during the interview and did not have access to the audio-taped recording of the interview when writing their summarized reports. Interviewers' written reports were compared to the interview transcriptions to score for accuracy. Results indicated that interviewees given the cognitive interview generated significantly more correct witness information during the interview than interviewees given a standard interview. When comparing interview reports with interview transcripts, the authors found that interviewers reported slightly more correct details after the cognitive than the standard interviews (Köhnken et al., 1994). They also found that approximately one-third of correctly recalled interviewee information was missing from interviewer reports, regardless of interview type.

In light of these findings the authors suggested that the cognitive interview be used in cases where electronic recording and later transcription of the interview are not possible. This study also provides evidence that valuable interviewee information can be lost between the actual interview and subsequent written reports. However, because 
interviewers were not permitted to take notes during the interview, it is unclear how notetaking would have altered these findings.

Although the Köhnken et al. study addresses the importance of interviewer memory, the authors only evaluated the accuracy of interviewee information contained in reports and failed to evaluate how accurately interviewers remembered their own utterances and questions. A plethora of research has demonstrated the effects of interviewing techniques on the veracity of witnesses' subsequent statements (e.g., Poole \& Lamb, 1998; Home Office, 2002; National Guidelines on Eyewitness Identification, 1999). For example, witness information elicited via open ended questions is more likely to be accurate than information elicited via specific, closed, or yes/no questions (Fisher, 1995; Eisen, Quas, \& Goodman, 2002). Therefore, remembering how interviewee information was elicited during the interview is important to evaluate the veracity of reported witness information.

Interviewer Recall

Since Köhnken et al.'s (1994) study, little additional research has been conducted on how accurately summarized reports reflect what actually occurred during witness interviews compared to audio/video recordings. Warren and Woodall (1999) evaluated how well investigators recall the questions they asked during interviews and the witnesses' responses to those questions. Experienced forensic interviewers conducted videotaped interviews with 3-5 year old children about an event that occurred in their preschool. Interviewers were given a question to start the interview, such as, "Tell me about the time you went with Tracy to play silly doctor" and were then told to elicit as much information as possible using their usual interviewing techniques. Immediately following 
the interview, interviewers participated in an audio-taped interview with an experimenter. Interviewers were asked to recall everything that they could remember from the interview, to report verbatim the specific types of questions asked to elicit information, and the child's verbatim responses to these questions. Interviewers were then asked to provide a written summary of the content and sequence of the interview in transcript format. Their verbal recollections of the interview and their written summaries were both compared to the actual interviews. Results indicated that a significant amount of witness information was lost between the actual interview and the interviewers' verbal recollections and that even more information was lost between the actual interview and the written summaries. In their written summaries, interviewers recalled only $22 \%$ of all specific questions they had asked indicating that the majority of interview exchanges were not remembered and/or recorded. The content of these specific questions was recalled correctly $94 \%$ of the time, although the exact format was not always recalled. When specific target questions were reported in written summaries, the child's responses were also reported and were found to be accurate $85 \%$ of the time. Most interviewers also believed that they had asked predominantly open-ended questions during the interview when in fact, $80 \%$ of the questions that they asked were specific or closed-ended. Thus, interviewers' recollections of their own interviews appear to be incomplete and interviewers seem to have difficulty recalling the types of questions asked and the specific interviewee information elicited by these questions.

There are, however, a few limitations to Warren and Woodall's study. Interviewers were asked to write an account of the interview immediately after they had already reported what occurred verbally to an experimenter which is unlikely to reflect 
real-world practices and may have influenced the written report. Furthermore, interviewers in this study were tested immediately following the interview with the child. In real life investigative interviews, there are likely to be longer time delays between the witness interview and the interview report. The delay is even longer between the report and when the interviewer actually testifies. Thus, a realistic time delay should be implemented when examining interviewer reports empirically. Furthermore, the authors did not address the impact of note-taking behavior on interviewer recall or written account generation and focused on child witness interviews only.

Interviewer Memory for Questions Asked

As noted above, it is also crucial that interviewers remember the types of questions they asked to elicit witness information during an interview. For example, whether a child witness answers "yes" to "Didn't he touch you?" or spontaneously says "He touched me," could potentially result in quite different veracity judgments. In these cases, it is likely that an interviewer would encode or remember the witness information from either case in the same manner: i.e., that the witness said she was touched. As a result the interviewer would testify in court accordingly that the child said she was touched. Clearly, this can be problematic as the first question could be considered suggestive in nature while the second statement offers information voluntarily. Especially in the case of child witnesses, it is crucial for the trier of fact to hear how information was elicited in order to assess the witness's accuracy/credibility. Because records of the original investigative interview are often unavailable, it is therefore important that question type and phrasing are properly accounted for in interviewer reports in order to trace back how witness information was elicited. 
One study examined the accuracy of people's memory for their own conversations and how question type and sentence structure may influence how information is later remembered. Bruck, Ceci, and Francoeur (1999) examined mothers' memories for conversations with their pre-school aged children to determine the influence of sentence structure and meaning of statements on mothers' verbatim accounts. In this study, mothers interviewed their pre-school aged children about a play activity. Immediately following the interview, mothers were interviewed by an experimenter and asked to report in detailed dialogue form everything that happened during the interview. Interviews with the mothers were transcribed and used to create a recognition test which contained actual passages from the interview with the child. In some of the passages the structure of sentences was changed but the gist of the conversation was left intact, while in other passages the gist of the conversation was changed. Mothers were instructed to look for syntactic and semantic errors in the passages and to make corrections when necessary. Additionally, the recognition test evaluated how well mothers could remember answers provided spontaneously or elicited via specific questions. The authors found that mothers were poor at recalling how they obtained information from their children. Overall, mothers recalled only $16 \%$ of the questions that they asked during the conversation and had difficulty identifying who introduced information into the interview. Mothers were also unable to accurately recall whether utterances were offered spontaneously by their child or whether the child offered a one word answer based on specific or even suggestive question.

In a legal setting, if only the gist of the interviewee's account is reported and the interviewer does not recognize that the information was elicited through specific or 
leading questioning, it may be difficult to evaluate the quality of a witness's statement in court. It is therefore imperative that investigative interview reports not only accurately account for interviewee utterances but also the types and content of interviewer questions eliciting the information. It should be pointed out however, that interviewers in this study were mothers who have a close relationship with their children and are hardly experienced in investigative interviewing. This situation is quite different from actual investigative interviews where children are interviewed by unfamiliar and trained individuals about their experiences. Finally, and similar to Warren and Woodall, this study did not include note-taking behavior as a variable and only looked at child interviewees.

\section{Notes from Investigative Interviews}

If recording is not an option, note-taking may be crucial in preserving the accuracy of interviews. Based on anecdotal evidence, investigators oftentimes take notes while conducting interviews. Surprisingly, only one study has examined the accuracy of these notes (Lamb, Orbach, Sternberg, Hershkowitz, \& Horowitz, 2000). The authors obtained contemporaneous verbatim notes from eight youth investigators across 20 realworld child witness interviews conducted in Israel. Contemporaneous notes consisted of either notes taken during the interview or written shortly after, left to the discretion of the interviewer. To facilitate scoring, interviewers' contemporaneous notes were transcribed and typed into interview format and were compared to the transcripts from the actual audio-taped interviews. The authors found that $57 \%$ of the statements made by the interviewers were not recorded in their notes, as well as $25 \%$ of incident relevant details that were provided by the children. Errors of commission were found to be quite rare; 
however, errors of omission occurred frequently in the study. Thus, a major problem with interviewers' notes may be that important information is not included. Interviewer notes also appeared to focus solely on interviewee responses; in general, more than $50 \%$ of interviewer utterances were omitted, regardless of type (e.g., invitation, $38 \%$; directive, $63 \%$; option posing, 54\%; and suggestive, 53\%). Although subsequent summarized reports based on interviewer notes were not examined by Lamb and colleagues, their findings nevertheless suggest that such reports would not accurately capture how information was elicited during interviews as a substantial amount of information was omitted in their notes.

A limitation of the Lamb et al. (2000) study is that interviewer notes taken during the interview were not distinguished from those taken shortly after. It is therefore unclear whether these two types of notes differ (what the authors meant by "shortly after" was also not specified). It seems reasonable to assume that taking notes while conducting an interview, when attention is divided, will result in quite different notes than after the interview, when investigators can pay full attention but have to base their notes on memory. The former task is considered cognitively demanding because note-taking, question generation, and listening to interviewee responses are all occurring simultaneously (Kolk, Born, van der Flier, \& Olman, 2002). Additionally, the interviewer's attention has to shift from listening and writing down witness information to generating follow-up questions to elicit additional witness information. On the other hand, the time delay between receiving witness information and writing it down is minimal, therefore decreasing forgetting and increasing the likelihood of accurate notes. If notes are taken after the interview the interviewer can more readily focus on question 
generation and listening to witness information during the interview. The longer the retention interval is between the interview, writing notes, and generating reports, the greater the chances of gradual forgetting and the greater the likelihood of after-the-fact reconstruction to fill in the gaps of memory from the interview (Reisberg, 2006). Thus, increased forgetting of interview information can be expected with longer delays, especially if note-taking is not occurring. Note-taking may help to facilitate storage of witness information in working and long-term memory as interviewers must verbally record witness responses rather than passively listen, which in turn may lead to more accurate reports at a subsequent time. However, taking notes during interviews may be a mixed blessing as it may come at the expense of question generation and encoding witness responses (Kolk et al., 2002).

To investigate whether note-taking may help interviewers preserve accurate information from their own investigative interviews and to inform cognitive models that make different predictions about the impact of note-taking on interview recall and reconstruction, this variable needs to be tested. The only study involving note-taking did not vary it systematically or ask interviewers to generate written reports based on their notes (Lamb et al., 2000).

\section{Note-Taking}

Note-taking is usually associated with students; therefore the majority of research on note-taking has generally focused on academic uses. However, note-taking may also be beneficial to individuals in non-academic settings who wish to retain information for subsequent use. Note-taking is quite common in other domains such as legal situations, counseling sessions, and interviewing areas (Hartley, 2002) but has not received much 
research attention. Particularly, there is a dearth of research on note-taking in investigative interviews despite the fact that in some jurisdictions (e.g., Israel) interviewer notes or written reports may be accepted in lieu of electronic recordings of investigative interviews (Lamb et al., 2000). It is therefore important to determine whether note-taking aids subsequent interviewer recall of investigative interviews.

In learning environments, Kiewra and colleagues have noted three functions of note-taking: encoding, external storage, and encoding plus external storage (Benton, Kiewra, Whitfill, \& Dennison, 1993; Kiewra, 1989; Kiewra, DuBois, Christian, McShane, Meyerhoffer, \& Reoskelley, 1991). Encoding facilitates learning through the process of note-taking itself whereas external storage facilitates recall through reviewing notes. The encoding plus external storage function enhances learning through both the process of encoding, while taking notes, and storage, by reviewing notes at a later time. External storage refers to instances where notes are only reviewed before recall (e.g., borrowing another's notes) and are not actually encoded first. Kiewra et al. (1991) found that there were no differences in performance scores for a lecture recall task between individuals who took notes and listened to a lecture and those who only listened. However, significant differences were found between those who did not review notes and those who either reviewed their own notes (encoding plus external storage) or reviewed borrowed notes (external storage). The encoding plus external storage group outperformed all other groups. The authors explain these findings as a repetition effect; in the encoding plus storage function information is accessed twice whereas in the other functions information is accessed only once. Similar effects of reviewing notes were reported by Rickards and McCormick (1988), who found that students who reviewed 
notes prior to testing produced 40 - 50\% more accurate recall than those who did not. If these findings generalize to note-taking during investigative interviews then interviewers will have to review their notes either before generating a report or before offering testimony, in order for increased recall to be facilitated. The process of taking notes itself may not be enough to increase interviewer recall at a later time.

For the encoding function of note-taking it is further believed that the process of note-taking itself increases recall due to generative processing (Benton et al., 1993). Benton and colleagues suggest that a generation effect occurs during encoding. Specifically, the generating process of note-taking leads to the reprocessing of information, which in turn facilitates long-term memory. The authors evaluated the effects of the three note-taking functions and the generation effect on writing processes. Participants wrote essays based on a lecture and note-taking was manipulated. Results indicated that those who used their notes to write the essay wrote longer, more coherent and cohesive essays than those who did not. Once again, findings support the superiority of the encoding plus storage function over the encoding function of note-taking. In their second study, the authors implemented a one week delay between the lecture and essay. They found that essays were significantly longer after a one-week delay for those participants using notes during recall. Using notes also had a significant effect on generating and organizing processes: Notes were used to compensate for the loss of memory associated with the delay. It appears then that taking notes during report writing may also aid the memory of investigative interviewers, especially if time delays are present. 
However, an important difference between note-taking in an academic learning setting and a forensic interviewing context should be pointed out. A note-taker in an academic setting is a rather passive recipient of information and is in limited interaction with the information giver. A forensic interviewer, on the other hand, stands in interaction with the interviewee and is in a rather active (listener) role. Unlike an academic learner, investigators' notes should also account for their own utterances and interactional parts to account for overall notes' veracity later. Therefore, the above study allows for only limited insight into note-taking in a forensic context.

\section{Note-Taking in Non-Academic Settings}

Although research is limited, benefits of note-taking have been found in nonacademic settings. According a review by Hartley (2002) on note-taking in non-academic settings such as counseling, personnel interviews, and legal settings (e.g., jurors), there appear to be few harmful effects of note-taking, with the exception of counseling, and some strong benefits. In occupational interviews, note-taking has been shown to help interviewers make more effective decisions and reduce bias in decision making (Hartley, 2002). Possible advantages of note-taking during interviews include an increase of accurate interviewer recall and a decrease in the influence of interviewer bias. Burnett, Fan, Motowidlo, and Degroot (1998) examined the impact of note-taking and the content of notes on validity ratings in selection interviews. Note-takers were found to make significantly more valid judgment ratings than non note-takers. Thus, there is limited evidence that even when note-takers are in interaction with the information giver, notetaking can be beneficial. However, there is still no evidence on note-takers' accuracy about their own behavior. 


\section{Interviewing and Expectation Bias}

Interviewers usually know the reason for conducting an interview; it is therefore likely that they enter interviews with certain expectations. Note-taking may keep interviewers focused on what is said during interviews as they may feel it is necessary to record as much pertinent information as possible. Recording notes may prevent interviewers from expressing pre-interview expectations during the interview as their cognitive resources may be consumed by the processes of obtaining complete notes. This may in turn influence both how interviewers conduct and later remember the interview. Biesanz, Neuberg, Judice, and Smith (1999) examined the influence of note-taking on interviewer expectations to determine whether note-taking could reduce cognitive bias created by expectations in job candidate interviews. When interviewers were provided with positive expectations of the candidate, they took more notes than when they were provided with negative expectations. However, note-takers' later evaluations of candidates expected to be either positive or negative did not differ whereas non notetakers judgments were consistent with their expectations; they differed between expected positive and negative candidates. When note-takers were provided with a goal to maintain accuracy, they were able to de-bias themselves of prior expectations. Based on these findings, the authors concluded that note-taking can reduce the impact of biased information and pre-interview expectations.

Given that investigative interviewers have usually been exposed to previous case information and may have mentally created a script of what occurred before conducting the interview, interviewer bias as a source of suggestive influence is of particular concern both during the interview and when recalling the interview at a later time. Based on 
Biesanz and colleagues' study, note-taking may serve as a potential safeguard against interviewer bias in that it may decrease interviewer suggestibility during the interview and at a time of later recall.

Note-Taking and Interview Quality

Taking notes during an investigative interview might influence the quality of the interview that is conducted by the interviewer. Several positive interviewing techniques identified by researchers such as engaging in reflective listening, allowing for pauses, and avoiding interruptions and repeat questions (Fisher \& Geiselman, 1992; Home Office, 2002) might possibly be influenced by interviewer note-taking. Recording notes during a witness interview may naturally lead the interviewer to repeat back to the witness the information s/he has provided. Additionally, taking notes might allow for pauses in the interview setting while the interviewer jots down information that would otherwise not be present if the interviewer is not taking notes. Interviewers who take notes during interviews might also be less likely to interrupt the witness because recording interview information may foster an environment of patience in the interview setting. For examples, the witness provides responses and patiently waits while the interviewer records this information, the interviewer in turn records the witness's responses without interruption because $\mathrm{s} / \mathrm{he}$ is too busy recording the information to interrupt the witness. Because notetakers are keeping track of what is said during the interview it is likely that they will not ask the witness repeat questions. Asking repeat questions during a witness interview (asking a witness for the same information the interviewer already asked for when the witness gave a clear response) has been identified as detrimental to witness recall. When the same information is asked for more than once, a witness may feel pressured to 
provide a response that is consistent with what $\mathrm{s} / \mathrm{he}$ thinks the interviewer is expecting to hear. When the interviewer later attempts to reconstruct the interview s/he might summarize information elicited from repeat questions as though the information was spontaneously offered by the witness. This may in turn lead to less accurate interviewer memory for the interview and subsequent reports.

Conversely, interviewer note-taking might be detrimental to interview quality. If the interviewer is too focused on recording notes it might come at a cost to listening carefully to the witness's responses, which in turn might cause the witness to feel that the interviewer is only concerned with recording information and not concerned about his/her well being. Additionally, note-taking interviewers may be more likely to interrupt the witness than non note-takers to ensure that they record all crucial witness information. It is therefore important to determine the impact of interviewer note-taking on interview quality.

\section{Potential Problems with Interviewer Note-Taking}

There may be some potential limitations associated with interviewer note-taking during investigative interviews. Interviewers have limited cognitive resources. The process of note-taking may therefore interfere with the processing of information (Burnett et al., 1998). Interviewers may divide their attention between recording information, formulating new questions, and listening to interviewee responses. Thus, important information may be lost as a result. Additionally, the parallel process of formulating questions and note-taking may prohibit the interviewer not only from recording all of the witness's responses (Fisher, 1995), but particularly from recording his or her own questions and statements. Under these circumstances, complete information 
would not be encoded or noted to be available for retrieval at a later time (Burnett et al., 1998). This can be particularly detrimental in investigative interview settings when both interviewer and interviewee information need to be accounted for to render credibility or reliability judgments.

Taken together, findings on note-taking outside of legal psychology research suggest that it is unclear whether note-taking can enhance or be potentially detrimental to accurate and complete interviewer recall. Based on Kiewra and colleagues' findings (1991) that interview recall is best for note-takers who review their own notes before recall, it is essential that note-taking and review of notes during report writing be examined. A beneficial effect of note-taking on interviewer memory may be most likely if interviewers have access to their notes when generating written reports. Study One

Only very few studies have examined investigators' memory for their prior witness interviews. Therefore, the overall objective of the proposed study is to investigate how accurate and complete investigators' memory (i.e., their written interview reports) is for their prior witness interviews. In addition, the role of several important variables possibly influencing the veracity of those reports will be investigated: Lamb et al. (2000) examined the accuracy of interviewers' contemporaneous notes in forensic interviews but did not systematically investigate the role of interviewer note-taking. Although investigators typically assume that note-taking will assist them in the later generation of accurate reports, the few studies and theoretical models available lead to mixed predictions. Therefore, the first objective of the current study is to examine the impact of note-taking on subsequent interviewer recall of the investigative interview and interview 
quality. The second objective of the current study is concerned with how recall format will affect how accurately interviewers' written reports reflect the actual witness interview - both witness information and how this information was elicited. It is likely that when interviewers write reports they may only summarize the gist of the witness's statement. By asking interviewers to account for all questions asked and answers during the interview subsequent interview reports may be more detailed and accurate. Finally, the current study will include a realistic time delay ( 2 weeks) in evaluating the accuracy of subsequent interviewer reports. By examining actual and potentially easy-toimplement interviewing and recall strategies, the results of the present study have the potential to add to the literature and policy recommendations on investigative interviewing and the accuracy of subsequent reports based on these interviews.

\section{Hypotheses}

Four hypotheses will be tested as part of the present study: First, it is hypothesized that note-takers will write more complete and accurate interview reports than non note-takers. Second, it is hypothesized that interviewers asked to recall verbatim what was said during the interview will write more complete and accurate reports than those asked to write a summary of what was said during the interview. Third, it is hypothesized that note-takers asked to write verbatim reports will have the most complete and accurate reports than all other groups. Fourth, it is hypothesized that note-takers will conduct interviews of higher quality than non note-takers. 


\title{
CHAPTER II
}

\author{
Study One Method
}

Design

Study one implemented a 2 (note-taking vs. no note-taking) x 2 (recall format: summarized vs. verbatim) between subjects factorial design. Participants were asked to interview a mock witness about a crime. Note-taking was manipulated such that half of the participants were permitted to take notes during the interview, while the other half was not given this option (see Appendices A and B). Two weeks later all interviewers were asked to recall the interview in either verbatim or summarized recall format (see Appendices C, D, E, and F).

\section{Participants}

Two hundred undergraduate students at Florida International University were recruited to participate in a study on "Interviewing and Memory" from the psychology department participant pool, Sona-Systems. Participants signed up for two appointments two weeks apart and received one research credit in exchange for their participation, to be applied as course credit for a psychology course.

The final sample consisted of 161 students (data elimination procedures are described in detail in the results section). Participants were approximately 20 years old $(M=19.93)$, and were predominately female $(70 \% ; 30 \%$ male $)$ and Latino $(66 \% ; 12 \%$ Caucasian, 9\% other, 7\% African-American, 6\% Asian).

\section{Procedure}

Upon arrival at the lab, participants were introduced to the experiment and consented to participate. Participants were informed that they were to put themselves in 
the shoes of a police investigator about to interview a witness of a crime with the objective to gather as much information as possible that could help to solve the crime. Participants received one of two instructions, note-taking or no note-taking (see Appendices A and B). Participants in the note-taking condition were provided with a note pad and pen and were permitted to take notes during the interview. Participants in the no note-taking condition were not provided with this option.

Mock witnesses were five undergraduate research assistants who watched a video tape of a staged crime and were trained via a script in standardized responses to provide to interviewers. The crime video was approximately one minute long and involved a male perpetrator stealing money from a female victim's purse. The video began with the perpetrator reading a book at a table when the victim entered the room, sat down, reached into her purse to remove money from her wallet and left the room. The perpetrator looked around, opened the woman's purse, removed her wallet, took out cash, placed the wallet back into her purse and fled.

Participants were given as much time as needed to conduct the interview with the mock witness. Interviews were videotaped and transcribed. Two weeks after the interviews, participants returned to the lab and were asked to recall the interview in one of two ways: Participants in the summarized report condition were asked to write a summary of everything that occurred during the interview providing as much information as possible that would help to solve the crime (see Appendices C and D). Participants in the verbatim report condition were asked to write in transcript format the questions that they had asked the witness and the witness' responses to their questions. Participants in 
this group were asked to specifically account for who said what during the interview (see Appendices E and F).

After writing the report, participants completed two questionnaires: an interviewer questionnaire regarding any prior experiences with interviewing (see Appendix $\mathrm{G}$ and $\mathrm{H}$ ) and a demographic questionnaire (see Appendix I). Upon completion of the questionnaires participants were thanked, debriefed, and awarded credit. Scoring

There were three main dependent variable categories of interest related to interviewer reports: accuracy of reported interview information, completeness of witness information, and completeness of interviewer questions. One additional dependent variable category related to interviewer behavior during the interview, interview quality, was also scored. Detailed descriptions of how each of these categories/variables were measured and scored are provided below. To determine accuracy and completeness of reported interview information, both sources (actual interview and report) were compared. To determine interview quality, only the interview (transcript) was examined. The main scoring document was interviewer reports. Interviewer notes were not scored and will not be discussed further.

Interview transcriptions were divided into turns. Each turn consisted of an interviewer utterance/question and the witness's response (e.g., Interviewer: What brings you here today? Interviewee: I witnessed a crime). Interviewer turns were divided into questions and interviewee turns were divided into units of information. All written interviewer reports were divided into sentences; each sentence was further divided into 
units of information. A unit of information was defined as any new piece of information that could help to solve the crime.

To score for accuracy, each unit of information in the report was compared to the interview transcript. Completeness of witness information and interviewer questions were scored reversely: by comparing each turn in the interview transcript with each sentence/unit of information in written interview reports. If a piece of relevant information was provided by the witness during the interview but not recorded in the interview report it was considered omitted. If a question was asked by the interviewer but not recorded in the subsequent reported it was considered omitted.

All materials were scored by 2 independent scorers according to an explicit set of scoring rules (See Appendices J, K, L, and M for complete scoring rules and forms). Weekly scoring meetings were held and any major disagreements in scoring were resolved. Interrater reliability was calculated via intraclass correlation (ICC) and was considered satisfactory when an ICC of .80 or higher was achieved for each variable. The mean ICC for all dependent variables in the study was .97 .

\section{Scoring Accuracy}

There were two types of accuracies to be scored: accuracy of witness information reported and accuracy of reporting how specific witness information was elicited by the interviewer via different types of questions. In order to score for accuracy, scorers first determined how many units of interview information interviewers reported in their interview reports. Inter-rater agreement for total informational units reported was .99. Scoring accuracy of witness information. To score for accuracy of reported witness information, scorers compared each unit of information in the interviewer's 
report to the interview transcript. If a unit of information from the interview report could be correctly identified in the interview transcript then the unit of information was considered accurate. Each participant received an accuracy score based on the number of accurate units of information reported divided by the total number of informational units in the written report. If a unit of information from the interview report could not be found in the interview transcript or if it was found but had been altered by the interviewer in his/her report the units of information was considered inaccurate. Each participant received an inaccuracy score based on the number of inaccurate units of information reported divided by the total number of informational units written in the report. Interrater agreement for total accurate informational units was .99 and for total inaccurate informational units was .96. Inaccurate units of information were further divided into two subcategories: False additions and false modifications.

Scoring false additions. False additions were defined as new information inserted into the report by the interviewer that was never mentioned by the witness during the interview. For example, if the report said "He was wearing a hat" but the witness never mentioned anything about the suspect wearing a hat then this unit of information was considered a false addition. False additions were determined by comparing each unit in the interview report with the interview transcript. Each participant received a false addition score that was calculated as the number of false additional units reported divided by the total number of informational units in the written report. Inter-rater agreement for total false additions was .94 .

Scoring false modifications. False modifications were defined as information mentioned by the witness that was altered by the interviewer and was 
determined by comparing written reports with interview transcripts. For example, if the report said "He was wearing a red shirt" but during the interview the witness stated that the suspect was wearing a gray shirt then this unit of information was considered a false modification. Each participant received a false modification score based on the number of false modification units reported divided by the total number of informational units in the written report. Inter-rater agreement for total false modifications was .93.

Scoring accuracy of how information was elicited vs. reported. In order to determine the accuracy of how interviewers reported eliciting witness responses through different question types, scorers first had to distinguish between verbatim and summarized reports. In verbatim reports, the participant specifically indicated which question elicited which piece of witness information, which was then simply compared to the interview transcript. For summarized reports however, scorers first needed to infer from the summary which type of question elicited the information. For example, "He stated that the thief entered the room, opened the purse and stole the money," implies that this information was elicited via an open ended question. Each reported informational unit was scored for one of four different question types reported as originally eliciting specific witness information: open-ended narrative (e.g., Tell me everything that happened), specific/closed (e.g., What color was the suspect's hair?), yes/no (e.g., Did the suspect have a weapon?), and multiple choice (e.g., Was the suspect White or Black?).

For both types of reports, once a question type had been determined, it was then matched with the transcribed question from the actual interview to determine how that information was actually elicited from the witness. Each participant received a score for each of the four question type categories through which information was reported as 
being elicited through: open-ended narrative, specific/closed, yes/no, and multiple choice. For example, percentage of units reported as being elicited through open-ended narrative questions was then calculated as the total number of informational units reported as being elicited through open-ended narrative questions divided by the total number of units in the report. Inter-rater agreement between the two scorers for these variables were as follows: total units reported as being elicited through open-ended questions (.99), total units reported as being elicited through specific/closed questions (.98), total units reported as being elicited through multiple choice questions (.97), total units reported as being elicited through yes/no questions (.94).

Each participant also received a score for each of the four question categories for how that informational unit was actually elicited from the witness during the interview. One additional question category, suggestive/leading questions (e.g., if the interviewer asked the witness "Which direction did he run off in?" if the witness never mentioned anything about the suspect running) was also included in the question type scoring to account for possible - albeit highly unlikely - interviewer reports of suggestive influence during the witness interview. This category was scored by first identifying the original interview question that elicited the information, matching the question to one of the four question type categories, and finally determining whether the original question was suggestive/leading. Question type scores for actually eliciting informational units were then calculated for each of the five question categories by dividing the total number of question type units elicited (open-ended narrative, specific/closed, yes/no, multiple choice, or suggestive/leading) by the total number of informational units reported. Intraclass correlations between the two raters for these variables were as follows:, total 
units elicited through open-ended questions (.98), total units elicited through specific/closed questions (.97), total units elicited through multiple choice questions (.94), total units elicited through yes/no questions (.98), and total units elicited through suggestive/leading questions (.87).

\section{Scoring Omissions}

Conversely, interview transcripts were also divided into informational units and were compared to the written reports to determine which units of information from the witness interview were missing in the report. An omission was scored when a crimerelevant question or answer from the witness interview was not found in the later report. Each participant received two overall omission scores: one for witness information omitted and one for interviewer questions omitted from the report.

Scoring completeness of witness information. Scorers went through the witness's responses from the transcript unit by unit to determine how many informational units provided by the witness were reported or omitted by the interviewer is his/her report. Percentage of witness information omitted was calculated as the number of omitted informational units divided by the total number of informational units provided by the witness during the interview. Inter-rater agreement for total units witness information provided by the witness was .99 and for total omitted units .99 .

Scoring completeness of interviewer questions. In order to determine how many questions and what types of questions interviewers omitted, scorers first needed to determine from the interview transcript how many questions interviewers asked in total and the types of questions that interviewers asked. Number of total questions asked was calculated by counting the total number of questions that interviewers asked during the 
interview. Inter-rater agreement for total questions asked was .99. Each of the questions asked by the interviewer were then broke-down into the four main question type categories: open-ended narrative, specific/closed, yes/no, multiple choice. Scorers then determined whether each question could be considered as a suggestive/leading question. For each question type category a percentage was calculated by dividing it by the total number of questions actually asked (e.g., \% yes/no questions asked $=$ number of yes/no questions asked divided by the total number of questions asked). This percentage was then compared to the percentage of each question type category actually recalled in the interviewer reports. Intraclass correlations between the two raters for these variables were as follows: total open-ended narrative questions asked (.97), total specific/closed questions asked (.99), total multiple choice questions asked (.99), total yes/no questions asked (.99), and total suggestive/leading questions asked (.86).

Once scorers had determined how many questions were asked by interviewers during the interview they then determined how many of these questions were reported or omitted by interviewers in their reports. Percentage of interviewer questions omitted was calculated as the total number of questions omitted by the interviewer in the report divided by the total number of questions asked by the interviewer during the interview. Inter-rater agreement for total questions omitted was .99. Omissions were also evaluated for each question type category to determine which types of questions interviewers were more likely to omit. For example, percentage of open-ended narrative questions omitted was calculated as the number of open-ended narrative questions omitted divided by the total number of all questions omitted. Intraclass correlations between the two raters for these variables were as follows: total open-ended narrative questions omitted (.96), total 
specific/closed questions omitted (.99), total multiple choice questions omitted (.98), total yes/no questions omitted (.99), and total suggestive/leading questions omitted (.90). Scoring Interview Quality

To score for interview quality, scorers evaluated interview transcripts for the presence of the following variables: number of units with reflective listening (interviewer repeats back the information provided by the witness for clarification), number of repeated questions (interviewer asks the witness for information they already asked for and the witness provided a clear response), number of interviewer interruptions (interviewer interrupted the witness when $\mathrm{s} / \mathrm{he}$ was providing a response), and number of pauses (interviewer paused for more than 4 seconds during the interview). The percentage of repeated questions was calculated as the total number of repeated questions divided by the total number of questions asked. Intraclass correlations between the two raters for these variables were as follows: total units reflective listening (.99), total repeat questions (.98), total pauses (.99), and total interviewer interruptions (.99). 


\section{Chapter III}

Study One Results

\section{Data Elimination Procedures}

Although 200 participants conducted an interview with the mock witness, data from only 161 participants were included in the sample. Three participants were excluded from the study because of video recording malfunctions (e.g., videotape was erroneously lost, forgetting to hit record on the video camera). Two participants clearly misunderstood the task and were therefore removed from all analyses. Thirty-four participants were eliminated from the study due to attrition; they failed to return to the lab 2 weeks after the interview to write the interview report.

Descriptive Measures

Across all groups interviews lasted approximately 6.5 minutes $(M=6: 22, \mathrm{SD}=$ 5:04) with an average of 28 exchanges between interviewer and witness $(M=28.20, \mathrm{SD}$ $=22.33)$. On average, interviewers asked the witness approximately 25 questions $(M=$ $25.32, \mathrm{SD}=19.39)$ and in turn witnesses provided interviewers with an average of 67 units of information $(M=66.95, \mathrm{SD}=36.54)$. In their written interview reports, interviewers wrote approximately 14 sentences $(M=14.30, \mathrm{SD}=7.48)$ that contained an average of 32 units of information $(M=31.58, \mathrm{SD}=13.18)$. Accuracy

Across all groups, of the informational units reported by interviewers in their written reports $73 \%$ were accurate while $27 \%$ were inaccurate. Of the inaccurately reported units, $40 \%$ were false additions and $60 \%$ were false modifications. 
Interviewers reported eliciting the majority of informational units through openended narrative questions (61\%), followed by specific/closed (21\%), yes/no (17\%), and multiple choice (1\%). However, at time of interview information was actually elicited through open-ended narrative (40\%), yes/no (35\%), specific/closed (20\%), and multiple choice questions (5\%). Additionally, $2 \%$ of the units were elicited from the witness through suggestive/leading questions.

Accuracy of witness information. To determine whether there were differences between groups for accuracy of reported witness information, a 2 (note-taking vs. no note-taking) x 2 (summarized vs. verbatim report) MANOVA was conducted for the following dependent variables: total sentences written, total informational units reported, percent accurate units, percent inaccurate units, percent false additions, and percent false modifications. Results indicated a significant main effect of note-taking $(F(5,153)=$ $11.76, p<.01)$ and a significant main effect of report type $(F(5,153)=17.27, p<.01)$. There was no interaction between note-taking and report type. Post hoc comparisons revealed that note-takers wrote longer written reports that contained significantly more sentences and units of information than non note-takers. Note-takers also included a greater percentage of accurate units of information in their reports than non note-takers ( $81 \%$ vs. $64 \%$ ) (see Table 1). Post hoc comparisons for the main effect of report type revealed a significant difference between summarized and verbatim report writers for total sentences $(t(159)=-8.12, p<.01)$ and total units reported $(t(159)=-3.48, p<.01)$ : Verbatim report writers wrote significantly more sentences $(M=18.07, \mathrm{SD}=7.63)$ that contained significantly more units of information $(M=34.85, \mathrm{SD}=13.31)$ than summarized report writers $(M=9.97, \mathrm{SD}=4.33 ; M=27.84, \mathrm{SD}=12.06)$. 
Accuracy of how information was elicited vs. reported. To determine whether there were differences between groups for accuracy of how information was reported as being elicited through the question type categories versus how that information was actually elicited from the witness a 2 (note-taking vs. no note-taking) x 2 (summarized vs. verbatim report) MANOVA was conducted for the following dependent variables: percent units reported as being elicited through open-ended narrative questions, percent units reported as being elicited through specific/closed questions, percent units reported as being elicited through multiple choice questions, percent units reported as being elicited through yes/no questions, percent units actually elicited through open-ended narrative questions, percent units actually elicited through specific/closed questions, percent units actually elicited through multiple choice questions, percent units actually elicited through yes/no questions, and percent units actually elicited through suggestive/leading questions. Results indicated that there was a significant main effect of report type $(F(12,146)=8.41, p<.01)$. There were no other significant main effects or interactions, all $p s>.05$. Post hoc comparisons indicated that summarized report writers reported eliciting a significantly greater percentage of informational units through openended narrative questions (67\%) than verbatim report writers (56\%). Verbatim report writers reported eliciting a significantly greater percentage of informational units through yes/no questions (21\%) and multiple choice questions (2\%) than summarized report writers (11\%; 0\%) (see Table 2).

\section{Omissions}

Across all groups, only $48 \%$ of relevant informational units provided by the witness during the interview were later recalled by interviewers in their written reports. 
Thus, $52 \%$ of the information provided by the witness was missing from interview reports. Across all groups, $50 \%$ of the questions asked by interviewers were later recalled in the written interview reports. Thus, $50 \%$ of the questions originally asked by interviewers were omitted from the written reports.

Completeness of witness information. A 2 (note-taking vs. no note-taking) x 2 (summarized vs. verbatim report) MANOVA was conducted for all dependent variables measuring completeness of witness information: percentage of units reported and percentage of units omitted. Results indicated a significant main effect of note-taking on completeness of witness information, $F(1,157)=27.72, p<.01$. No significant main effect of report type was found. There was no significant interaction between note-taking and report type for completeness of witness information. Post-hoc comparisons of the main effect of note-taking revealed a significant difference for the percentage of witness information reported $(t(159)=5.35, p<.01)$ and for the percentage of witness information omitted $(t(159)=-5.35, p<.01)$ : note-takers reported a significantly greater percentage of witness information $(M=.53, \mathrm{SD}=.13)$ and omitted a smaller percentage of witness information $(M=.47, \mathrm{SD}=.13)$ than non note-takers $(M=.41, \mathrm{SD}=.16 ; M=$ $.59, \mathrm{SD}=.16)$ in their written interview reports.

Completeness of interviewer questions. Before evaluating the types of questions reported/omitted by interviewers in their reports, first questioning behavior during the interview must be evaluated. The only variable related to questioning behavior during the interview is note-taking. To determine whether note-takers and non note-takers differ in the total mean number of questions asked and the mean percentage of each type of question asked when conducting the interview independent samples t-tests were 
conducted on the following dependent variables: total mean questions asked, percent open-ended narrative asked, percent specific/closed asked, percent multiple choice asked, percent yes/no asked, and percent suggestive/leading asked. Because these variables focus exclusively on questioning behavior during the interview, report type was not included in these analyses, as the type of interview report written at recall is unrelated to questioning behavior during the interview. No significant differences were found between note-takers and non note-takers for any of the dependent variables, all ps >.05.

A 2 (note-taking vs. no note-taking) x 2 (summarized vs. verbatim report) MANOVA was conducted for the main dependent variable category completeness of interviewer questions on the following variables: percent questions reported, percent questions omitted, percent open-ended narrative reported, percent specific/closed reported, percent multiple choice reported, percent yes/no reported, percent suggestive/leading reported, percent open-ended narrative omitted, percent specific/closed omitted, percent multiple choice omitted, percent yes/no omitted, and percent suggestive/leading omitted. Results revealed a significant main effect of notetaking $(F(10,148)=2.39, p<.01)$ and a significant main effect of report type $(F(10,148)$ $=3.22, p<.00)$. There was no significant interaction. Post hoc comparisons for the main effect of note-taking indicated a significant difference for the percentage of specific/closed questions reported $(t(159)=3.95, p<.01)$ and the percentage of yes/no questions reported $(t(159)=-2.07, p<.05)$ : note-takers reported a greater percentage of the specific/closed questions that they asked (30\%) than non note-takers $(20 \%)$. Non note-takers reported a greater percentage of the yes/no questions they asked (43\%) than note-takers (37\%). Post hoc comparisons for the main effect of report type indicated that 
summarized report writers implied asking a greater percentage (53\%) of the questions they asked during the interview than verbatim report writers (47\%) in their written interview report. Summarized report writers also reported a greater percentage of the yes/no questions they asked (44\%) than verbatim report writers (37\%). Verbatim report writers also omitted a greater percentage of specific/closed questions (20\%) than summarized report writers (12\%). However, summarized report writers omitted a greater percentage of yes/no questions (68\%) and suggestive/leading questions (5\%) than summarized report writers $(58 \% ; 3 \%)$ (see Table 3$)$.

\section{Interview Quality}

To determine whether note-takers and non note-takers differ in the quality of interviews conducted, independent samples t-tests were conducted on the following variables: total reflective listening units, percentage of repeat questions asked, total pauses, and total interviewer interruptions. The only significant difference found between note-takers and non note-takers for interview quality was for the total number of pauses $(t(159)=4.00, p<.01)$ : Interviewers who took notes paused significantly more times $(M$ $=6.15, \mathrm{SD}=7.73)$ throughout out the interview than non note-takers $(M=2.33, \mathrm{SD}=$ 2.87). There were no significant differences for any of the other variables.

\section{Hypotheses}

Hypothesis 1 . The first hypothesis expected note-takers to write more complete and accurate interview reports than non note-takers. This hypothesis was supported. Note-takers wrote significantly longer reports that contained more sentences and units of information than non note-takers. Note-takers' interview reports were significantly more accurate (81\%) than non note-takers' reports (64\%). There was a significant main effect 
of note-taking for completeness of witness information. Note-takers reported significantly more witness information (53\%) than non note-takers (41\%). Differences for the percentage of questions reported was in the predicted direction: Note-takers reported a greater percentage of the questions they asked (52\%) than non note-takers (47\%).

Hypothesis 2. The second hypothesis expected verbatim report writers to write more complete and accurate reports than summarized report writers. This hypothesis was not supported. No differences in report type were found for the accuracy measures or for completeness of witness information measures. Despite writing longer reports, verbatim report writers did not report any more witness information than summarized report writers. There was a significant main effect of report type for completeness of interviewer questions. However, contrary to the hypothesis summarized report writers reported a greater percentage of the questions they asked (53\%) than verbatim report writers (47\%).

Hypothesis 3. The third hypothesis expected note-takers writing verbatim reports were expected to have the most complete and accurate reports than all other groups. This hypothesis was not supported. There was no interaction between note-taking and report type for any of the dependent measures.

Hypothesis 4. The fourth hypothesis predicted that note-takers would conduct higher quality interviews than non note-takers. This hypothesis was not supported. No significant differences were found between note-takers and non note-takers for reflective listening, interviewer interruptions, and repeat questions. However, a significant difference between groups was for total number of pauses: note-takers paused significantly more times during the interview than non note-takers. 


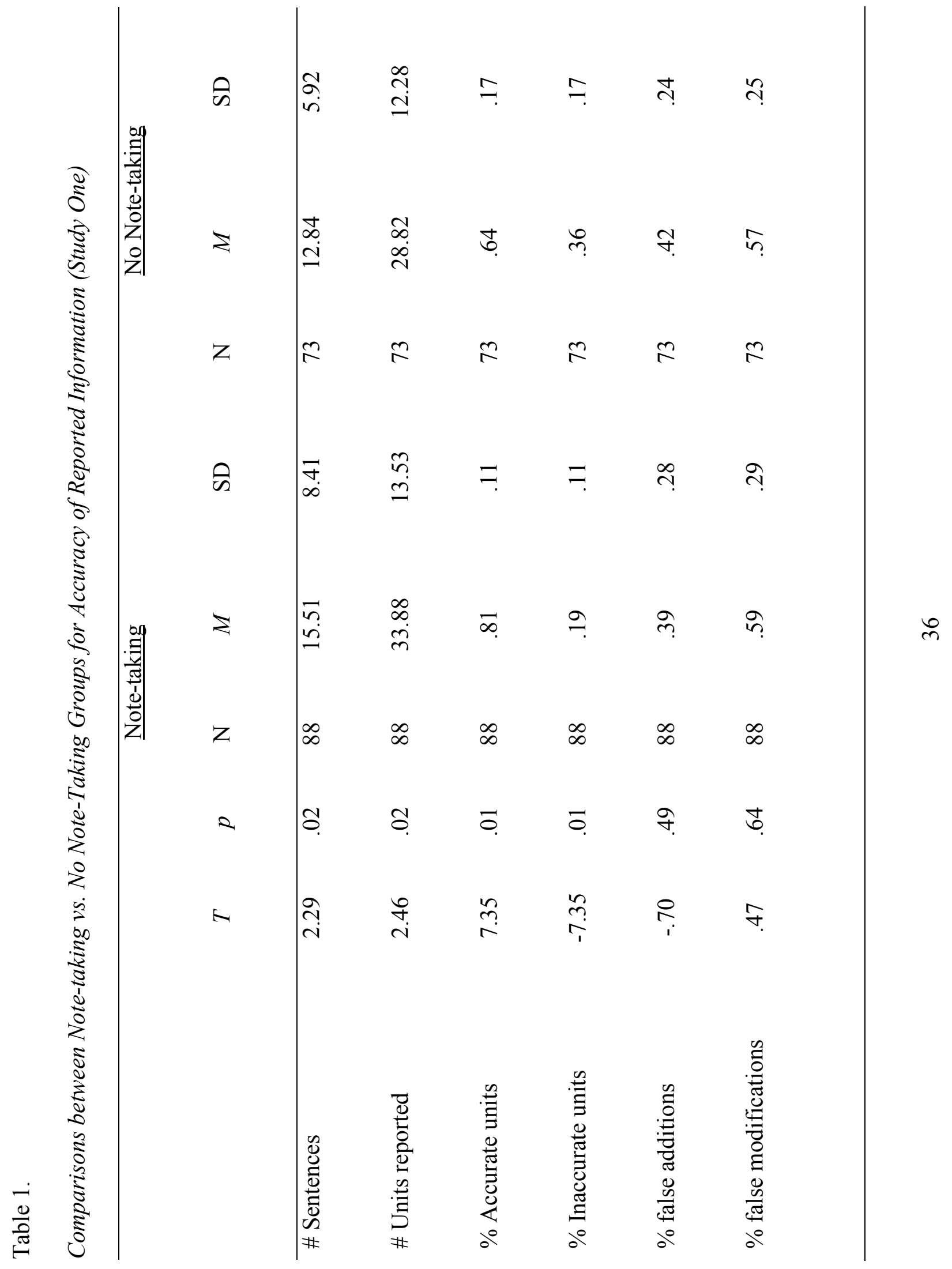




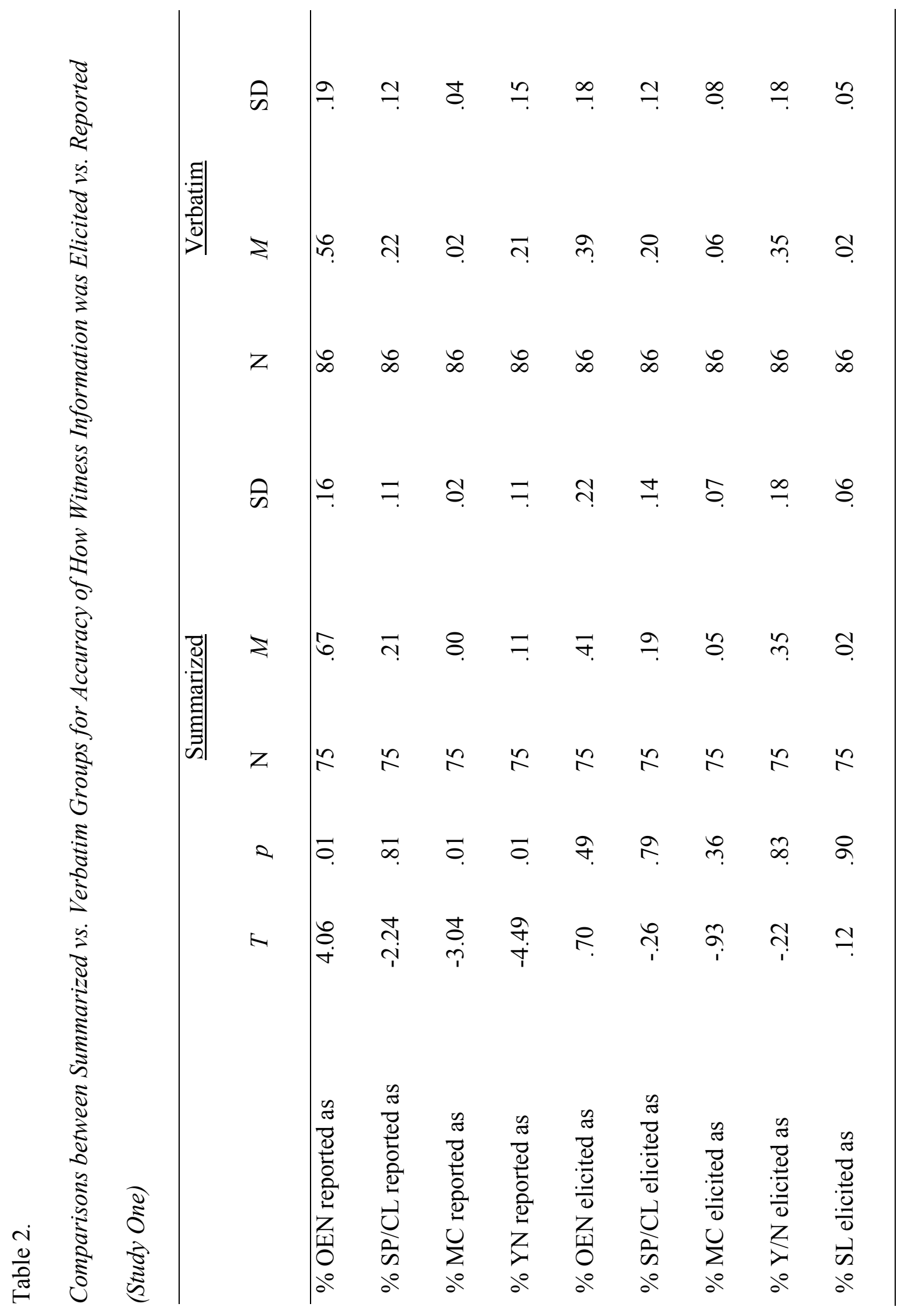

n 


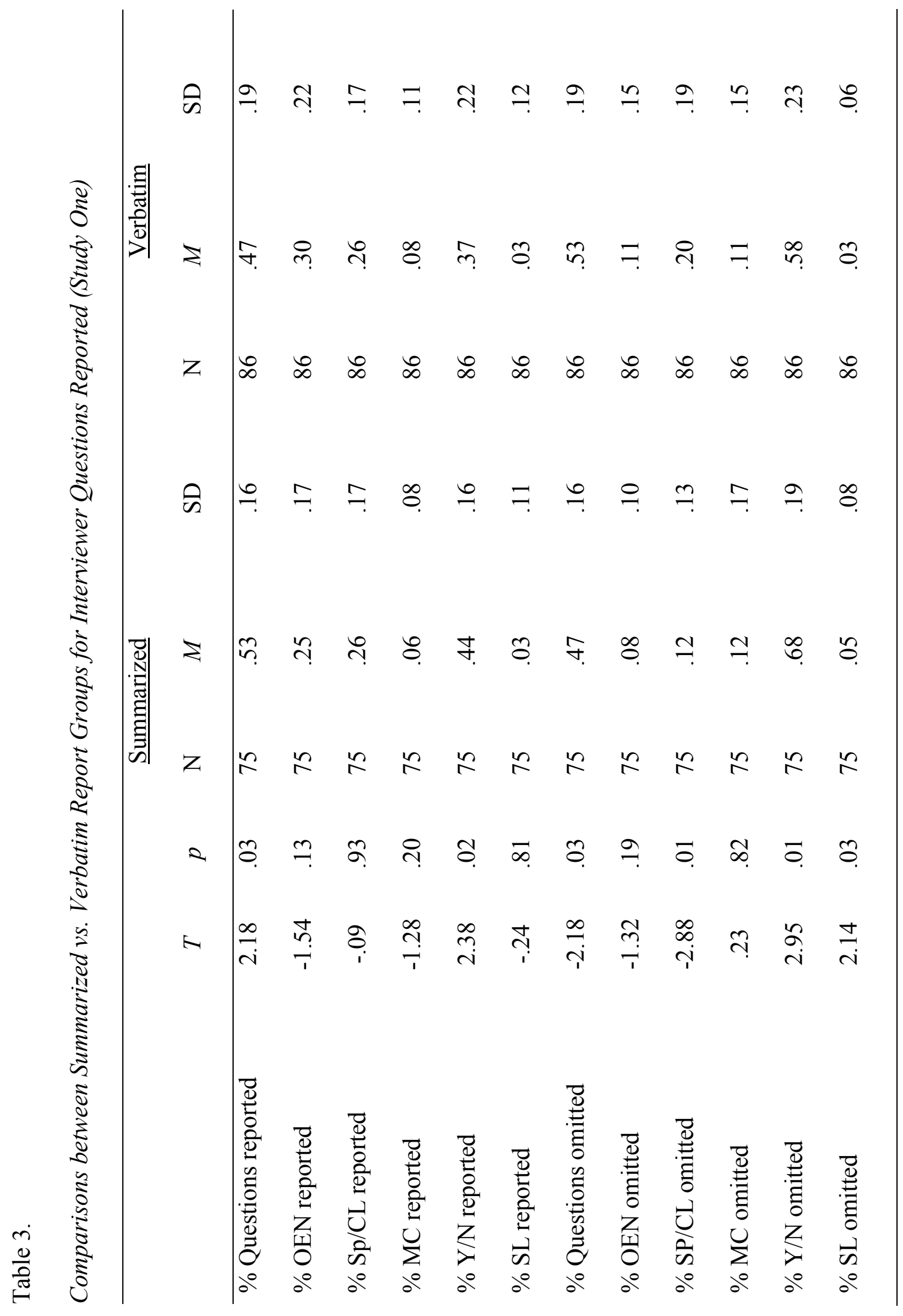




\title{
Chapter IV
}

\author{
Study One Discussion
}

\section{Interviewer Recall}

The findings of Study One indicate that interviewer memory for a prior witness interview is impaired after a two week delay. Although seventy-three percent of recalled information was accurate, over a quarter was inaccurate. This is especially problematic if interviewers testify in court based on these written reports. Interviewer testimony should be as accurate as possible; therefore relying on subsequent interview reports may lead to imprecise testimony. Of even greater concern than the percentage of commission errors were errors of omission. Approximately half of the questions asked by interviewers and the witness's responses to these questions were not recalled by interviewers in their written reports. These findings are in line with the Köhnken et al. (1994) study which found that one-third of witness information is lost between interview and interviewer recall.

\section{Interviewer Questions}

Findings of Study One suggest that interviewers lack insight into how information was elicited from the witness at the time of the interview. Interviewers reported eliciting the majority of witness information via open-ended narrative questions (61\%). Although a moderate portion of witness information was indeed elicited through open-ended narrative questions (40\%) an equally moderate percentage of information was elicited through yes/no questions (35\%). In other words interviewers attributed $21 \%$ of the information elicited from the witness to open-ended narrative questions when this information was in fact elicited via yes/no, specific/closed, and multiple choice questions. 
Because a plethora of studies have confirmed that information elicited via open-ended narrative questions is more likely to be accurate than information elicited via yes/no and specific/closed questions (e.g., Eisen et al. 2002; Fisher, 1995), incorrect and incomplete accounting for questions asked can impact evaluations of statement veracity. This finding is also consistent with Warren and Woodall (1999) who found that interviewers thought they asked predominantly open-ended narrative questions when $80 \%$ of the questions that they asked were specific/closed in nature.

When recalling questions, interviewers were more likely to recall asking openended questions than all other question types. This finding suggests that open-ended narrative questions may be the least likely to be forgotten by interviewers. Asking predominately open-ended narrative questions during a witness interview may actually help interviewers recall more of their own questions at a later point in time. Future research should investigate which interview conditions increase and decrease the accuracy of interviewer question retrieval.

Benefits of Note-Taking

Importantly, the findings of Study One support the benefits of interviewer notetaking during investigative interviews with witnesses. After a two week delay interviewers who initially took notes were seventeen percent more accurate than those who did not. Note-takers also recalled more information overall and a greater percentage of the questions they asked than non note-takers. This finding is contrary to that of Kolk and colleagues (2002) who proposed that as a result of interviewers' divided attention, interviewer note-taking during interviews may come at a cost of encoding of witness responses. In this study no differences were found between note-takers and non note- 
takers for question generation and note-takers recalled a greater percentage of witness information than non note-takers. This study therefore confirmed that note-taking may have little impact on (divided) attention. Interviewers who took notes during the interview were provided with their notes to review and use when writing their interview reports. The superior performance of note-takers compared to non note-takers therefore supports the encoding plus external storage function of note-taking as identified by Kiewra and colleagues (1991). The benefits of interviewer note-taking during witness interviews are clear based of the findings of this study. Thus, the note-taking literature can be generalized from academic settings to a forensic interview setting.

It should be pointed out however, that note-takers still made a considerable number of omission errors. Note-takers omitted close to half of their own questions and the witness's responses to these questions. Thus, this limitation of note-taking should be acknowledged when evaluating the veracity of interviewer written reports. Although it can be expected that an interviewer who took notes during a witness interview will write a more accurate report than one who did not, it is important to note that note-taking is by no means a safeguard against interviewer memory errors.

Although it was predicted that note-taking would increase the quality of witness interviews, this prediction was not supported - with one exception. Note-takers paused more often during the interview than non note-takers, possibly to write down interview information. Although note-taking did not increase the quality of witness interviews it is important to note that it did not serve to decrease the quality of the interviews. Thus, there appear to be no known consequences of taking notes during investigative interviews with witnesses on the interview itself. 


\section{Report Type}

In contrast to the hypotheses, report type did not appear to be as beneficial as an interviewer recall tool as interviewer note-taking. It was expected that verbatim report writers would recall more of their own questions than summarized report writers because they were specifically asked to record in question and answer format everything that was said during the interview and that recall of their questions would help trigger additional information. Surprisingly, summarized report writers were better at recalling their own questions than verbatim report writers. One possible explanation for this finding is that verbatim report writers may have been subjected to an increased cognitive load when writing their reports as they were asked to write each specific question and answer from the interview in transcript format. Summarized report writers were able to write everything that happened during the interview in a continuous manner. Thus, verbatim report writers were expected to add an extra step to their retrieval process.

Another possible explanation for this finding is measurement artifact. When scoring summarized reports, scorers had to infer whether interviewers had reported asking a question based on the summary of information. In verbatim reports interviewers clearly indicated their questions so it was clear whether questions had been omitted by interviewers. Thus, this finding may have resulted from how we measured omission of questions.

The type of report that is written by an interviewer (summarized or verbatim) two weeks following a witness interview did not make a difference in the accuracy of reported information or in the amount of witness information recalled by the interviewer. 
Therefore, the current study does not allow for any recommendations regarding the best type of report interviewers should write after a witness interview.

\section{Limitations}

One main criticism of Study One could be that the sample was hardly representative of actual investigative interviewers. Interviewers were undergraduate psychology students who had no formal training or experience in interviewing witnesses or in writing subsequent interview reports. Although participants were instructed to put themselves into the shoes of a police investigator and elicit crime-relevant information, it is difficult to recreate investigators' experience when interviewing witnesses and writing reports. Study Two was designed to address this sampling concern and therefore included a sample of police investigative interviewers to determine the effects of recall format and note-taking in this population. The inclusion of this sample allowed for a comparison of police investigators' performance and recall to undergraduate students' performance and recall. It was expected that police officers would show better recall of witness interviews than student interviewers based on their experience with conducting witness interviews and writing interview reports. 


\title{
CHAPTER V
}

\author{
Study Two
}

\section{Hypotheses}

Five hypotheses will be tested as part of Study Two: First, it is hypothesized that experienced police interviewers will write more complete and accurate interview reports than lay interviewers. Second, it is hypothesized that note-takers will write more complete and accurate interview reports than non note-takers. Third, it is hypothesized that interviewers writing verbatim reports will write more complete and accurate reports than interviewers writing summarized reports. Fourth, it is hypothesized that police notetakers writing verbatim reports will write the most complete and accurate interview reports than all other groups. Fifth, it is hypothesized that police note-takers will conduct the highest quality interviews than all other groups. 


\section{CHAPTER VI}

Study Two Method

Design

Study Two implemented a 2 (interviewer experience: novice vs. expert) x 2 (notetaking vs. no note-taking) x 2 (recall format: summarized vs. verbatim) between subjects factorial design. Participants were asked to interview a mock witness about a crime. Note-taking was manipulated in the same fashion as Study One such that half of the participants were permitted to take notes during the interview, while the other half were not given this option (see Appendices $\mathrm{N}$ and O). However unlike Study One, Study Two asked all interviewers to recall the interview in either verbatim or summarized recall format immediately following the interview (see Appendices C, D, E and F). Because of time constraints of police investigators it was difficult to find participants willing to participate in the study on two occasions. Therefore, all interviewers' recall took place immediately after the witness interview.

\section{Participants}

The expert interviewer sample consisted of 25 police investigators from various local law enforcement agencies in South Florida who were tested either in the lab or onsite in their respective departments. Police officers either volunteered to participate in the study if they were on-duty or were paid $\$ 30$ for their participation. Police officers were not allowed to accept monetary compensation if they participated in the experiment while on-duty.

The novice interviewer sample consisted of 24 undergraduate students from Florida International University. Students were recruited to participate in a study on 
"Interviewing and Memory" from the psychology department participant pool, SONASystems. Participants signed up for one appointment and received one research credit in exchange for their participation, to be applied as course credit for a psychology course.

The final sample consisted of 24 students and 24 police officers (data elimination procedures are described in detail in the results section). Police participants were approximately 42 years old $(M=41.58)$, and were predominately male ( $88 \% ; 12 \%$ female) and Latino (54\%, 25\% Caucasian, 17\% African American, 4\% other). Experienced police interviewers had approximately 15 years of experience interviewing witnesses $(M=15.06)$. Student participants were approximately 22 years old $(M=$ $21.58)$, and were predominately female $(75 \% ; 25 \%$ male) and Latino $(50 \% ; 21 \%$ AfricanAmerican, $17 \%$ other, $12 \%$ Caucasian).

Procedure

The procedure for Study Two followed the same procedure as Study One with the exception of time delay. Interviewers in Study Two recalled the interview immediately after they conducted the interview (not 2 weeks later) either in verbatim or summarized format. Additionally, a questionnaire was created for police interviewers to gauge their experience in law enforcement and in interviewing witnesses, victims, and suspects to crimes (see Appendices P and Q).

Scoring

Scoring procedures for Study Two were identical to Study One. The main dependent variables of interest for Study Two are the same as Study One and are as follows: accuracy of reported interview information, completeness of witness information, and completeness of interviewer question. Interview quality was also scored. 
All materials were scored by two independent scorers according to the same explicit set of scoring rules (See Appendices J, K, L and M for complete scoring rules and forms). Weekly scoring meetings were held where any major disagreements in scoring were resolved. Inter-rater reliability was calculated via intraclass correlation (ICC) and was considered satisfactory when an ICC of .80 or higher was achieved for each variable. The mean ICC for all dependent variables in the study was .97.

Scoring accuracy of witness information. Intraclass correlations between the two raters for variables associated with accuracy of witness information were as follows: total units reported (1.00), total accurate units (.99), total inaccurate units (.99), total false additions (.98), and total false modifications (.98).

Scoring accuracy of how information was elicited vs. reported. Intraclass correlations between the two raters for variables associated with the accuracy for how information was reported as being elicited from the witness and how information was actually elicited were as follows: total units reported as being elicited through open-ended questions (.99), total units reported as being elicited through specific/closed questions (.99), total units reported as being elicited through multiple choice questions (.99), total units reported as being elicited through yes/no questions (.99), total units elicited through open-ended questions (.98), total units elicited through specific/closed questions (.99), total units elicited through multiple choice questions (.99), total units elicited through yes/no questions (.99), and total units elicited through suggestive/leading questions (.98).

Scoring completeness of witness information. Intraclass correlations between the two raters for variables measuring completing of witness information were as follows: total units witness information provided (.99) and total omitted units (.99). 
Scoring completeness of interviewer questions. Intraclass correlations between the two raters for variables measuring types of questions asked, omitted, and reported were as follows: total questions asked (.99), total open-ended narrative questions asked (.97), total specific/closed questions asked (.99), total multiple choice questions asked (.99), total yes/no questions asked (.99), total suggestive/leading questions asked (.89), total omitted units (.99), total questions omitted (.99), total open-ended narrative questions omitted (.94), total specific/closed questions omitted (.99), total multiple choice questions omitted (.99), total yes/no questions omitted (.99), and total suggestive/leading questions omitted (.84).

Scoring interview quality. Intraclass correlations between the two raters for interview quality variables were as follows: total units reflective listening (.99), total repeat questions (.94), total pauses (.99), and total interviewer interruptions (.97). 


\title{
Chapter VII
}

\author{
Study Two Results
}

\section{Data Elimination Procedures}

Although 25 police participants conducted an interview with the mock witness, data from only 24 police participants were included in the sample. One police participant was excluded from the sample due to a video recording malfunction (the tape did not record).

Descriptive Measures

Across all groups interviews lasted approximately 8 minutes $(M=8: 11, \mathrm{SD}=$ 4:53) with 47 exchanges between interviewers and witnesses on average $(M=46.94$, SD $=34.60)$. Interviewers asked the witness approximately 42 questions $(M=42.44, \mathrm{SD}=$ 34.57) and in turn witnesses provided interviewers with an average of 84 units of information $(M=83.92, \mathrm{SD}=37.99)$. In their written interview reports, interviewers wrote approximately 20 sentences $(M=19.94, \mathrm{SD}=28.68)$ that contained an average of 44 units of information $(M=43.98, \mathrm{SD}=36.40)$.

Novices. For student interviewers, interviews lasted approximately 5.5 minutes $(M$ $=5: 33, \mathrm{SD}=3: 16)$ with 25 exchanges between interviewers and witnesses on average $(M$ $=24.67, \mathrm{SD}=13.86)$. Interviewers asked the witness approximately 22 questions $(M=$ $21.50, \mathrm{SD}=11.90)$ and in turn witnesses provided interviewers with an average of 62 units of information $(M=61.79, \mathrm{SD}=27.36)$. In their written interview reports, interviewers wrote approximately 13 sentences $(M=12.83, \mathrm{SD}=8.12)$ that contained an average of 33 units of information $(M=32.96, \mathrm{SD}=17.08)$. 
Experts. For police interviewers, interviews lasted approximately 10.5 minutes ( $M$ $=10: 49, \mathrm{SD}=4: 52$ ) with 69 exchanges between interviewers and witnesses on average $(M=69.21, \mathrm{SD}=34.91)$. Interviewers asked the witness approximately 63 questions $(M$ $=63.37, \mathrm{SD}=37.22)$ and in turn witnesses provided interviewers with an average of 106 units of information $(M=106.04, \mathrm{SD}=32.03)$. In their written interview reports, interviewers wrote approximately 27 sentences $(M=27.04, \mathrm{SD}=38.85)$ that contained an average of 55 units of information $(M=55.00, \mathrm{SD}=46.50)$.

Accuracy

Across both groups, of all informational units reported by interviewers $82 \%$ were accurate while $18 \%$ were inaccurate. Of the inaccurately reported units $37 \%$ were false additions and $63 \%$ were false modifications. For accuracy of how information was elicited from the witness, interviewers reported eliciting the majority of informational units through open-ended narrative questions (65\%), followed by specific/closed (20\%), yes/no (13\%), and multiple choice (1\%). However, informational units were actually elicited from the witness during the interview through the four main question categories as follows: open-ended narrative (43\%), yes/no (33\%), specific/closed (17\%), and multiple choice (8\%). Additionally, $1 \%$ of the units were elicited through suggestive/leading questions.

Novices. Of all informational units reported by student interviewers $81 \%$ were accurate while $19 \%$ were inaccurate. Of the inaccurately reported units $37 \%$ were false additions and $63 \%$ were false modifications. For accuracy of how information was elicited from the witness, interviewers reported eliciting the majority of informational units through open-ended narrative questions (62\%), followed by specific/closed $(23 \%)$, 
yes/no (14\%), and multiple choice ( $0 \%)$. However, informational units were actually elicited from the witness during the interview through the four main question categories as follows: open-ended narrative (42\%), yes/no (35\%), specific/closed (16\%), and multiple choice (7\%). Additionally, $2 \%$ of the units were elicited through suggestive/leading questions.

Experts. Of all informational units reported by police interviewers $82 \%$ were accurate while $18 \%$ were inaccurate. Of the inaccurately reported units $37 \%$ were false additions and 63\% were false modifications. For accuracy of how information was elicited from the witness, interviewers reported eliciting the majority of informational units through open-ended narrative questions (68\%), followed by specific/closed (17\%), yes/no (12\%), and multiple choice (3\%). However, informational units were actually elicited from the witness during the interview through the four main question categories as follows: open-ended narrative (43\%), yes/no (31\%), specific/closed (17\%), and multiple choice (9\%). Additionally, $1 \%$ of the units were elicited through suggestive/leading questions.

Accuracy of witness information. A 2 (experts vs. novices) x 2 (note-taking vs. no note-taking) x 2 (summarized vs. verbatim report) MANOVA was conducted for the main dependent variable category accuracy of witness information on the following variables: total sentences written, total informational units reported, percent accurate units, percent inaccurate units, percent false additions, and percent false modifications. Results indicated a significant main effect of report type $(F(4,37)=2.68, p<.05)$. There were no other significant main effects or interactions, all $p s>.05$. Post hoc analyses for the main effect of report type indicated a significant difference for the number of 
sentences written in interview reports, $t(46)=-2.52, p<.02$. Verbatim report writers wrote more sentences in their interview reports $(M=31.65, \mathrm{SD}=41.89)$ than summarized report writers $(M=11.57, \mathrm{SD}=4.76)$. There were no other significant differences.

Accuracy of how information was elicited vs. reported. To determine whether there were differences between groups for accuracy of how information was reported as being elicited through the question types categories versus how that information was actually elicited a 2 (experts vs. novices) x 2 (note-taking vs. no note-taking) x 2 (summarized vs. verbatim report) MANOVA was conducted for the following dependent variables: percent units reported as being elicited through open-ended narrative questions, percent units reported as being elicited through specific/closed questions, percent units reported as being elicited through multiple choice questions, percent units reported as being elicited through yes/no questions, percent units actually elicited through openended narrative questions, percent units actually elicited through specific/closed questions, percent units actually elicited through multiple choice questions, percent units actually elicited through yes/no questions, and percent units actually elicited through suggestive/leading questions. Results indicated a significant main effect of report type $(F(8,33)=3.97, p<.01)$. There were no other significant main effects or interactions, all $p s>.05$. Post hoc comparisons for the main effect of report type (see Table 4) indicated that summarized report writers reported eliciting a greater percentage of informational units through open-ended narrative questions (70\%) than verbatim report writers $(58 \%)$. Verbatim report writers reported eliciting a greater percentage of informational units 
through multiple choice $(3 \%)$ and yes/no questions $(20 \%)$ than summarized report writers ( $1 \%$ and $9 \%$, respectively).

\section{Omissions}

Across all groups, only $56 \%$ of the informational units provided by the witness during the interview were later recalled by interviewers in their written reports. Thus, $44 \%$ of the information originally provided by the witness was missing from interview reports. Similarly, across all groups, $56 \%$ of the questions asked by interviewers were later recalled in interview reports. Thus, $44 \%$ of the questions asked by interviewers were omitted from written reports.

Completeness of witness information. A 2 (experts vs. novices) x 2 (note-taking vs. no note-taking) x 2 (summarized vs. verbatim report) MANOVA was then conducted for both dependent variables measuring completeness of witness information: percentage of units reported and percentage of units omitted. Results indicated a marginally significant main effect of note-taking $(F(1,40)=3.30, p<.08)$ on completeness of witness information: note-takers reported a greater percentage of witness information $(M$ $=.59, \mathrm{SD}=.17)$ and omitted a smaller percentage of witness information $(M=.41, \mathrm{SD}$ $=.17)$ than non note-takers $(M=.51, \mathrm{SD}=.15 ; M=.49, \mathrm{SD}=.15)$ in their interview reports. There were no other significant main effects or interactions, all $p>.05$.

Completeness of interviewer questions. To determine whether police interviewers and student interviewers differ in their questioning behavior during witness interviews, the mean number of questions and type of questions asked during the interview were examined. Specifically, a series of independent samples t-tests was conducted for the following variables: total questions asked, percent open-ended narrative questions asked, 
percent specific/closed questions asked, percent multiple choice questions asked, percent yes/no questions asked, and percent suggestive/leading questions asked. Since no differences were found between note-takers and non note-takers in Study One for the types of questions asked during the interview, this variable was not included in the analyses. Results for experience revealed a significant difference for total number of questions asked, percentage of open-ended narrative questions asked, and percentage of multiple choice questions asked (see Table 5). Police interviewers asked three times as many questions overall as student interviewers. Student interviewers asked a significantly greater percentage of open-ended narrative questions (20\%) than police interviewers $(13 \%)$. Police interviewers asked a significantly greater percentage of multiple choice questions (14\%) than student interviewers (8\%).

A 2 (experts vs. novices) x 2 (note-taking vs. no note-taking) x 2 (summarized vs. verbatim report) MANOVA was conducted for all dependent variables measuring completeness of interviewer questions: percent questions reported, percent questions omitted, percent open-ended narrative reported, percent specific/closed reported, percent multiple choice reported, percent yes/no reported, percent suggestive/leading reported, percent open-ended narrative omitted, percent specific/closed omitted, percent multiple choice omitted, percent yes/no omitted, and percent suggestive/leading omitted. There was a significant main effect of experience $(F(11,30)=3.57, p<.01)$ which was qualified by significant interactions between experience and report type $(F(11,30)=4.07$, $p<.01)$ and between note-taking and report type $(F(11,30)=2.23, p<.04)$. There were no other significant main effects or interactions, all $p s>.05$. Post hoc comparisons for the interaction between experience and report type (see Table 6) revealed that students who 
wrote verbatim reports reported a significantly greater percentage of the questions they asked during the interview (75\%) and omitted a significantly smaller percentage of their questions $(25 \%)$ than police participants regardless of report type (police summarized reported: 52\%, omitted: $48 \%$; police verbatim reported: $33 \%$, omitted: $67 \%$ ). Students who wrote verbatim reports reported a greater percentage of the open-ended narrative questions they asked (25\%) than students who wrote summarized reports $(23 \%)$.

Post hoc comparisons for the interaction between note-taking and report type (see Table 7) revealed a significant difference for the percentage of suggestive/leading questions omitted from interview reports: Non note-takers who wrote summarized reports omitted a greater percentage of suggestive leading questions (11\%) than all note-takers irrespective of report type (note-taking summarized: 1\%; note-taking verbatim: $1 \%$ ). Interview Quality

To determine the effect of note-taking and experience on interview quality a 2 (experts vs. novices) x 2 (note-taking vs. no note-taking) MANOVA was conducted on the following interview quality variables: total reflective listening units, percentage of repeat questions asked, total pauses, and total interviewer interruptions. Results indicated a significant main effect of experience $(F(4,41)=3.89, p<.01)$ and a significant main effect of note-taking $(F(4,41)=3.82, p<.01)$ on interview quality variables with no interaction between the variables, $p>.05$. Post hoc comparisons revealed that experienced police interviewers paused significantly more often $(M=8.62, \mathrm{SD}=8.04)$ and engaged in reflective listening for more informational units throughout out the interview $(M=29.00, \mathrm{SD}=26.44)$ than student interviewers $(M=4.00, \mathrm{SD}=4.95 ; M=$ $8.92, \mathrm{SD}=7.18), t(46)=2.40, p<.02$ and $t(46)=3.59, p<.00$, respectively. There were 
no other significant differences between experienced and lay interviewers for any of the other dependent variables, $p s>.05$.

Post hoc comparisons for the main effect of note-taking indicated that note-takers paused significantly more often $(M=8.54, \mathrm{SD}=8.28)$ and engaged in reflective listening more often throughout the interview $(M=24.23, \mathrm{SD}=26.69)$ than non note-takers $(M=$ $3.68, \mathrm{SD}=3.86 ; M=12.73, \mathrm{SD}=11.37), t(46)=2.67, p<.01)$ and $t(46)=1.99, p<.05$, respectively. There were no other differences between note-takers and non note-takers for any of the other dependent variables, $p>.05$.

\section{Hypotheses}

Hypothesis 1. The first hypothesis expected experienced police interviewers to write more complete and accurate interview reports than lay interviewers. This hypothesis was not supported as no significant main effects of experience were found for any of the accuracy measures or completeness of witness information measures. Contrary to the hypothesis, students who wrote verbatim reports were found to account for questions asked during the interview better than police interviewers.

Hypothesis 2. The second hypothesis predicted that note-takers would write more complete and accurate interview reports than non note-takers. This hypothesis was only partially supported. Differences between note-takers and non note-takers were not significant for any of the accuracy measures. However, note-takers did report a greater percentage of accurate informational units than non note-takers. Note-takers also reported more and omitted less witness information than non note-takers and better accounted for their own questions asked during the interview than non note-takers. 
Hypothesis 3. The third hypothesis predicted that verbatim report writers would write more complete and accurate reports than summarized report writers. This hypothesis was partially supported. Verbatim report writers were found to writer longer reports than summarized report writers. Verbatim report writers were also more likely to report eliciting information through problematic questions types such as multiple choice and yes/no questions, than summarized report writers. Summarized report writers on the other hand reported eliciting a greater percentage of informational units through openended narrative questions than verbatim report writers. Thus, verbatim report writers reported eliciting information from the witness that was more consistent with how information was actually elicited from the witness during the interview than summarized report writers. Finally, writing a verbatim report appeared to be particularly beneficial for novice interviewers: student verbatim report writers reported a greater percentage of the questions they asked than all police participants.

Hypothesis 4. The fourth hypothesis predicted that police note-takers who wrote verbatim reports would write the most complete and accurate interview reports than all other groups. This hypothesis was not supported as no three-way interactions were found between experience, note-taking, and report type for any of the accuracy, completeness of witness information, or completeness of interviewer questions measures.

Hypothesis 5. The sixth hypothesis predicted that police note-takers would conduct the highest quality interviews compared to all other groups. This hypothesis was not supported as there was no interaction between note-taking and experience for any of the interview quality measures. 


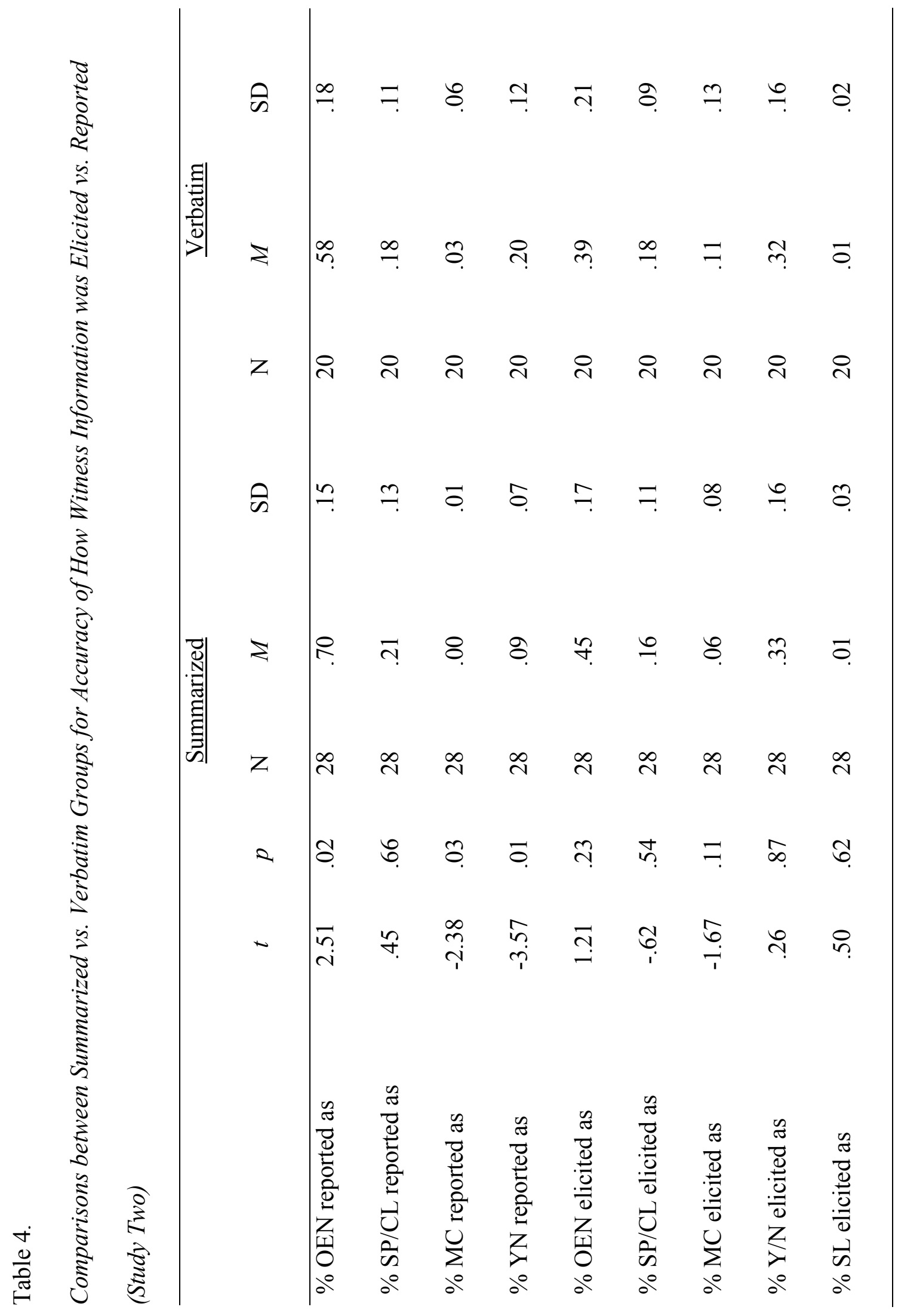




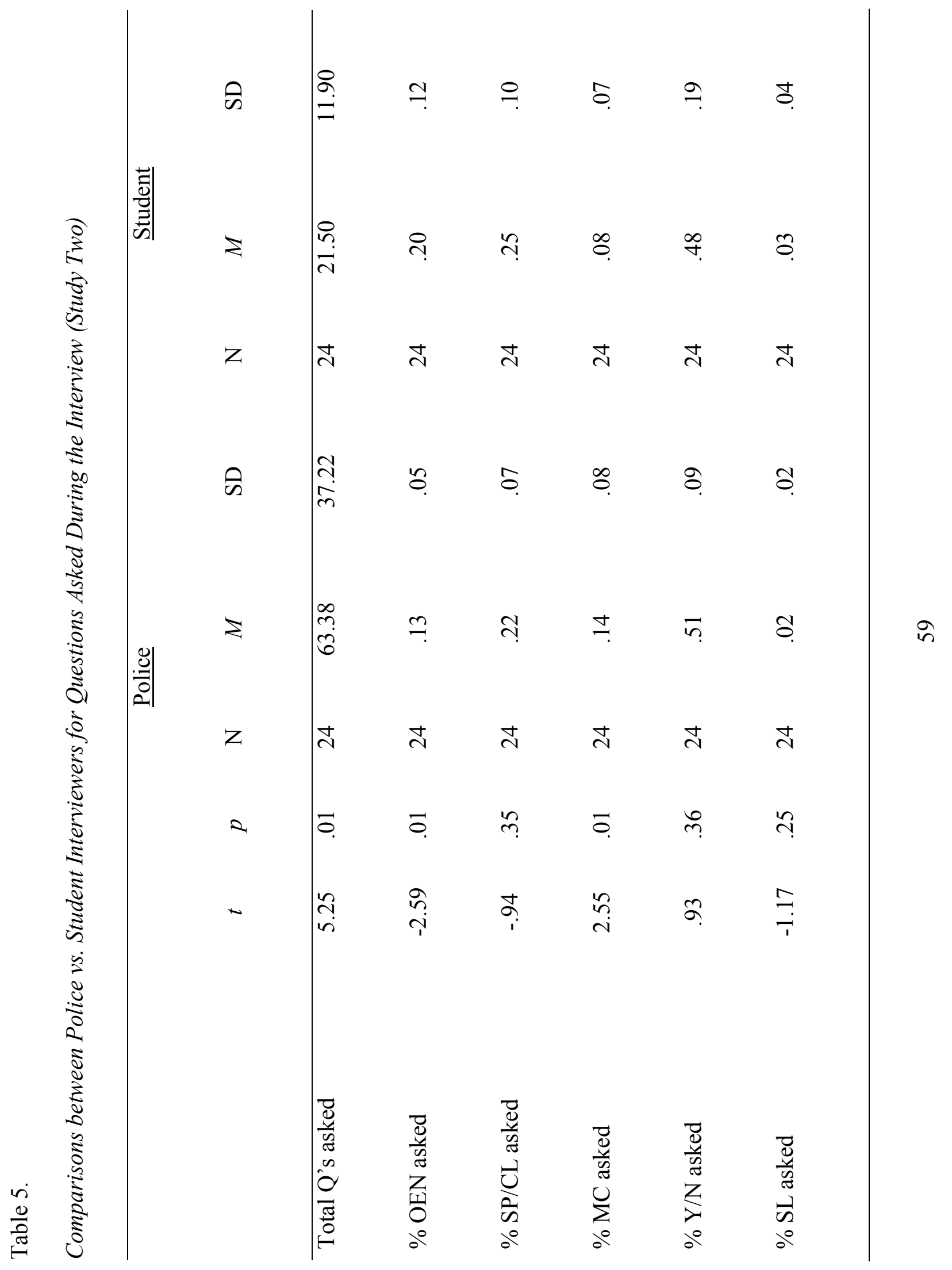




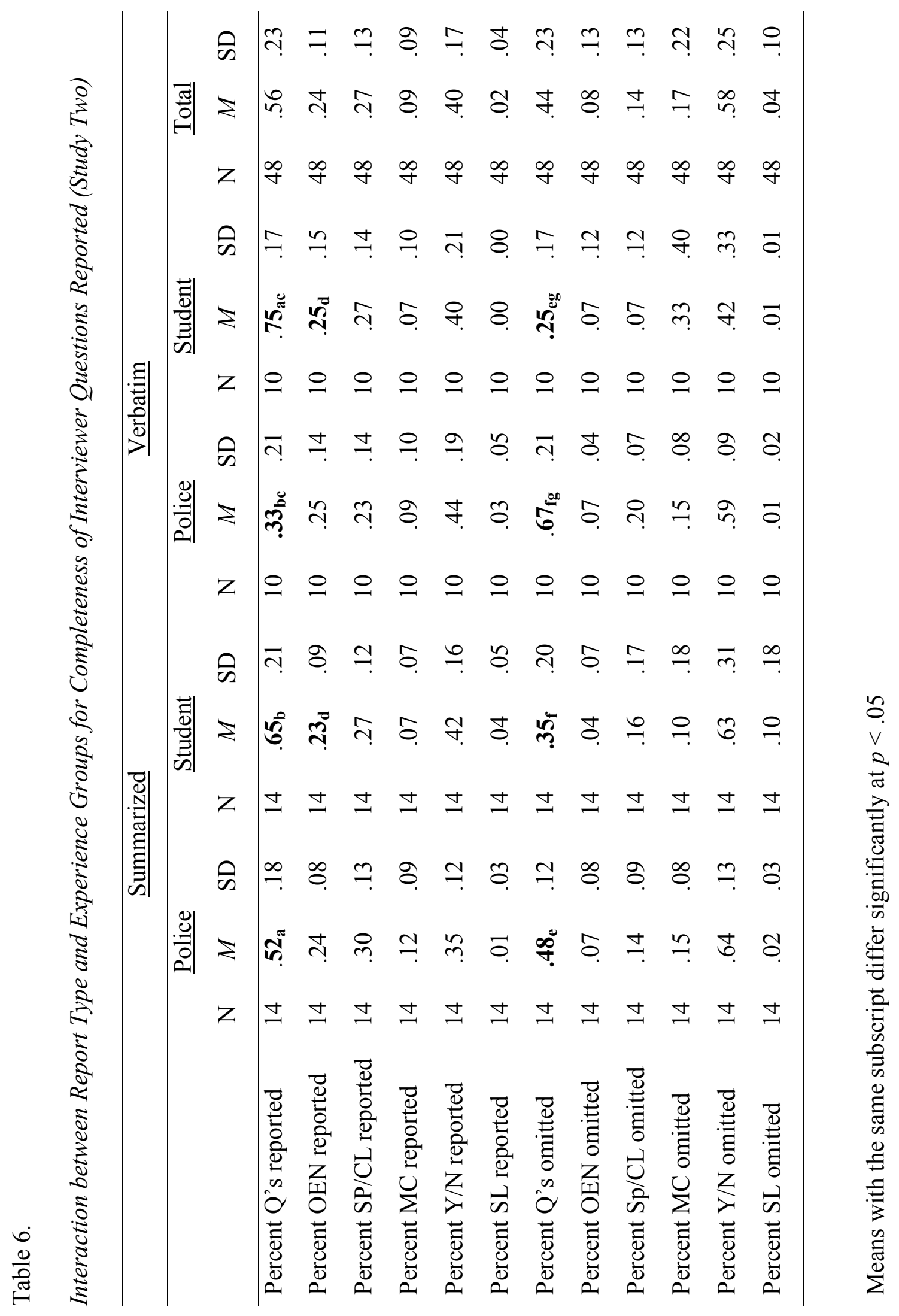




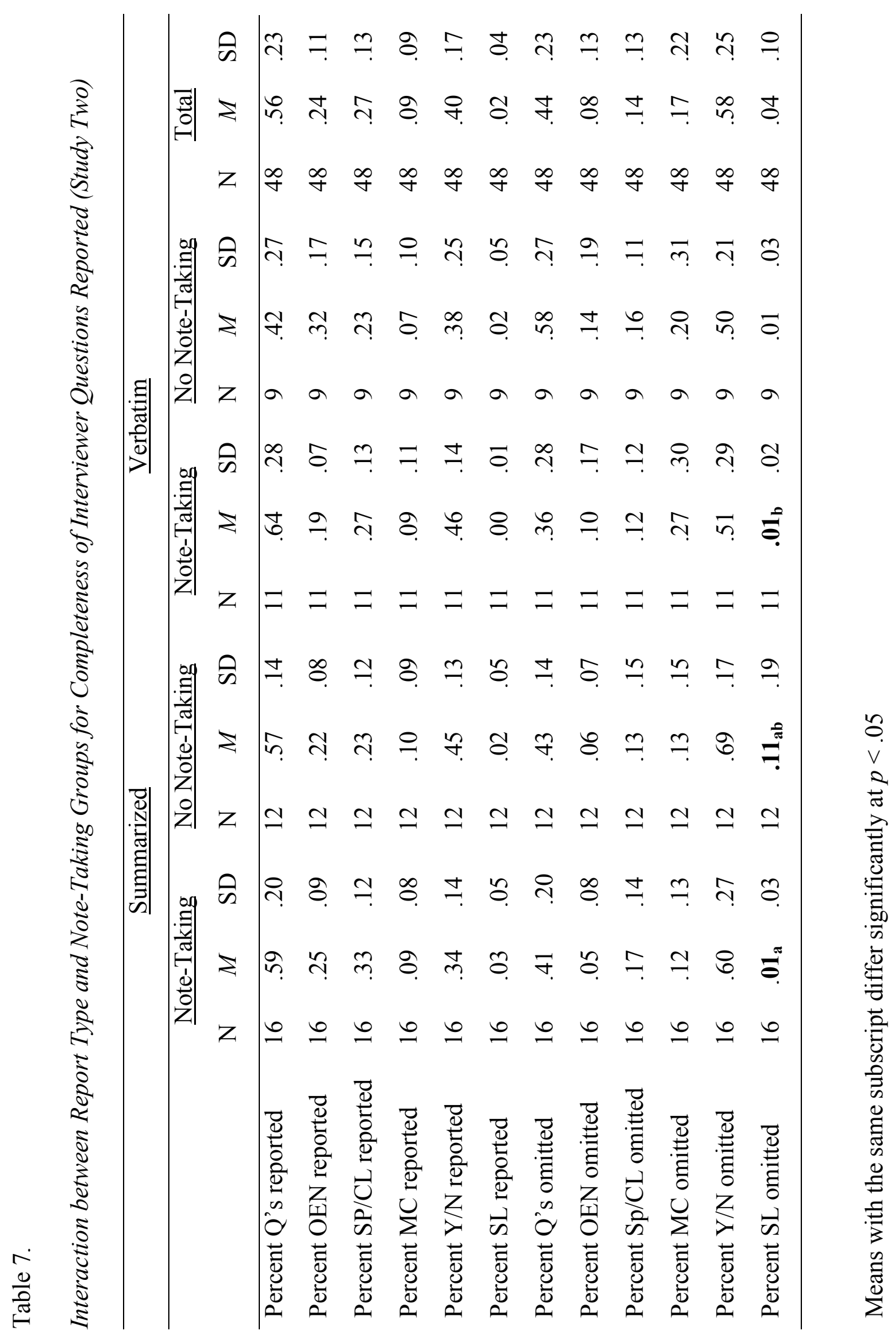




\title{
Chapter VIII
}

\author{
Study Two Discussion
}

\section{Interviewer Recall}

The findings of Study Two confirmed Study One's findings and suggest that interviewer memory for a prior witness interview is lacking even when recall occurs immediately following the interview. Although most information stated in interviewers' written reports was again accurate $(82 \%)$, a troubling one-fifth of interview information reported was inaccurate - even without any delay between interview and report. Even more alarming was the high frequency of errors of omission: Interviewers failed to report over half of the questions they asked the witness and the witness's responses to these questions.

These findings confirm the earlier notion that if witness interviews are not recorded via video or audio equipment, interviewers run the risk that a large portion of the interview will be undocumented. Furthermore, if interviewers testify in court regarding a witness interview while relying solely on their subsequent interview report, the trier of fact is likely only provided with slightly more than half of the content of the actual interview. These findings highlight the importance of electronically recording all witness interviews.

\section{Interviewer Questions}

Extending Study One's findings, Study Two also suggests that both interviewer groups lack insight into how information was originally elicited from a witness during a witness interview. Regardless of experience, interviewers reported eliciting the majority of witness information via open-ended narrative questions (65\%). Although a moderate 
portion of witness information was in fact elicited through open-ended narrative questions (43\%) a considerable percentage of information was elicited through yes/no questions (33\%). Interviewers in Study Two erroneously attributed $22 \%$ of the information elicited from the witness to open-ended narrative questions when in fact this information was actually elicited via yes/no, specific/closed, and multiple choice questions. When proffering testimony in court is it important for interviewers to indicate how witness information was elicited because misattributing a witness's response originally elicited via a yes/no or specific/closed question to an open-ended narrative question may result in an erroneous credibility judgment regarding the witness's statement. For example, when assessing a child witness's credibility it would make a great difference whether the child spontaneously told an interviewer about his/her sexual abuse after being prompted by an open-ended question or if the child simply acquiesced to a yes/no question asking the child if s/he had been inappropriately touched. Numerous studies have confirmed that how child witnesses are interviewed can greatly affect the accuracy of their subsequent statements (e.g., Eisen et al., 2002; Poole \& Lamb, 2002; Sternberg, Lamb, Esplin, Orbach, \& Hershkowitz, 2002). It is therefore crucial for interviewers to account for how witness information was originally elicited from a witness so that an accurate credibility judgment can be made.

Regardless of experience, when recalling questions interviewers were again most likely to recall asking predominantly open-ended narrative questions than all other question types. Across both studies, all interviewers were most likely to forget asking yes/no questions than all other question types. It is likely that interviewers failed to recall yes/no questions as these were the questions that interviewers asked the most during the 
interview, therefore rendering them harder for interviewers to keep track of. Furthermore, yes/no questions do not provide a lot of witness information. The failure to recall many yes/no questions suggests that memory for interviewer questions might be directly tied to the amount of information they elicit and the memory for this witness information. Thus, if the interviewer asked a yes/no question that did not elicit a meaningful response from the witness it seems plausible that the interviewer may not have recalled the question or the witness's response. For example, if the interviewer asked "Did the suspect walk with a limp?" and the witness responded "no," the interviewer may have felt that this information was irrelevant and therefore may not have recorded it in their notes (if they took notes) or did not retain this information in memory. These findings are further evidence that interviewers should strive to ask predominantly open-ended narrative questions as these questions may be easier to recall later on than yes/no and specific/closed questions.

Experience

Commonsense would predict that police interviewers are better at conducting and remembering witness interviews than lay people. Police interviewers spend much of their time interviewing witnesses/victims and receive at least some training in this area either in the academy or on the job (Fisher \& Schreiber, 2007). Study Two was designed to examine whether experienced police interviewers were better at conducting (see Interview Quality) and later recalling (see Experience) a witness interview than lay interviewers while manipulating note-taking and report format. Findings suggest that despite the 15 years of experience interviewing witnesses, police officers were not better at recalling their interviews than student interviewers. Police officers wrote reports that 
were no more accurate than student reports. Contrary to what was expected, police officers in the verbatim report condition recalled the smallest percentage of questions they originally asked (33\%), compared to students who wrote verbatim reports, who reported the largest percentage $(75 \%)$ of their questions. It appears then that student interviewers benefited the most from the verbatim report format. However, police officers were clearly not receptive to this report format. A possible explanation for this finding is that police officers generally write summarized reports. When they interview witnesses they may therefore seek to elicit information that is consistent with the information that needs to be included in a police report. When later writing a verbatim report, they are at a disadvantage recalling the information using a different recall structure than they are used to. As police interviewers are not accustomed to keeping track of the questions they ask, this information might not be viewed as important when attempting to solve a case and completing a police report.

Interview quality. Although note-taking and experience did not impact police investigators' later recall of the interview, there was some evidence that experience had a positive impact on interview quality. Specifically, police interviewers paused more often throughout the interview, engaged in a greater amount of reflective listening, conducted longer interviews, and asked more questions overall than student interviewers. Taken together, these findings suggest that police officers conducted more thorough witness interviews; they took their time when asking questions, asked more follow-up questions, and made sure they understood the witness's responses. Interestingly, conducting more thorough witness interviews did not translate into better memory for the witness interview afterwards. 
Questions asked. What types of questions interviewers ask during witness interviews has been found to influence the quantity and accuracy of witness responses (Eisen et al., 2002; Fisher, 1995). Therefore, question type can also be used as an indicator of interview quality. Although experienced police interviewers conducted interviews that were more thorough than student interviewers, the majority of questions police investigators asked were of problematic types (yes/no, specific/closed, and multiple choice). Although the majority of questions asked by students were also of problematic types, student interviewers asked significantly more open-ended narrative questions than police interviewers, while police interviewers asked significantly more multiple choice questions than students.

A possible explanation for this finding is that police officers may be likely to ask questions that are consistent with information needed to complete a police report therefore seeking out specific information via specific/closed and yes/no questions. Students on the other hand, had no prior experience interviewing witnesses or writing police reports. Thus, when asking the witness questions they were likely interested in obtaining as much information as possible about the crime without a preconceived interview structure. As a result, they may have been more inclined to ask open-ended narrative questions. Ironically, police officers' experience with interviewing witness and writing departmental police reports might have actually led to more possibly problematic interviewing techniques than lay interviewers without the same experience. Note-Taking

Although note-takers and non note-takers did not differ significantly in accuracy as they did in Study One, note-takers still reported a greater percentage of accurate 
information than non note-takers in Study Two (not significantly so). The lack of a difference between note-takers and non note-takers in Study Two is likely due to the fact that interviewers recalled the interview immediately after as opposed to a two week delay. Interview information was likely readily available in interviewers' memory and therefore less vulnerable to forgetting, interference, and decay. Note-taking may therefore not have added to this already existing ceiling effect. Interestingly, although recall in Study Two occurred immediately afterwards, interviewers were still only $82 \%$ accurate (84\% after note-taking). This finding suggests that even under "perfect" conditions, i.e., immediate recall with the option to take notes, memory for a prior witness interview is less accurate than should be expected, especially considering that participants had not been exposed to any misinformation or distracter task in the interim.

This finding also has direct implications for the criminal justice system especially if interviewers submit written interview reports as evidence in court. It is troubling to know that one-sixth of the information that interviewers submit and/or may later testify to is inaccurate even when interviewers take notes during the interview!

Similar to Study One note-takers reported a greater percentage of witness information and a greater percentage of the questions they asked during the interview than non note-takers, suggesting that note-taking does have a positive effect on completeness of interview information reported. However, errors of omission were quite frequent in both studies even when interviewers took notes. Interviewers still failed to report approximately $40 \%$ of the interview content when they took notes and recalled the interview immediately after. 
Interview quality. Similar to the findings of Study One, Study Two also found that note-takers paused more often and engaged in more reflective listening than non notetakers. Taken together these findings suggest that note-takers may have been more motivated to understand the witness's statement and to take their time when asking questions and recording the witness's responses. Interviewer pausing and reflective listening can be considered indicators of higher quality interviews. However, there were no differences between note-takers and non note-takers for "negative" interviewing techniques such as interviewer interruptions or repeated questions, suggesting that notetaking in Study Two only had a select effect on "positive" techniques. Consistent with what was found in the previous study; there appear to be no known negative consequences associated with interviewer note-taking during investigative interviews. Thus, note-taking should be considered a beneficial tool for investigative interviewers when conducting witness interviews.

Report Type

The type of report written by interviewers after a witness interview does not appear to be as beneficial to interviewer recall as note-taking during the interview. Similar to the previous study, report type only made a difference in recall of interviewer questions. However, unlike Study One, in Study Two differences between verbatim and summarized reports were in the expected direction such that verbatim reports led to a greater percentage of questions recalled and a more accurate recall of how information was elicited than summarized reports. It appears then that the effect of report type may be contingent upon the recall delay and the type of information recalled or reported. Shortly after a witness interview, a more detailed report option can assist in better accounting for 
interviewer portions of the interview, while the information is still available. As memory for conversations is likely be encoded as a gist memory with time, a verbatim retrieval format at a later time may be unsuccessful due to the way conversational information has been stored (Bruck et al., 1999). 


\section{Chapter IX}

\section{General Discussion}

When interviewers or expert witnesses testify in court regarding a written interview report, the information contained in the report is generally believed to be accurate. Rarely is it the case that additional sources of information such as audio/video recording or notes are available to cross-check interviewers' verbal or written memory. The current studies suggest that both lay and expert interviewers' written interview reports contain a considerable amount of inaccurate witness information and are missing a great deal of interview content. Whether interviewers took notes and how they recalled interview information appeared to be of only limited importance.

\section{Evaluating Accuracy}

Although accuracy rates in Study One (73\%) and Study Two (82\%) could be considered reasonably high, this amount of inaccurate information can have detrimental consequences. Specifically, if such interviewer reports are considered evidence, the inability to tell which $20 \%$ of the information reported is fraught with error, has the potential to lead to false conclusions and possibly convictions. Importantly, the error rate seemed to depend little on recall delay or note-taking: even immediately following the interview interviewers inaccurately reported almost one-fifth of the interview information. Only after a two week delay, were note-takers at an advantage and reported less inaccurate information than those who did not. Potential differences between immediate (Study Two) and delayed note-takers (Study One) may be explained in terms of simple forgetting or by differences in referring back to one's notes. Note-takers in Study Two may not have referred back to their notes when writing their reports as 
interview information was still very much available and "fresh" in their memories and therefore their notes may have been considered unnecessary. As was found by Kiewra and colleagues (1991), simply taking notes but not reviewing those notes at a later time does not lead to more accurate recall than listening alone. In line with Study Two's findings, the encoding function of note-taking would predict that unless note-takers review and rely on their notes when generating their reports no differences should be found between note-takers and non note-takers for immediate recall. Interviewers in Study One may have been more likely to rely on their notes after the two-week delay because they anticipated that their memory performance was likely to benefit from potential cues provided by their original notes. This finding is consistent with the encoding plus external storage function of note-taking (Kiewra et al., 1991). Thus, reviewing their notes helped interviewers in Study One remember the interview more accurately than non note-takers.

\section{Evaluating Omissions}

What is more concerning than the amount of incorrect information reported by interviewers is the high frequency of omissions of both interviewer questions and witness responses. Even when interviewers took notes and recalled the interview immediately after, $40 \%$ of the interview remained undocumented. It is not clear whether this information was forgotten by interviewers or whether interviewers simply did not report some questions or answers because they did not deem the information relevant. Future studies should include a recognition test that asks interviewers to indicate which questions they asked during the interview and a free recall test to test why certain pieces of information were not reported. 
In Bruck, Ceci, and Francoeur (1999), a recognition test was created for mothers to recall a conversation they had with their pre-school aged child. The recognition test contained actual passages from the conversation with the child and included passages where the structure of sentences was changed but the gist of the conversation was intact and passages where the gist of the conversation was changed. Mothers were poor both at recognizing how information was obtained from their children and at identifying surface structural changes to the conversation. Mothers recalled even fewer questions they asked during the conversation (16\%) than interviewers in the current study. Taken together, these findings suggest that interviewers show limited abilities to recall which questions they asked. Future recognition tests should include a multiple choice format so that interviewers can identify the specific questions they asked during an interview. This will allow researchers to examine whether memory for interviewer questions is lacking due to retrieval or encoding factors.

The findings of the present studies likely underestimate the occurrence of errors of omission and commission in interview reports. Across both studies interviews lasted approximately seven minutes. It seems likely that real witness interviews likely last longer. Furthermore, the crime viewed by mock witnesses in the current studies was rather uncomplicated; interviews involving more complex crimes should likely take longer to conduct. Although the frequency with which errors of omission and commission occur in longer interviews is unclear, it seems plausible that longer interviews will further decrease interviewer recall because there is simply more interview information to retain. 


\section{Interviewer Questions}

Police and student interviewers asked predominately yes/no and specific/closed questions, and rarely asked open-ended narrative questions when interviewing the witness. Questioning witnesses, especially child witnesses, with predominately yes/no and specific/closed questions decreases the quantity of information provided by the witness and may lead to inaccurate witness information (Eisen et al., 2002; Fisher, 1995). Although it is not surprising that lay interviewer, who had no experience and training in witness interviewing used a closed interview style, it is noteworthy that even experienced investigators used mostly closed questions at a time when evidence-based investigative interviewing guidelines are readily available. All guidelines emphasize that interviewers should be cognizant of the types of questions asked during a witness interview and that open-ended questions are preferable over closed questions. However, this finding is in line with other research showing that real-world investigators ask mostly yes/no and specific/closed questions (Schreiber Compo, Hyman Gregory, \& Fisher, 2009).

Regardless of experience and the types of questions asked, interviewers were inaccurate in recalling how pieces of information were elicited from the witness. Interviewers incorrectly reported eliciting the majority of witness information through open-ended narrative questions when witness information was actually elicited through a combination of open-ended narrative, yes/no, and specific/closed questions. These findings are consistent with the Bruck et al. (1999) study which found that mother's were unable to accurately identify whether their child offered a one word response to a specific/closed question or as a spontaneous response to an open-ended prompt. Relatedly, Warren and Woodall (1999) found that interviewers thought they had asked 
predominately open-ended questions when $80 \%$ of the questions they asked were specific/closed.

If interviewers testify in court regarding the credibility of a witness's statement then they need to be able to specify precisely how the information was elicited. This information is crucial for evaluating the veracity of the witness's statement. Different credibility judgments can be made regarding a witness's statement if the information was provided in a free narrative form rather than through a series of responses to yes/no, specific/closed, and multiple choice questions. As was found in the present studies, interviewers' reports falsely suggested that the majority of witness information was elicited via open-ended narrative questions, implying a higher credibility of the witness's statement than would have been warranted based on the actual questions asked.

As there is a crucial need for interviewers to accurately indicate in a court of law how witness information was actually elicited from a witness, it is indispensable for interviewers to record this information. The most efficient way to do so is to electronically record witness interviews and to base later reports on these recordings. As demonstrated, interviewer note-taking is not a sufficient substitute. However, if electronic recording devices are not available and the interview cannot be conducted at a later time when these devices are available then interviewers should try to take verbatim notes during the interview. As the current studies suggest, there are no known negative consequences of interviewer note-taking during witness interviews. Report Type

Surprisingly, there was no predicted effect of the type of report written by interviewers on the quantity or quality of information reported. However, summarized 
report writers in Study One reported a greater percentage of the questions they asked than verbatim report writers. In Study Two, students who wrote verbatim reports reported more than twice the questions they asked than police officers who wrote verbatim reports. Writing verbatim reports did not appear to help police interviewers recall more of the questions they asked.

A possible explanation for this finding is that police officers are not used to accounting for the questions they ask. When filling out police reports, police interviewers are not expected to indicate the questions they asked to elicit witness information. Additionally, police officers may have assumed that the questions they asked were irrelevant and therefore may have put little effort into recalling and reporting them. Students on the other hand, had no prior experience with a specific interview (recall) format when reporting interview information resulting in little or no conflict with prior interview recall strategies. Student verbatim report writers may have had fewer assumptions than police verbatim report writers about whether specific questions asked were more or less crucial to solving the case.

Because of the mixed findings regarding report type, it is impossible to draw firm conclusions regarding the best type of report for interviewers to write to increase accuracy and recall of interview information. Rather, to increase accuracy and recall of interview information it might be best for interviewers to incorporate a verbatim format into note-taking instead of or in addition to writing subsequent verbatim interview reports. In verbatim notes interviewers could record verbatim each question asked and the witness's response. Verbatim notes could then be used to assist interviewers to write more accurate reports that better account for how information was elicited from the 
witness. In their summarized reports interviewers could list the types of questions that elicited information so those reading the report would be able to determine which witness information to give the greatest credence to. Future research should address this possibility.

Conflicting findings for report type between Study One and Study Two may also have resulted from measurement error. In order to determine whether questions were reported by interviewers in summarized reports, scorers had to infer question type based on how the summary was written and the reporting of witness information. In verbatim reports interviewers clearly reported the questions they recalled asking, therefore no inference had to be made. This inference may have made it appear as though summarized report writers in Study One reported more of their questions than verbatim report writers. Instead, summarized report writers may simply have reported more witness information than verbatim report writers. This inference may have translated to a greater percentage of questions reported for summarized report writers. This inference may also account for an increase in interviewers reporting more information as being elicited through openended narrative questions in summarized reports. When writing a summary of what occurred during the interview, interviewers were more likely to report information as though it was elicited from the witness via a free narrative. This measurement error should be considered when interpreting the findings of the current studies.

\section{Recommendations}

Several recommendations for investigative interviewing and the legal system can be made based on the findings of the present studies. First, investigative interviews with witnesses should always be recorded via video or audio equipment, preferably the former. 
Watching these recordings can assist interviewers to recognize better how information was elicited from the witness and to recall all aspects of the interview and information provided by the witness than interviewer reports without those recordings. Second, if it is not possible to record a witness interview and it is not possible to postpone the interview until media equipment is available, then interviewers should take thorough verbatim notes during the interview that account for the questions asked, the content of questions, and the witness's verbatim responses. Keeping track of this information will likely increase the accuracy and completeness of interviewer notes and subsequent written reports. Third, in their reports interviewers should indicate the types of questions that elicited witness information so that the trier of fact can evaluate the credibility of the witness's statement. Interviewers should report whether information was provided spontaneously by the witness based on an open-ended narrative or whether the witness provided information based on a series of yes/no or specific/closed questions. Fourth, investigative interviewers should be aware of the limitations of their own memory and should disclose this when testifying in court. Fifth, investigators and the legal system should be educated regarding the problems associated with relying on interviewer reports of non-recorded witness interviews regardless of when the reports were written. Judges, jurors, and attorneys should be informed that interview reports are likely to contain inaccurate information, are suboptimal at accounting for questions asked and are likely to exclude considerable amounts of witness information originally provided. Members of the legal arena should also be informed that years of experience interviewing witnesses appear to play no role in the accurate recall of witness interviews. 


\section{Limitations and Future Directions}

There are limitations to the current studies that should be considered when interpreting the findings. First, witnesses in the present studies were not exposed to a real crime and interviewers were informed that they were to interview a mock witness about a crime. Knowing this information may have affected the way interviews were conducted by interviewers (e.g., the questions they chose to ask), the notes taken by interviewers, and the information reported in subsequent interview reports. Future studies should evaluate interviewer memory for interviews with real witnesses. Second, the majority of participants were undergraduate psychology students with nothing else at stake than research credit. Thus, it is unclear how motivated these participants were to interview mock witnesses thoroughly and remember accurately what occurred during the interview. Anecdotal evidence supports that some participants were not interested in asking many questions. In fact, some participants even conducted interviews that lasted less than three minutes. Across both studies interviews lasted approximately seven minutes. It is unclear how long investigative interviews with witnesses for various types of crimes generally last. Thus, future research should evaluate interview length across various types of crimes. Third, the mock crime used in the present study was rather uncomplicated and mundane: A male student stole money from the wallet of a female student. It is unclear whether this crime scenario is consistent with cases that interviewers routinely testify about. It is seems unlikely that a police officer in lieu of the witness would testify in court regarding this type of crime. Cases where interviewers are called to testify likely involve serious and complicated crimes such as child sexual abuse, murder, and rape. It seems plausible that more complicated crimes might increase the reporting of inaccurate 
information and omissions by interviewers as they are likely to include more details and various parties with more information for interviewers to recall at a later time. It is unclear how interviewer memory for a prior witness interview might be influenced by the type of crime witnessed. Future studies should vary the type of crime witnessed, violent versus non-violent, to determine its effect on interviewer recall. It also seems possible that an interviewer's emotions could play a role in recall of a witness interview.

Interviewers and witnesses in the present study were not likely to have experienced emotional arousal during the interview. It seems likely that emotional arousal during a witness interview has an impact on both interviewer and interviewee recall. Currently, no studies have evaluated the impact of interviewer emotions on interviewer recall for a prior witness interview. Future studies should vary the emotionality of a witnessed event to determine its influence on interviewer memory. 


\section{REFERENCES}

Benton, S. L., Kiewra, K. A., Whitfill, J. M., \& Dennison, R. (1993). Encoding and external-storage effects on writing processes. Journal of Educational Psychology, 85(2), 267-280.

Biesanz, J. C., Neuberg, S. L., Judice, T. N., \& Smith, D. M. (1999). When interviewers desire accurate impressions: The effects of notetaking on the influence of expectations. Journal of Applied Social Psychology, 29(12), 2529-2549.

Bruck, M., Ceci, S. J., \& Francoeur, E. (1999). The accuracy of mothers' memories of conversations with their preschool children. Journal of Experimental Psychology: Applied, 5(1), 89-106.

Burnett, J. R., Fan, C., Motowidlo, S. J., \& Degroot, T. (1998). Interview notes and validity. Personnel Psychology, 51(2), 375-396.

Ceci, S. J. \& Bruck, M. (1993). Suggestibility of child witnesses: A historical review and synthesis. Psychological Bulletin, 113(3), 403-439.

Eisen, M. L., Quas, J. A., Goodman, G. S. (2002). Memory and suggestibility in the forensic interview. Mahwah, NJ, US: Lawrence Erlbaum Associates Publishers.

Fisher, R. P. (1995). Interviewing victims and witnesses of crime. Psychology, Public Policy, and Law, 1(4), 732-764.

Fisher, R. P., \& Geiselman, R. E. (1992). Memory-enhancing techniques for investigative interviewing: The cognitive interview. Springfield, IL: Charles C. Thomas.

Fisher, R. P., \& Schreiber, N. (2007). Interview protocols for improving eyewitness memory. In M. P. Toglia, D. J. Read, D. F. Ross, \& R. C. L. Lindsay (Eds.) The handbook of eyewitness psychology, Volume I: Memory for events (pp. 53-80). Mahwah, NJ: Lawrence Erlbaum Associates Publishers.

Hartley, J. (2002). Notetaking in non-academic settings: A review. Applied Cognitive Psychology, 16, 559-574.

Home Office (2007). Achieving Best Evidence in Criminal Proceedings: Guidance on interviewing victims and witnesses and using special measures. London, UK: Author.

Kiewra, K. A. (1989). A review of note-taking: The encoding-storage paradigm and beyond. Educational Psychology Review, 1, 147-172. 
Kiewra, K. A., DuBois, N. F., Christian, D., McShane, A., Meyerhoffer, M., \& Reoskelley, D. (1991). Note-taking functions and techniques. Journal of Educational Psychology, 83(2), 240-245.

Kohnken, G., Thurer, C., \& Zoberbier, D. (1994). The cognitive interview: Are the interviewers' memories enhanced, too? Applied Cognitive Psychology, 8, 13-24.

Kolk, N. J., Born, M., van der Flier, H., \& Olman, J. M. (2002). Assessment center procedures: Cognitive load during the observation phase. International Journal of Selection and Assessment 10 (4), 271-278.

Lamb, M. E., Orbach, Y., Sternberg, K. J., Hershkowitz, I., \& Horowitz, D. (2000). Accuracy of investigators' verbatim notes of their forensic interviews with child abuse victims. Law and Human Behavior, 24(6), 699-708.

Poole, D., \& Lamb, M. E. (1998). Investigative interviews of children: A guide for helping professionals. Washington, DC: American Psychological Association.

Reisberg, D. (2006). Cognition: Exploring the Science of the Mind. New York: W.W. Norton \& Company.

Rickards, J. P. \& McCormick, C. B. (1988). Effects of interspersed conceptual prequestions on note-taking in listening comprehension. Journal of Educational Psychology, 80(4), 592-594.

Schreiber Compo, N., Hyman Gregory, A., \& Fisher, R. P. (2009). Interviewing behaviors in police investigators and implications for training policy. Manuscript in preparation, Florida International University.

Sternberg, K. J., Lamb, M. E., Esplin, P. W., Orbach, Y., \& Hershkowitz, I. (2002). Using a structured interview protocol to improve the quality of investigative interviews. In M. L. Eisen, J. A. Quas \& G. S. Goodman (Eds). Memory and suggestibility in the forensic interview. (pp. 409-436). Mahwah, NJ: Lawrence Erlbaum Associates Publishers.

Warren, A. R. \& Woodall, C. E. (1999). The reliability of hearsay testimony: How well do interviewers recall their interviews with children? Psychology, Public Policy, and Law, 5(2), 355-371. 


\section{APPENDIX A}

\section{Initial Interviewer Instructions:}

Place yourself in the shoes of a police investigator. You are about to interview a person about a crime that they just witnessed. Please gather as much information as possible from the witness about the crime. As an investigator, you will want to obtain as many details as you can from the witness, to piece together what the witness saw. You should ask the witness questions that will help to later solve the crime. You will be provided with paper to take notes during the interview. Feel free to record as much information as you would like. Please try and remember as much information as possible. You will be asked to return in weeks at which point you will be given back your notes and will be asked to recall the interview. 


\section{APPENDIX B}

\section{Initial Interviewer Instructions:}

Place yourself in the shoes of a police investigator. You are about to interview a person about a crime that they just witnessed. Please gather as much information as possible from the witness about the crime. As an investigator, you will want to obtain as many details as you can from the witness, to piece together what the witness saw. You should ask the witness questions that will help to later solve the crime. Please try and

remember as much information as possible. You will be asked to return in weeks at which point you will be asked to recall the interview. 


\section{APPENDIX C}

\section{Interviewer Report Instructions}

During the study, you interviewed a witness about a videotaped staged event. Please write a summary of everything that occurred during the interview with the witness. Please summarize the witness's statement providing as much information as possible that would be important to investigators solving a crime. If you took notes during the interview, feel free to refer back to them when summarizing the interview. If you have any questions about this task, please ask the experimenter. 


\section{APPENDIX D}

\section{Interviewer Report Instructions}

During the study, you interviewed a witness about a videotaped staged event. Please write a summary of everything that occurred during the interview with the witness.

Please summarize the witness's statement providing as much information as possible that would be important to investigators solving a crime. If you have any questions about this task, please ask the experimenter. 


\section{APPENDIX E}

\section{Interviewer Report Instructions}

During the study, you interviewed a witness about a videotaped staged event. Please write a summary of everything that occurred during the interview with the witness. Please record word-for-word the questions that you asked the witness and the witness's responses to your questions. Please try and record information in transcript format indicating specifically who said what during the interview, providing information that would be important to investigators solving a crime. If you took notes during the interview, feel free to refer back to them when summarizing the interview. If you have any questions about this task, please ask the experimenter.

\section{Example of transcript format:}

Q: Where were you standing when the balloon popped?

A: I was standing in front of the North entrance of the Graham Center. 


\section{APPENDIX F}

\section{Interviewer Report Instructions}

During the study, you interviewed a witness about a videotaped staged event. Please write a summary of everything that occurred during the interview with the witness. Please record word-for-word the questions that you asked the witness and the witness's responses to your questions. Please try and record information in transcript format indicating specifically who said what during the interview, providing information that would be important to investigators solving a crime. If you have any questions about this task, please ask the experimenter.

\section{Example of transcript format:}

Q: Where were you standing when the balloon popped?

A: I was standing in front of the North entrance of the Graham Center. 


\section{APPENDIX G}

\section{Interviewer Questionnaire-Note-Taking}

1. Do you have any experinece in interviewing people?

Check one:

1b. If yes, please explain:

No

2. Has a situation similar to the one that the interviewee told you about ever happened to you?

Check one:

Yes No

$2 b$. If yes, please explain what exactly happened:

3. If your response to Question 2 was yes, please explain your emotional reaction to the situation and how the situation was resolved.

4. Do you think your previous experience with a situation such as this, may have affected the way you participated in this experiment?

Check one:

Yes

No

4b. If yes, please explain:

5. You were given the option to take notes during the interview. Did you take notes?

Check one:

Yes No

5 b. If yes, in what way did taking notes affect you during the interview? 
6. If you took notes during the interview, did you use these notes to help you write your report? Check one:

Yes No

6 b. If yes, how did using your notes to write the written account affect you?

7. If you took notes during the interview, please rate how helpful you felt the note-taking to be during the interview from 1-9, Circle one.

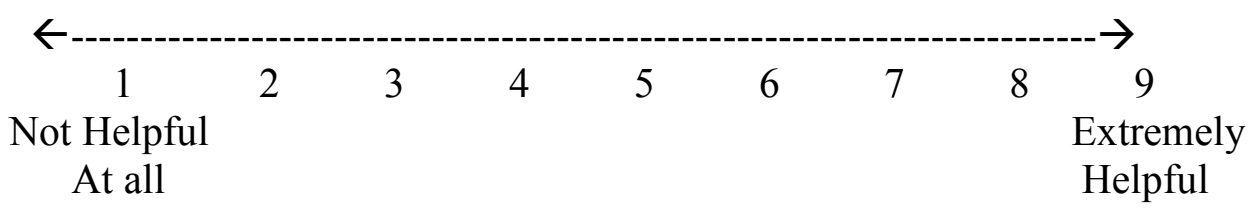

8. If you took notes during the interview, please rate how helpful you felt the note-taking to be in later remembering the interview from 1-9, Circle one.

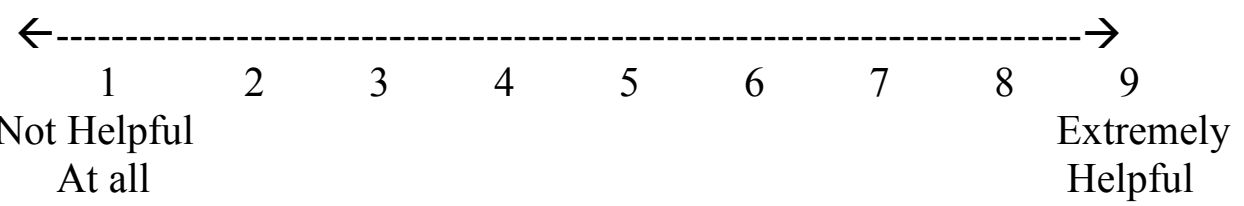

9. Please rate how well you remembered the interview from 1-9, Circle one.

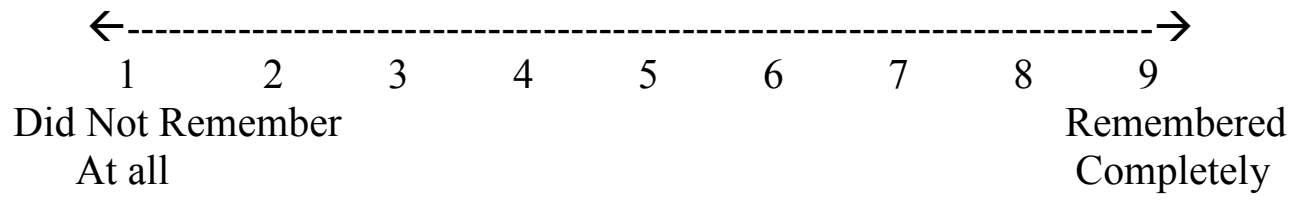


10. Please rate how comfortable you felt talking to the interviewee during the interview from 1-9, Circle one.

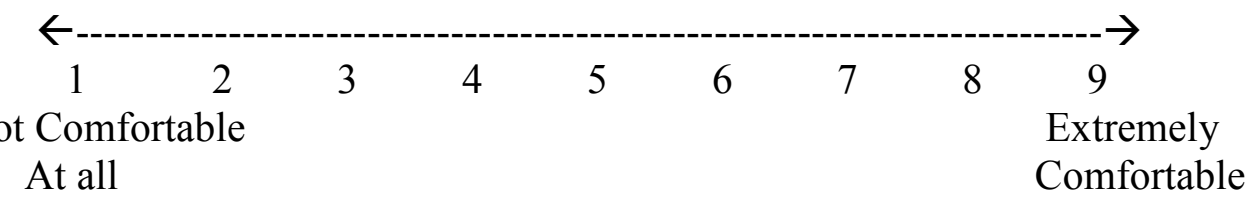

11. Please rate how competent of a witness you felt the interviewee to be from 1-9, Circle one.

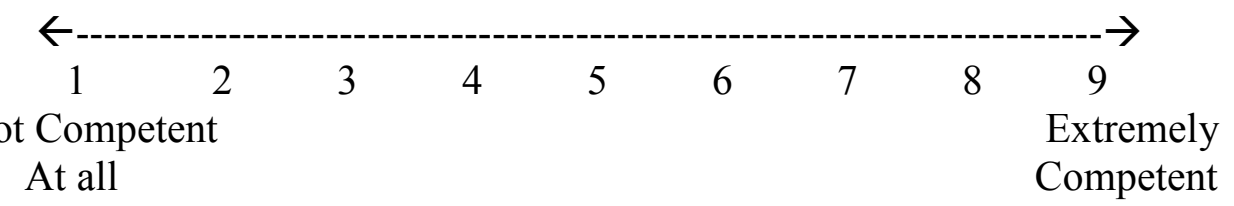

12. Please rate how easy it was for you to understand the interviewee's explanation of what occurred in the video from 1-9, Circle one.

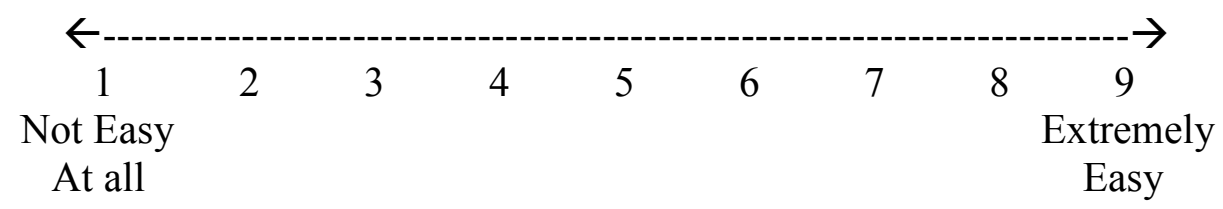

13. Please rate the amount of information that the interviewee provided you with during the interview from 1-9, Circle one.

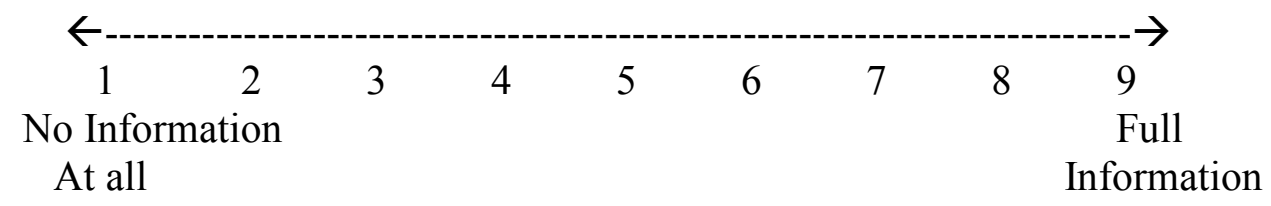

14. Please rate your ability to elicit information from the interviewee during the interview from 1-9, Circle one.

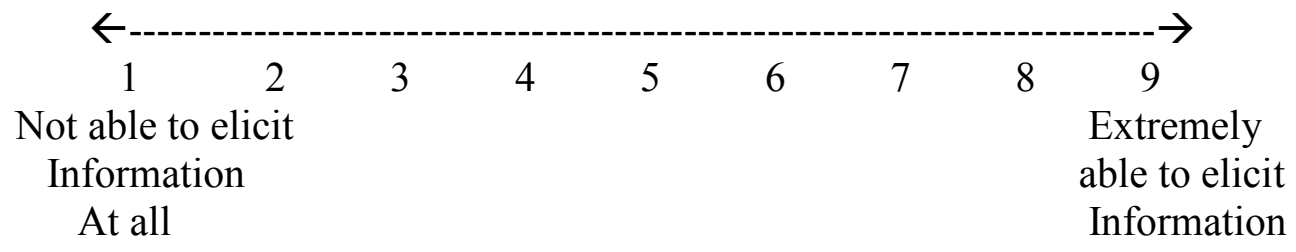


15. Please rate your overall satisfaction with your interview and interviewee from 1-9, Circle one.

\begin{tabular}{|c|c|c|c|c|c|c|c|c|}
\hline $\begin{array}{c}1 \\
\text { t Satisfied } \\
\text { At all }\end{array}$ & 2 & 3 & 4 & 5 & 6 & 7 & 8 & $\begin{array}{c}9 \\
\text { Extremely } \\
\text { Satisfied }\end{array}$ \\
\hline
\end{tabular}

16. Please rate how similar your interview was to a "real world" police interview from 1-9, Circle one.

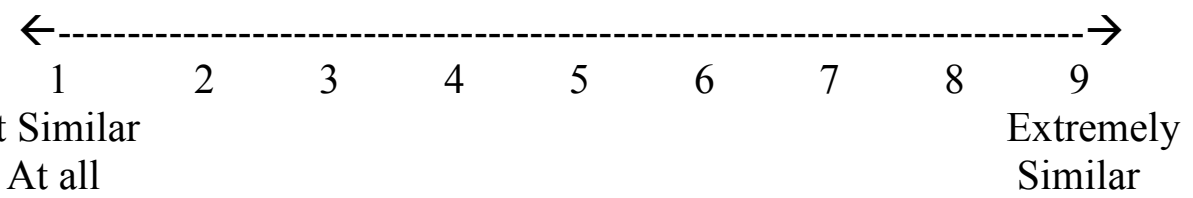




\section{APPENDIX H}

Interviewer Questionnaire-No Note-Taking

1. Do you have any experinece in interviewing people?

Check one:

Yes

No

1b. If yes, please explain:

2. Has a situation similar to the one that the interviewee told you about ever happened to you?

Yes No

$2 b$. If yes, please explain what exactly happened:

3. If your response to Question 2 was yes, please explain your emotional reaction to the situation and how the situation was resolved.

4. Do you think your previous experience with a situation such as this, may have affected the way you participated in this experiment?

Check one:

Yes

No

4b. If yes, please explain: 
5. Please rate how well you remembered the interview from 1-9, Circle one.

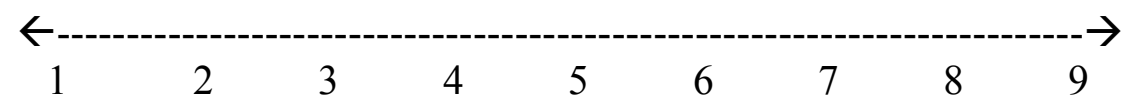

Did Not Remember

Remembered

At all

Completely

6. Please rate how comfortable you felt talking to the interviewee during the interview from 1-9, Circle one.

\begin{tabular}{|c|c|c|c|c|c|c|c|}
\hline 2 & 3 & 4 & 5 & 6 & 7 & 8 & 9 \\
\hline $\begin{array}{l}\text { Not Comfortable } \\
\quad \text { At all }\end{array}$ & & & & & & & $\begin{array}{l}\text { Extremely } \\
\text { Comfortable }\end{array}$ \\
\hline
\end{tabular}

7. Please rate how competent of a witness you felt the interviewee to be from 1-9, Circle one.

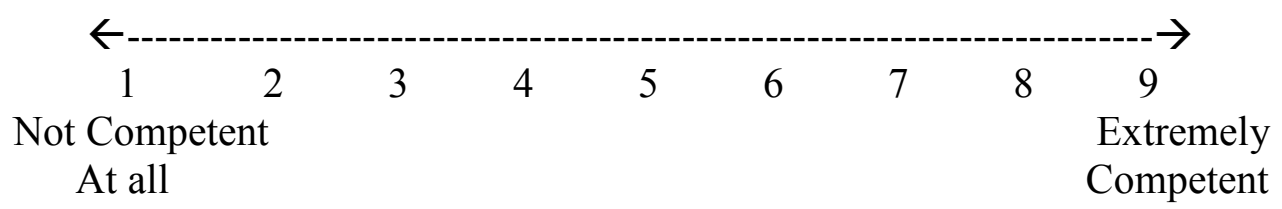

8. Please rate how easy it was for you to understand the interviewee's explanation of what occurred in the video from 1-9, Circle one.

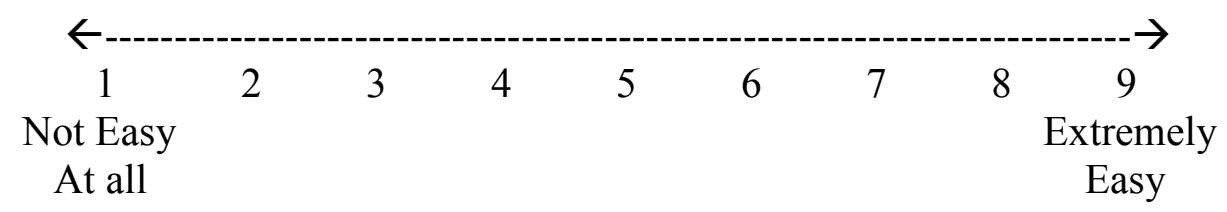

9. Please rate the amount of information that the interviewee provided you with during the interview from 1-9, Circle one.

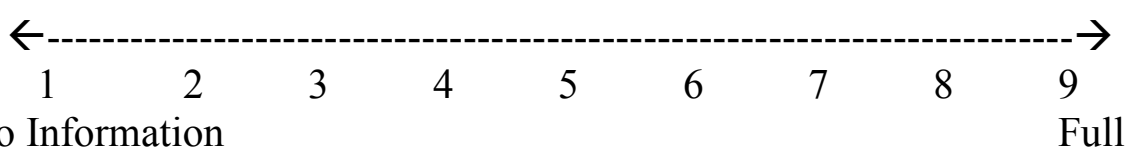

At all Information


10. Please rate your ability to elicit information from the interviewee during the interview from 1-9, Circle one.

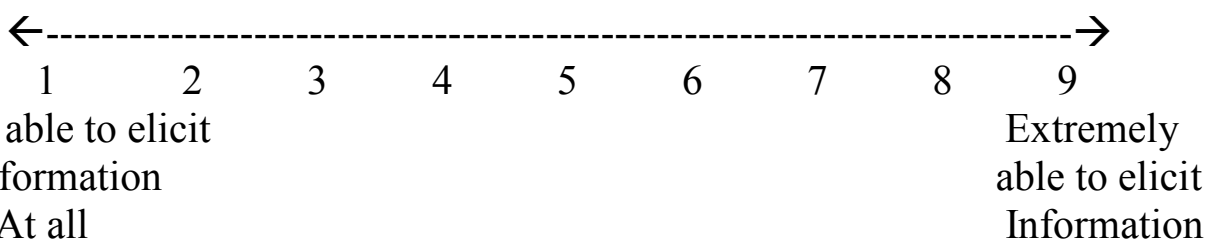

11. Please rate your overall satisfaction with your interview and interviewee from 1-9, Circle one.

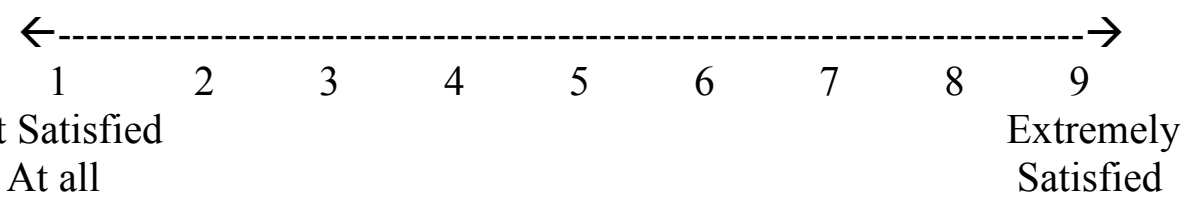

12. Please rate how similar your interview was to a "real world" police interview from 1-9, Circle one.

\begin{tabular}{|c|c|c|c|c|c|c|c|c|}
\hline 1 & 2 & 3 & 4 & 5 & 6 & 7 & 8 & 9 \\
\hline $\begin{array}{l}\text { Similar } \\
\text { At all }\end{array}$ & & & & & & & & $\begin{array}{c}\text { Extremely } \\
\text { Similar }\end{array}$ \\
\hline
\end{tabular}




\section{APPENDIX I}

\section{Demographic Questionnaire}

1. What is your age? Years

2. What is your gender?

Check one:

Male

Female

3. Which of the following categories best reflects your ethnic/racial identity? (check only one)

$\begin{array}{ll}\text { African American } & \text { Asian/Pacific Island } \\ \text { Caucasian: Non-Hispanic } & \text { Hispanic } \\ \text { Native American } & \quad \text { Other }\end{array}$

4. What is the highest education level you have completed?

high school graduate

freshman year in college sophomore year in college
junior year in college senior year in college graduate school or other Yes No

5. Is English your primary/native language? luently?

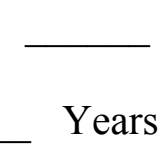

If English is not your native language, what is your native language?

6. What is your current work status? Check one:

7. What is your occupation? 


\section{APPENDIX J}

\section{Interviewing \& Memory Scoring Rules \& Instructions}

Before you begin scoring it is important to note that only crime relevant information needs to be scored. Irrelevant information such as questions regarding what should be done in the study or statements such as, umm, hmmm, etc., should not be scored.

In addition to the interview transcript and the report that participants were asked to write after their witness interview, there are two scoring sheets and two types of scoring you will need to do. First, you will score interviewer (i.e. participants') reports for accuracy of both information elicited and accuracy of interviewer question assigned that elicited that information. There are two different types of interviewer reports; summarized and verbatim. Determining accuracy will be slightly different for each of these reports. For the summarized report participants were asked to provide a summary of the witness's statement based on what was said by the witness in the interview. For the verbatim report participants were asked to write word for word the questions that they asked and the witness's answers to those questions. It will most likely be easier to score verbatim reports as you can directly compare interviewer questions noted in the report to questions in the transcript from the actual interview. Summarized reports will be trickier to score for interviewer question eliciting a specific piece of information because all statements may be written as though the witness provided the information in open-ended narrative form (for more details see below).

After you score for accuracy (scoring sheet 1), you will need to score for omissions, i.e., what the interviewer forgot to mention in his report (scoring sheet 2) by comparing interview transcripts from the actual interview to the written reports. In contrast to scoring sheet 1 , for scoring sheet 2 your source document will be the transcript, not the report. So you will be doing the reverse of what you did when scoring for accuracy.

Before you begin scoring, it is important to note that sentences in interviewer reports have been pre-divided into units of information within each turn to make scoring easier for you. Therefore you can disregard the division into turns (i.e., exchanges between interviewer and witness) and just focus on the units, which will contain smaller pieces of information.

\section{Scoring for Accuracy}

When scoring for accuracy you will compare interviewer reports (source document) with the interview transcripts to find out whether the report is an accurate reflection of the interview. At the top left hand corner of each scoring sheet you will need to write the following:

Participant \#:

Scorer:

Transcriber:

Date: 
Page \#:

First, write down the participant \#. You can find this on either the written report or the transcript. Next, write your name next to the scorer row. Then indicate the date that you are scoring the materials. For page \#, write the page of the scoring sheet for each participant that you are scoring. Note that you will likely need to use several scoring sheets for each participant.

To begin scoring, write the number of the sentence you are scoring in the sentence \# column. Unit \#'s are already included in the scoring sheet. Start with sentence 1 and unit 1.

First, you will score the accuracy of the witness information provided in the report.

1. Look at the unit you are scoring and compare the information provided by the interviewer in the report with the interview transcript. It may be useful to read the entire report and transcript before you begin scoring so you can access and compare information more easily.

2. Determine whether the information provided in the unit is accurate. An accurate response is one that is a correct interpretation and/or an objective reflection of what the witness said during the interview. If the information in the report can be objectively inferred from the interview transcript then it is correct. For example for the unit: "she reported the incident to University Police" the Y column would be marked with an $\mathrm{X}$ if this information was provided by the interviewee during the interview according to the transcript. If the information written in the unit can not be verified from the transcript mark an $\mathrm{X}$ in the $\mathrm{N}$ column.

3. If $\mathrm{N}$ has been marked; you will need to score for error type. There are 2 categories of error types that can be scored (if $\mathrm{Y}$ has been marked, you may move on to score for questions type - see below).

\section{Error Types:}

a. Addition (ADD): an addition should be scored if information has been added in the report which was not stated by the witness during the interview. The information is new and cannot be found in the transcript.

i. An example of an addition would be:

Report: Witness said the he was wearing a gray shirt with black stripes

Transcript: 12E: He was wearing a gray shirt with black stripes and a hat.

b. Modification (MOD): a modification should be scored if the information provided has been slightly changed from what was actually said by the witness in the interview.

i. An example of a modification would be: 
Report says: Witness said that he was wearing a gray shirt with blue stripes

Transcript: 12E: He was wearing a gray shirt with black stripes.

\section{TYPES OF QUESTION: "REPORTED AS"}

4. Next, you will need to score for accuracy of question type and if the interviewer correctly remembered the type of questioned used to elicit that specific piece of witness information reported. You will indicate this information in the "reported as" column. First, you will need to determine the question type reported in the report. Here you are scoring for the question type that the writer reported using to obtain information from the witness.

5. In general it will be much easier to score for type of question with verbatim reports than summarized reports. Interviewers were either asked to write a report in a question-answer format (verbatim) or to simply write a summary of what the witness has said (summarized). In case of the summarized format, the scorer will need to infer the question format. Most likely you will score more open ended narrative questions for summarized reports, as it will appear as though the witness provided most of the information to the interviewer in an open ended format. This may be different from what actually happened during the interview. Since the instructions for the summarized reports asked participants to summarize the witness's statement, it is likely that participants wrote their reports from a different perspective.

- There are 4 question type categories that can be scored:

1. OEN-Open Ended Narrative

2. OES-Open Ended Specific

3. MC-Multiple Choice Questions

4. YM-Yes/No Questions

\section{Open Ended Narrative}

This is an open-ended question that allows the witness to answer freely, with either a short or long narrative that is likely to contain a verb. It should be scored when the interviewer uses an open question format ("Can you tell me what happened?") or an open command ("Tell me everything you saw").

Examples: Why \& How questions, prompts such as: describe, tell me, what did you see? What happened?

For summarized reports, an OEN question should be scored if the interviewer reports the witness information as a free narrative (e.g., "The witness reported that the suspect took the money out of the wallet and left the room"). This implies that the witness reported this information in response to the question "What happened?" Hence, the most likely inferred question that the interviewer asked to elicit this information is an OEN question. If this is the case, please mark the OEN box under "reported as" with an X. 
Another example: If the report says: "The man was wearing a blue shirt with gray stripes and jeans," you will infer that the question that the witness answered here was "What was he wearing?" You will then need to use your best judgment in determining the question and question type that is implied from each unit of information written in the report. For a verbatim report the interviewer will more specifically indicate which question he asked, for example "I asked the witness to tell me what happened." If this is the case, please mark the OEN box under "reported as" with an X.

\section{Specific/Closed}

This category includes questions that can be sufficiently answered with a one word response, a few words, or a short sentence.

Example: "What color was the shirt?" "At what time did the crime occur?" "How tall was the guy?"

If the unit is part of an open ended specific question that was reported by the writer in the report then an X should be marked in the OES box under the "reported as" column. For verbatim reports, the report will probably say something like: "I asked her if the guy had any distinguishing characteristics?"

For summarized reports, the report will probably say something like: "The witness said that he was average height." You can therefore infer from this information that the witness was asked an OES question like "How tall was he?"

\section{Multiple Choice}

This category includes questions that offer choices in answers. The interviewee is expected to base their answers upon the choices offered by the interviewer.

Example: "Did you see where he went or did he just leave?" "Did he have any tattoos or birthmarks or facial hair?" "Was he Hispanic or Caucasian?"

If the question written in the report gives the witness choices then the MC box should be marked with an X under the "reported as" column.

For verbatim reports, the report will probably say something like: "I asked her if the guy was black or Hispanic?"

For summarized reports, the report will probably say something like: "The witness said that the guy was not black but Hispanic." You can therefore infer from this information that the witness was asked a MC question like "Was he black or Hispanic?"

$\underline{\text { Yes/No }}$

A Yes/No question is any question that can fully be answered with "yes" or "no." Examples: "Did you see where he went?" "Were they talking to each other?" "Did you ever see him before?"

If the unit is part of a Yes/No question that is reported by the writer then the YN box should be marked with an X under the "reported as" column.

For verbatim reports, the report will probably say something like: "Did you see where the guy went?"

For summarized reports, the report will probably say something like: "The witness did not see where the guy went after." You can therefore infer from this information that the witness was asked a $\mathrm{Y} / \mathrm{N}$ question like "Did you see where the guy went after the crime?" 


\section{TYPES OF QUESTIONS: "ELICITED AS"}

5. Next, you will need to score for the type of question that actually elicited the information during the interview. You will need to look at the transcript to score for this part and determine the type of question the interviewer actually used to elicit the information from the witness in the unit you are scoring. You should not score for the type of question that was provided in the report, as this has already been scored for in the "reported as" column. Note that oftentimes the question type used in the actual interview (in the transcript) may not match the question type that was reported in or can be inferred from the report.

1. You will first need to locate the information in the transcript by matching it to the information in the unit you are scoring.

2. You will score for question type based on the question from the transcript that was used to elicit the unit of information that you are scoring.

For example if the report says:

"I asked the witness what he looked like."

You would look for the turn in the transcript that includes this question:

14R: What did the guy look like?

Or if the report said:

"The witness then said that he was a white Caucasian."

You would look for the turn in the transcript that elicited that information:

23 R: Was he Caucasian?

23E: Yes.

\section{Suggestive/Leading}

A suggestive or leading question is one that implies information that the witness has not previously provided.

Example: "When he ran away from the table how many people saw him?" This question is suggestive if the witness never mentioned that the perpetrator ran away.

Note that Suggestive/Leading questions will not be reported by interviewers, thus they can only be marked off in the "elicited as" column.

Information units from summarized reports can also be scored for "elicited as" question type. Note that most of the "reported as" questions will be marked as open ended narrative, since the writer may have reported the information as though the witness gave a free narrative rather than being asked other types of questions. However, you can still score for the "elicited as" question types by finding the unit of information in the 
transcript to see the type of question that was actually used to render that piece of information.

For example if the report says:

"The witness said that she was on the $6^{\text {th }}$ floor of the library when she witnessed a theft."

Under the "reported as" column the above unit of information would be marked as OEN.

The transcript actually says:

1R: What type of crime did you witness?

1E: I saw a theft of some money when I was at the library

1R: Where in the library?

1E: The $6^{\text {th }}$ floor

Under the "elicited as" column the OES box should be marked with an X for all of the units of information making up the sentence "The witness said that she was on the $6^{\text {th }}$ floor of the library when she witnessed a theft" that was in the report.

III. Scoring of Omissions (Scoring Sheets 2 \& 3)

Please note that there are 2 different omissions scoring sheets, one for interviewer questions/utterances, and one for interviewee responses only. When scoring for omissions, you will now compare interview transcripts with the interview report (reverse order). Transcripts are divided into turns between the interviewer $(\mathrm{R})$ and the interviewee (E). Each turn is numbered starting with 1;1R, 1E;2R, 2E; etc.

For example:

1R: So you witnessed a crime? Tell me what happened.

1E: I was at the library and I saw a man steal money out of a girl's wallet.

2R: When did this happen?

2E: Yesterday at $7 \mathrm{pm}$.

Since you will be scoring interviewer $(\mathrm{R})$ and the interviewee $(\mathrm{E})$ responses on separate scoring sheets, please be aware that each type of response will be handled differently. It is not necessary to score crime-irrelevant information. Therefore, you may find yourself starting with turn 3 rather than turn 1. Start with the first exchange that pertains to crime related information and its first unit of information.

1. Interviewer Questions/ Utterances only:

First, enter the turn number where the first meaningful exchange between the interviewer and the interviewee occur. When scoring for interviewer utterances 
you should find the first question asked to the witness. Enter the turn \# in the turn \# column.

Second, identify the type of question that is being asked (for an explanation of question types see pages 3-5 above). There will be times when interviewers ask more than one question per turn. There is room for you to score 5 questions per turn. If more than 5 questions were asked at once, feel free to use additional rows to score for these. Once you have identified the type of question asked mark and $\mathrm{X}$ under the appropriate question type column.

Third, now you will need to look at the interview report to determine whether each question was reported or omitted by the interviewer in the report, this will be easier to determine for verbatim reports. If the question is reported then mark an $\mathrm{X}$ under the $\mathrm{Y}$ column in the question reported section. It will be a bit more difficult to determine whether questions were reported in summarized reports. This will be similar to when you scored the summarized reports for accuracy. You will need to infer whether the interviewer acknowledges having asked this question in the report. For example:

If the transcript says:

12R: Where were you when his happened?

$12 \mathrm{E}$ : I was sitting at a nearby table.

And the report says:

Witness stated that she was sitting at a nearby table when the crime occurred.

In this case you can infer that the interviewer has reported asking the question in the written report. You can then mark an $\mathrm{X}$ in the $\mathrm{Y}$ column. If the information and the question are not mentioned in the report then you should mark an $\mathrm{X}$ in the $\mathrm{N}$ column.

Fourth, for questions/utterances that were not reported, you should then check off the type of information that was omitted. There are different categories for interviewer questions/utterances and interviewee responses/info. For interviewer questions/utterances there only 4 different categories listed. You should mark off all of the categories that apply.

a. Suspect (SUS): The question/utterance omitted pertains to the crime suspect.

b. Victim (VICT): The question/utterance omitted pertains to the crime victim.

c. Description (DEC): The question/utterance omitted pertains to the physical description of the suspect or the victim (e.g. hair color, eye color, clothing, etc.) 
d. Action (ACT): The question/utterance omitted pertains to an action that involves either the suspect or victim (e.g. he ran away, she was reading, etc.)

Fifth, continue following the above procedure for all of the questions in the each turn. Next, you will need to indicate whether the interviewer engaged in any reflective listening during the turn that you are scoring. Reflective listening is defined as "listening with the intent to understand," evidence for reflective listening can be seen when the interviewer repeats back to the witness what the witness said previously for clarification. The interviewer wants to understand exactly what the witness experienced and therefore repeats witness information to make sure that he/she understands what happened correctly. Here is an example:

13R: What were you doing at this time?

13E: Studying in the study area, in the library.

14R: So, this happened at the library.

14E: Yes.

In this example, 14R would be scored as reflective listening because the interviewer repeated back what the witness just stated. When this occurs, you would mark off an $\mathrm{X}$ under the $\mathrm{Y}$ column for the reflective listing category. If the interviewer does not engage in any reflective listing during the turn mark off and $\mathrm{X}$ in the $\mathrm{N}$ column. If you marked off an $\mathrm{X}$ in the $\mathrm{Y}$ column, you will need to indicate the number of units of information that the interviewer engaged in reflective listening for. In the above example for $14 \mathrm{R}$, this would be considered 1 unit of info.

Sixth, you will need to determine whether each question per turn has been asked before. If the same question was asked at any point prior during the interview then it should be considered a repeat question. Reflective listening and repeat questions may seem quite similar at first. However, reflective listening applies to repeating back witness information that was provided earlier by the witness. Where as a repeat question is a question that essentially asks the witness for the same information he/she already provided. For example:

10R: Were their other people around to see this happen?

10E: I didn't see anyone else, but I'm really not sure.

20R: So do you think there were other witnesses who saw?

20E: I really don't know for sure.

In this example, $20 \mathrm{R}$ is a repeated question. Here the interviewer asks the witness essentially the same question that he/she had already asked. In this case you would mark off an $\mathrm{X}$ under the $\mathrm{Y}$ column in the repeat question section. If the 
question was not repeated then mark an $\mathrm{X}$ in the $\mathrm{N}$ column. Continue to check for repeat questions for all questions in each turn. Move on to the next $\mathrm{R}$ turn and repeat the above listed procedure for each question/utterance in the turn.

Once you have scored all of the $\mathrm{R}$ turns that include crime relevant information you will need to indicate the totals that are asked for at the top of the sheet. You only need to write the totals on the $1^{\text {st }}$ scoring sheet for each participant, it is not necessary to write the totals on all of the sheets. However, you will need to indicate the following on each sheet.

Participant \#: Indicate the participant \# here.

Scorer:

Transcriber:

Date:

Page \#:

Total \# Turns:

Total Questions Asked:

Total Repeat Q's:

Total Reflective Listening Units: Total the \# of units of reflective listening by adding all the

Total \# Pauses:

Total OEN asked:

Total OES asked:

Total MC asked:

Total Y/N asked:

Total SL asked:

Total OEN Omitted: units up from each turn.

Write you initial here on each page.

Indicate who transcribed the transcript you are working with

Write the date you scored each page.

Most likely you will use multiple pages for each participant.

Number each sheet starting with 1.

Total the number of turns scored for each participant.

Count the total \# of questions asked by the interviewer during the interview. Determine this by counting the number of questions asked during each turn.

Total the number of X's for the Y repeat question column.

Count the number of pauses in the transcript.

Count the number of X's in the OEN column.

Count the number of X's in the OES column.

Count the number of X's in the MC column.

Count the number of $\mathrm{X}$ 's in the $\mathrm{Y} / \mathrm{N}$ column.

Count the number of X's in the SL column.

Determine the \# of OEN questions not reported based on the $\mathrm{N}$ question reported column. 
Total OES Omitted:

Total MC Omitted:

Total Y/N Omitted:

Total S/L Omitted:

Total Q's Reported:
Determine the \# of OES questions not reported based on the $\mathrm{N}$ question reported column.

Determine the \# of MC questions not reported based on the $\mathrm{N}$ question reported column.

Determine the \# of $\mathrm{Y} / \mathrm{N}$ questions not reported based on the $\mathrm{N}$ question reported column.

Determine the \# of S/L questions not reported based on the $\mathrm{N}$ question reported column.

Count the number of $X$ 's in the question reported $Y$ column.

Now you're ready to move onto interviewee responses.

2. Interviewee Responses:

First, you should fill out the same information in the top left hand corner as you did for the other scoring sheets. Next, indicate the turn number that you are starting with in the turn \# box. You will score each unit of information in the turn separately. Note that turns have already been pre-broken down into units of information for you. There may be several units of information for each turn. There is room to score 10 units for every turn. If there are more than 10 units, feel free to add more rows on the bottom or back of the scoring sheet.

After you have recorded the turn number begin with the 1t unit of information provided by the witness. Look through the written interview report to determine whether the interviewer has reported that unit of info. If the info was reported mark an X in the Y column under "Info Reported" and move on to the next unit in the turn. If the info was not reported then mark an $\mathrm{X}$ in the $\mathrm{N}$ column and indicate the type of information that was omitted. There are 7 categories of witness information. Feel free to mark an X in the column for all the categories that apply. They are listed below

a. Suspect (SUS): information that the witness mentioned about the suspect.

b. Victim (VICT): information that the witness mentioned about the crime victim.

c. Central Detail (CNT): information that is directly related to solving the crime, stated by the witness (e.g. time, date, place, sequence of crime events, suspect's appearance, etc.)

d. Peripheral Detail (PER): information that may not be directly related to solving the crime but was provided by the witness (e.g. what the witness was doing, how long the witness was sitting in the library, etc.)

e. Description (DES): information provided by the witness regarding the suspect's or the victim's physical description (e.g. weight, height, hair color, clothing, accessories, etc.) 
f. Action (ACT): information provided by the witness that relates to an action occurring before, during, or after the crime. (e.g. running, talking, moving, etc.)

g. Subjective (SUB): information provided the witness that contains assumptions or opinions about what occurred.

You should mark off all the categories that the omitted information applies to with an X. Once you finish scoring all of the units in the turn, you should move on to the next turn and score all of the units in that turn. Until there are no more turns/units left to score.

Once you have finished scoring all the turns in the transcript, you will need input the totals, listed in the upper right hand corner of the sheet, for each participant.

Total \# Turns:

Total \# Omitted Units:

Total \# Reported Units:
Count the total number of turns in the transcript that were scored.

Count the total number of X's marked down the "Info Reported" N column.

Count the total number of X's marked down the "Info Reported"Y column.

Once you have completed all of the totals you may move on to score the next participant. 

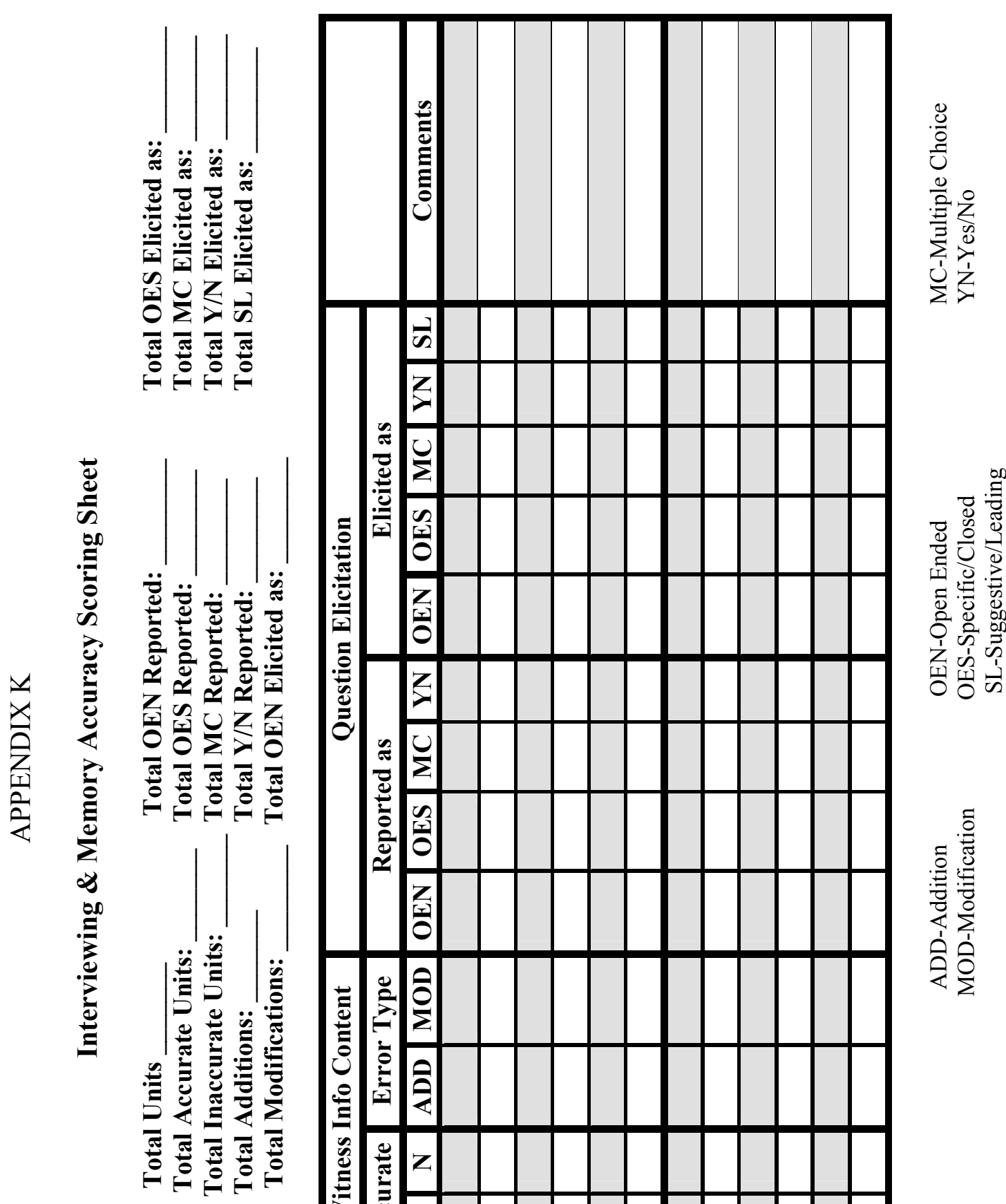

으
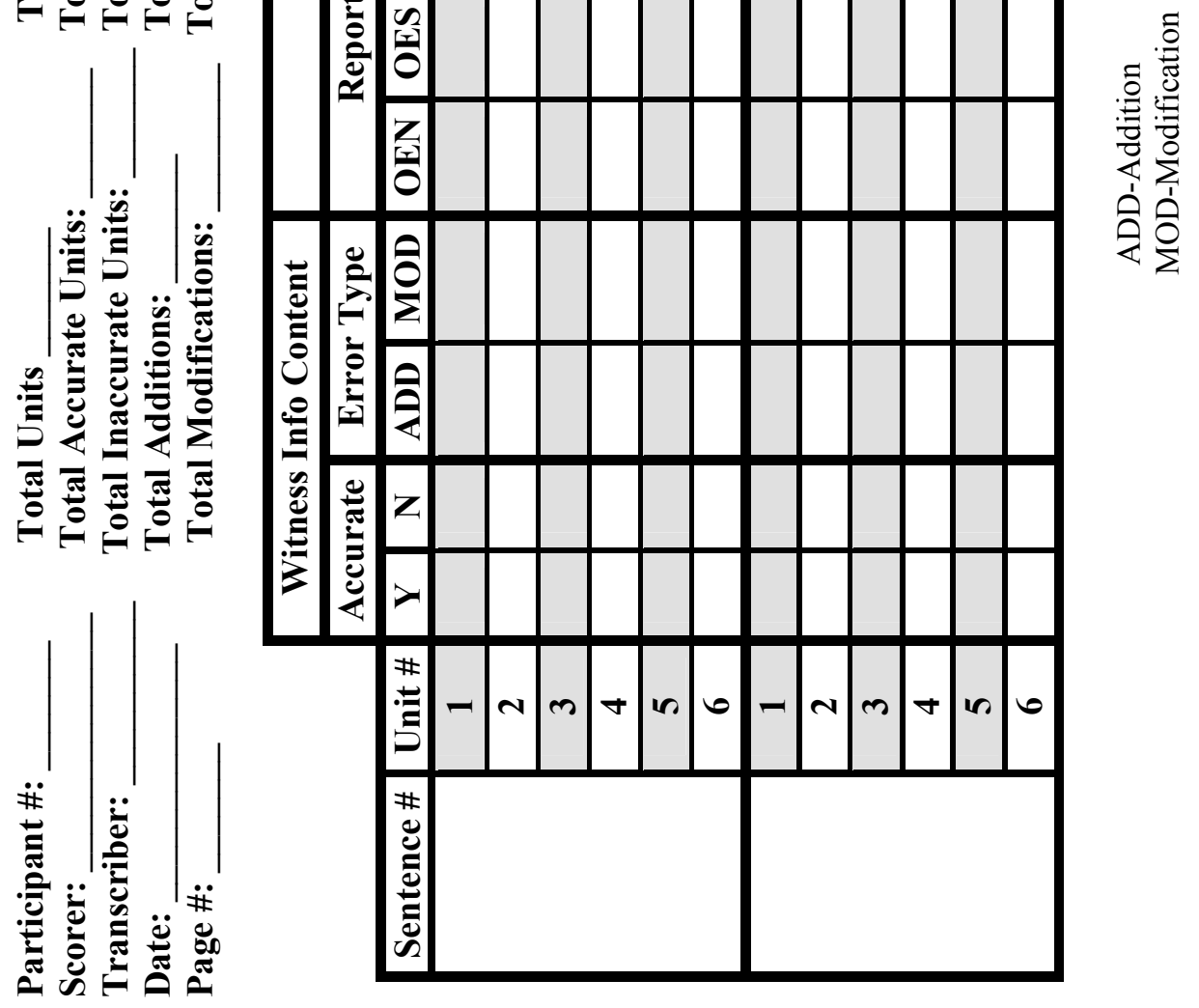


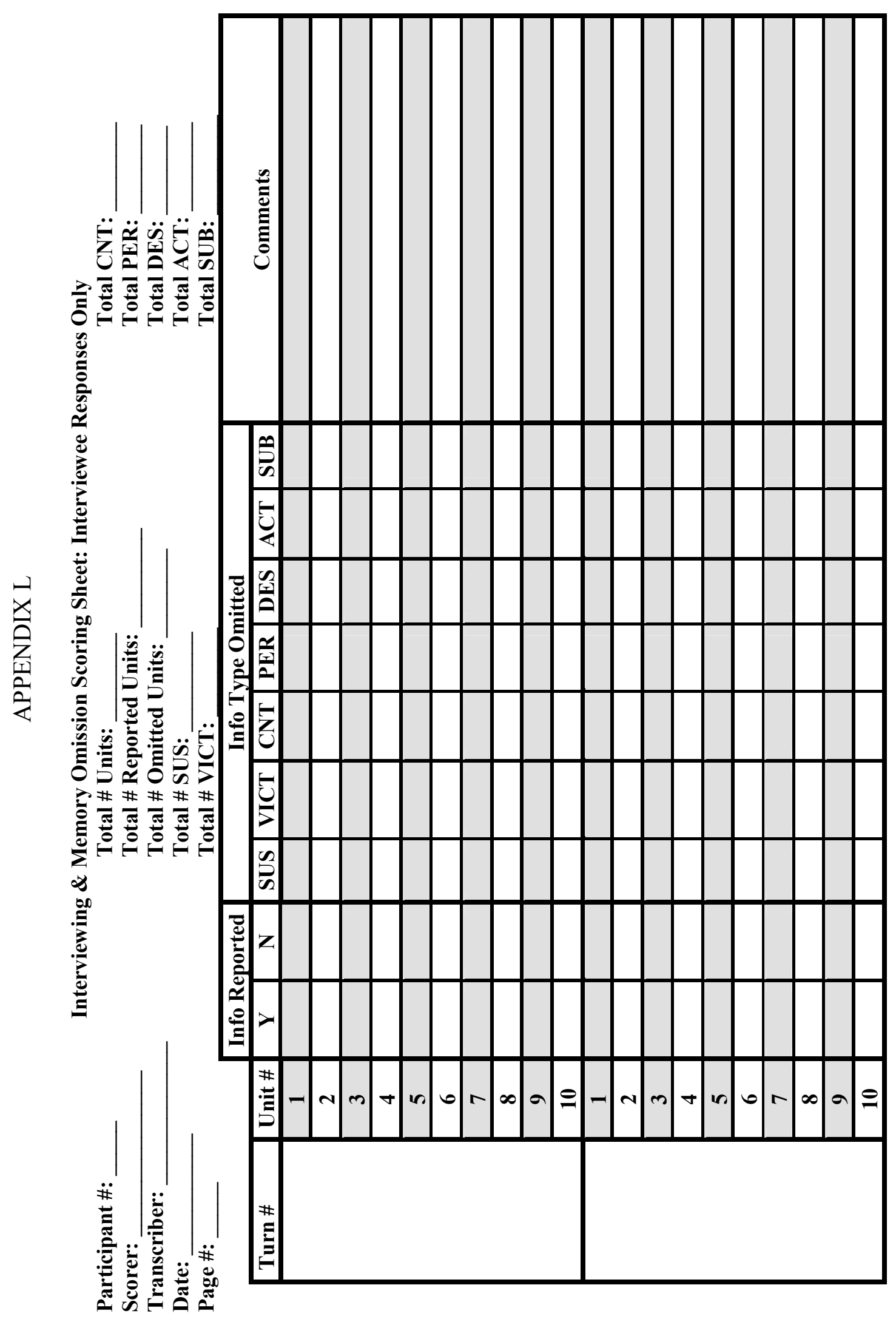




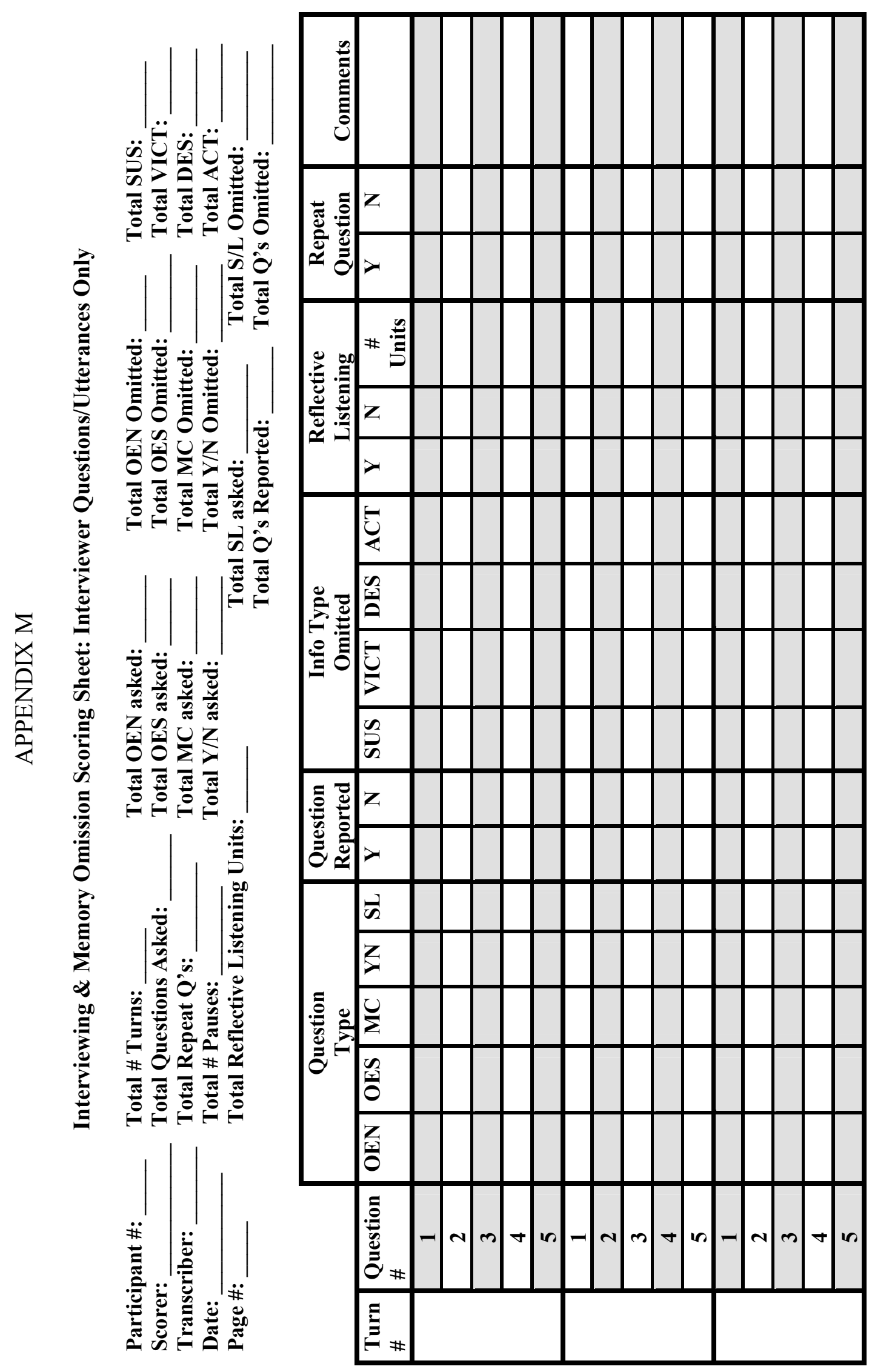




\section{APPENDIX N}

\section{Initial Interviewer Instructions:}

Place yourself in the shoes of a police investigator. You are about to interview a person about a crime that they just witnessed. Please gather as much information as possible from the witness about the crime. As an investigator, you will want to obtain as many details as you can from the witness, to piece together what the witness saw. You should ask the witness questions that will help to later solve the crime. You will be provided with paper to take notes during the interview. Feel free to record as much information as you would like. Please try and remember as much information as possible. You will be asked to recall the interview shortly after. 


\section{APPENDIX O}

\section{Initial Interviewer Instructions:}

Place yourself in the shoes of a police investigator. You are about to interview a person about a crime that they just witnessed. Please gather as much information as possible from the witness about the crime. As an investigator, you will want to obtain as many

details as you can from the witness, to piece together what the witness saw. You should ask the witness questions that will help to later solve the crime. Please try and remember as much information as possible. You will be asked to recall the interview shortly after. 


\section{APPENDIX P \\ Police Questionnaire - Note-Taking}

1. How many years have you worked in law enforcement?

2. What police department do you currently work for?

3. How many years have you worked for the police department where you currently work?

4. In which unit within your police department do you work?

5. How many years have you been working in your current unit?

6. How many years experience do you have interviewing witnesses in total?

7. How many years experience do you have interviewing witnesses in your current department?

8. How many years experience do you have questioning suspects in total?

9. How many years experience do you have questioning suspects in your current department?

10. In what city and state is your department located?

City:

State:

11. What shift do you usually work? Please check one.
Day:
Night:
Varies:

Other (Please Explain): 
12. When interviewing witnesses do you usually take notes during the interview?

Check one:

Yes No

12b. If yes, how often would you say you take notes during witness interviews?

13. When interviewing suspects do you usually take notes during the interview?

Check one: Y Yes No

13b. If yes, how often would you say you take notes during suspect interviews?

14. When writing case reports, do you usually refer back to interview notes, if taken?
Check one:
Yes
No

$14 \mathrm{~b}$. If yes, how often do you refer back to your notes?

15. You were given the option to take notes during the interview today? Did you take notes? Check one: Yes No

15b. If yes, in what way did taking notes affect you during the interview?

16. If you took notes during the interview, did you use these notes to help you write your report? Check one: Yes No

16b. If yes, how did using your notes to write the written account affect you?

17. If you took notes during the interview, please rate how helpful you felt the notetaking to be during the interview from 1-9, Circle one.

$\begin{array}{ccccccccc}1 & 2 & 3 & 4 & 5 & 6 & 7 & 8 \\ \begin{array}{c}\text { Not Helpful } \\ \text { At all }\end{array} & & & & & & & & \begin{array}{c}\text { Extremely } \\ \text { Helpful }\end{array}\end{array}$


18. If you took notes during the interview, please rate how helpful you felt the notetaking to be in later remembering the interview from 1-9, Circle one.

\begin{tabular}{|c|c|c|c|c|c|c|c|c|}
\hline $\begin{array}{c}1 \\
\text { Helpful } \\
\text { At all }\end{array}$ & 2 & 3 & 4 & 5 & 6 & 7 & 8 & $\begin{array}{l}\quad 9 \\
\text { Extremely } \\
\text { Helpful }\end{array}$ \\
\hline
\end{tabular}




\section{APPENDIX Q \\ Police Questionnaire- No Note-taking}

1. How many years have you worked in law enforcement?

2. What police department do you currently work for?

3. How many years have you worked for the police department where you currently work?

4. In which unit within your police department do you work?

5. How many years have you been working in your current unit?

6. How many years experience do you have interviewing witnesses in total?

7. How many years experience do you have interviewing witnesses in your current department?

8. How many years experience do you have questioning suspects in total?

9. How many years experience do you have questioning suspects in your current department?

10. In what city and state is your department located?

City:

State:

11. What shift do you usually work? Please check one.
Day:
Night:
Varies:

Other (Please Explain): 
12. When interviewing witnesses do you usually take notes during the interview?

Check one:

Yes No

12b. If yes, how often would you say you take notes during witness interviews?

13. When interviewing suspects do you usually take notes during the interview?

Check one: Yes No

13b. If yes, how often would you say you take notes during suspect interviews?

14. When writing case reports, do you usually refer back to interview notes, if taken?
Check one:
Yes
No

$14 \mathrm{~b}$. If yes, how often do you refer back to your notes?

15. Please rate how well you remembered details from the interview when writing your report today from 1-9, Circle one.

$\begin{array}{ccccccccc}1 & 2 & 3 & 4 & 5 & 6 & 7 & 8 & 9 \\ \text { Well } & & & & & & & & \text { Extremely } \\ \text { At all } & & & & & & & \end{array}$

16. Please rate how well you remembered what the witness said during the interview when writing your report today from 1-9, Circle one.

$\begin{array}{ccccccccc}1 & 2 & 3 & 4 & 5 & 6 & 7 & 8 & 9 \\ \text { Not Well } & & & & & & & & \begin{array}{c}\text { Extremely } \\ \text { At all }\end{array} \\ & & & & & & & & \end{array}$

17. Please rate how well you remembered what you said during the interview when writing your report today from 1-9, Circle one.

$\begin{array}{ccccccccc}1 & 2 & 3 & 4 & 5 & 6 & 7 & 8 & 9 \\ \text { t Well } & & & & & & & & \text { Extremely } \\ \text { At all } & & & & & & & \end{array}$




\section{AMY HYMAN GREGORY}

December 3, 1980

2002

2005

2005-2006

2006-2009
Born, New York, New York

B.A., Political Science

Binghamton University

Binghamton, New York

M.A., Forensic Psychology

John Jay College of Criminal Justice

New York, New York

Teaching Assistant

Florida International University

Miami, Florida

Instructor

Florida International University

Miami, Florida

\section{PUBLICATIONS AND PRESENTATIONS}

Charman, S. D., Hyman, A. R., \& Carlucci, M. (March 2009). The diagnostic utility of facial composites: Beliefs of guilt inflate similarity between suspect and composite. Paper to be presented at American Psychology-Law Society, San Antonio, TX.

Charman, S. D., Hyman Gregory, A., \& Carlucci, M. (2009). The diagnostic utility of facial composites: Beliefs of guilt can bias perceived similarity between composite and suspect. Journal of Experimental Psychology: Applied, 15(1), 76-90.

Hyman, A., Garcia, L., \& Penrod, S. (August, 2005). Eyewitness misidentification and unconscious transference: Fact or fiction? Part II. Paper presented at American Psychological Association, Washington DC.

Hyman, A., Garcia, L., \& Penrod, S. (March, 2006). Eyewitness misidentification and unconscious transference: Fact or fiction? Part III. Paper presented at American Psychology -Law Society, St. Petersburg, FL.

Hyman, A. R., Schreiber, N., Abril, L., Pena, C., Carol, R., Rodriguez, E., \& Diaz, V. (March, 2007). Investigative interviewing and memory: How accurate are interviewers' recollections of investigative interviews? Poster presented at Off the Witness Stand: Using Psychology in the Practice of Justice, John Jay College of Criminal Justice, New York, NY. 
Hyman, A. R., Schreiber, N., Abril, L., Pena, C., Carol, R., Rodriguez, E., \& Diaz, V. (July, 2007). Investigative interviewing and memory: How accurate are interviewers' recollections of investigative interviews after retention interval is manipulated? Paper presented at Society for Applied Research in Memory and Cognition Seventh Biennial Meeting, Lewiston, ME.

Hyman, A. R., Schreiber Compo, N., Rodriguez, E., Diaz, V., Alonso, T., Charosky, M., Sylvester, K., Ortega, L., Lobos, A., Hernandez, E., \& Roque, S. (March, 2008). How accurate are interviewers' recollections of investigative interviews: Examining omissions from interview to report. Poster presented at American Psychology-Law Society, Jacksonville, FL.

Hyman, A. R., Winter, R. J., \& O’Neil, K. M. (March, 2006). Mental vs. physical pain: Itemizing the elements of non-economic damages. Paper presented at American Psychology-Law Society, St. Petersburg, FL.

Hyman Gregory, A., Carol, R., \& Schreiber Compo, N. (in press). Talking with children about past events: Children's memory and suggestibility. In E. Hollister Sandberg \& R. Spritz (Eds.) A Clinician's Guide to Normal Cognitive Development in Childhood. New York, NY: Routledge Press.

Hyman Gregory, A. R., Schreiber Compo, N., Alonso, T., Lobos, A., Roque, S., Alvarez, A., \& Rodriguez, J. (March, 2009). Do real-world investigators remember prior witness interviews better than lay interviewers? Paper to be presented at American PsychologyLaw Society, San Antonio, TX.

Rodriguez, E., Diaz, V., Carol, R. Abril, L., Hyman, A., \& Schreiber, N. (March, 2007). Interviewing techniques in lay interviewers: Are they intuitively good? Poster presented at Off the Witness Stand: Using Psychology in the Practice of Justice, John Jay College of Criminal Justice, New York, NY.

Winter, R. J., \& Hyman, A. (March, 2007). Victim responses in same-sex sexual harassment cases: Aggressive \& submissive reactions to approach \& rejection based harassment. Paper presented at Off the Witness Stand: Using Psychology in the Practice of Justice, John Jay College of Criminal Justice, New York, NY.

Winter, R. J., \& Hyman, A. R. (December, 2007). OJ's courtroom legacy lives on. Judicial notebook, APA Monitor on Psychology, 38(11), 15.

Winter, R. J., \& Hyman, A. R. (November, 2008).Cooperate and you're fired: Retaliation in sexual harassment cases. Judicial notebook, APA Monitor on Psychology, 39(10), 18. 